\title{
Current Approaches to Seasonal to Interannual Climate Predictions
}

\author{
L. GODDARD \\ International Research Institute for Climate Prediction, Lamont-Doherty Earth Observatory of Columbia \\ University, Palisades, NY 10964 \\ email: goddard@iri.ldeo.columbia.edu \\ S. J. MASON \\ Climate Research Division, Scripps Institution of Oceanography, La Jolla, CA 92093-0235 \\ email: smason@ucsd.edu \\ S. E. ZEBIAK, C. F. ROPELEWSKI, R. BASHER \\ International Research Institute for Climate Prediction, Lamont-Doherty Earth Observatory of Columbia \\ University, Palisades, NY 10964 \\ email: steve@iri.ldeo.columbia.edu,chet@iri.ldeo.columbia.edu,rbasher@iri.ldeo.columbia.edu
}

AND

M. A. CANE

Lamont-Doherty Earth Observatory of Columbia University, Palisades, NY 10964

email: mcane@.ldeo.columbia.edu 


\begin{abstract}
This review paper presents an assessment of the current state of knowledge and capability in seasonal climate prediction at the end of the $20^{\text {th }}$ century. The discussion covers the full range of issues involved in climate forecasting, including (1) the theory and empirical evidence for predictability; (2) predictions of surface boundary conditions, such as sea surface temperatures (SSTs) that drive the predictable part of the climate; (3) predictions of the climate; and (4) a brief consideration of the application of climate forecasts. Within this context, the research of the coming decades that seeks to address shortcomings in each area is described.
\end{abstract}

KEYWORDS: Seasonal climate variability, ENSO, statistical prediction, dynamical prediction, ensembles, probabilistic forecasts 


\section{INTRODUCTION}

Research over the last century, and particularly in the last couple of decades, has shown that in many regions of the world the seasonal climate is potentially predictable. Useable predictions are possible under certain conditions: when the boundary conditions that force the atmosphere (e.g. sea-surface temperatures (SSTs) and land surface characteristics) are strongly perturbed, significant shifts are produced in the probabilities of different weather regimes that occur over a season (Palmer and Anderson, 1994). To the extent that the relevant boundary conditions and their associated climate impacts are predictable, skillful seasonal forecasts are possible.

Climate prediction efforts have existed for many hundreds of years. Very early approaches sought to identify environmental indicators that could suggest likely shifts in next season's climate (Inwards, 1994). Certain plants or animals may be sensitive to evolving climate patterns, for example, and the appearance of flowering plant or the tendency of birds to build nests on a particular side of the tree may indicate that the next rainy season will be good or bad. Within some villages of Andean South America, predictions of summer rainfall and autumn harvests are based on changes in the visibility of stars in the Pleiades constellation. Recently such changes in visibility have been attributed to changes in cloud cover over the tropical Pacific as a result of developing El Niño conditions (Orlove, et al., 2000). Today, the physics behind such climate environment relationships is better understood and the tools for predicting them are more sophisticated. Similarly, our recognition of which elements of the climate system greatly affect future seasonal climate has grown considerably through the $20^{\text {th }}$ century as modeling and observational studies continue to add to our understanding.

Progress in diagnosing, modeling and predicting seasonal climate variability represents a major scientific advancement of the $20^{\text {th }}$ century; however, progress in the effective utilization of forecasts has lagged behind. Until recently, the burden rested on the user community to learn what prediction information was available and how it might be applied. While this is still largely the case, there are now increasing efforts to systematically engage the user communities in actively voicing their needs and participating in the development of forecast products and applications. For example, certain users might be interested more in the prediction of the duration of dry spells than the standard average 3-month rainfall anomaly. The prediction community is increasingly considering user requests when planning its research. At the other end of the prediction spectrum, the requirements for observations become better defined when users identify what prediction information they find most useful. This is an exciting time, as the view of climate variability across the disciplines become more coherent and researchers from seemingly disparate disciplines begin to understand each other better.

The primary objective of this paper is to offer a comprehensive view of seasonal to interannual climate prediction - what methods are currently used, what information they provide, how they are typically judged, and their generally recognized advantages and disadvantages. No one approach is endorsed. In fact, benefits are likely gained from considering a variety of approaches. In practice the method chosen will vary according to the type and use of information desired from the prediction and also according to the resources available to produce the prediction. Much, but not all, attention is given to ENSO because it has such a large global impact and because so much of our forecasting efforts and skill derive from it. Given the rapid evolution during the recent few years in the understanding and techniques behind climate forecasting it seems appropriate to stand back and assess what we know and what we need to know at this time, as society prepares to put this information to use. 


\section{THEORY OF PREDICTABILITY OF SEASONAL-TO-INTERANNUAL CLIMATE}

\subsection{Sources of predictability}

Boundary conditions $v$. initial conditions. In the atmosphere, memory is short. An instantaneous realization of the weather will exert influence on future realizations only 5 to 10 days into the future. It has been long recognized that accurate observations of the initial atmospheric state are crucial for short and medium-range weather forecasts (Thompson, 1957; Lorenz, 1963, 1984, 1990; Shukla, 1981; Reinhold, 1987; Somerville, 1987; Murphy, 1988; Palmer et al., 1990; Mureau et al., 1993; Palmer and Anderson, 1994). For seasonal timescales, although atmospheric initial conditions do have a detectable influence, their importance is considerably weakened (Brankovic et al., 1990; Barnett, 1995). The relatively longer time scales of variability in the surface boundary layer allows for predictability of climate that potentially extends for many seasons - far beyond the predictability limit for the atmosphere alone (Charney and Shukla, 1981). Even simple thermal inertia of the upper ocean and persistence of land surface characteristics provide a degree of predictability out to a few months (Frankignoul, 1985). When other elements of the climate system such as the upper ocean or the land surface are dynamically coupled to the atmosphere and are allowed to evolve, even longer timescales of predictability are attainable (Rosati et al., 1997; Zeng and Neelin, 1999). However, because these elements have differing intrinsic time scales, the issue of initialization in each of the air-sea-land components becomes far more complex (Larow and Krishnamurti, 1998; Pielke, 1998). At this time, most dynamical climate prediction involves only the atmosphere (as is discussed in Section 3.2), and it is assumed that atmospheric initial conditions are secondary to predictions of land and sea surface conditions.

Sea surface $v$. land surface boundary conditions. The decorrelation time scale of sea surface temperature (SST) variability is about one year over much of the tropical Pacific ocean, where El Niño and La Niña events dominate the variability. These events are extreme phases in the SST manifestation of the coupled ocean-atmosphere phenomenon, ENSO (El Niño - Southern Oscillation), which represents the single most prominent mode of climate variability at seasonal to interannual time scales. These slowly evolving boundary conditions exert an influence on the tropical atmosphere by redistributing the surface heating, and thus the low level wind fields, tropical convection and subsequent atmospheric heating that drives the global atmospheric circulation.

The land surface potentially provides additional sources of extended predictability for climate. The intrinsic time scales for land surface processes, though considerably longer than those of atmosphere-only processes, are typically less than the timescales of the ocean. Land surface variability also is fundamentally less dynamic than the atmosphere or ocean. Accordingly, much less research has focused on the impacts of land-atmosphere interactions, or the role of land surface initialization in forecasting. This is now changing, as recent studies (Fennessey and Shukla 1999, and references therein; Zeng et al., 1999; Koster, 2000) are highlighting a potentially important role for the land surface.

\subsection{ENSO predictability}


The current understanding of ENSO has developed substantially over the past two decades (Neelin et al., 1998), but rests heavily on earlier contributions. During an El Niño event (see Figure 1), the central and eastern tropical Pacific warms as the warm upper ocean waters of the western Pacific extend eastward. This reduces the equatorial SST gradient and results in an eastward migration of active convection and rainfall, a slackening or even reversal in nearsurface easterly winds, and a decrease (increase) in atmospheric surface pressure in the eastern (western) Pacific (the Southern Oscillation proper) (McPhaden et al., 1998). The changes in near-equatorial winds allow even more of the warm western Pacific waters to move eastward. As the changes in the ocean lead to changes in the atmosphere, and vice versa, positive feedback is established. During the opposite extreme, now commonly called La Niña, anomalies of the opposite sign are observed to grow through analagous positive feedback. The period for a complete El Niño/La Niña cycle is typically three to seven years. 

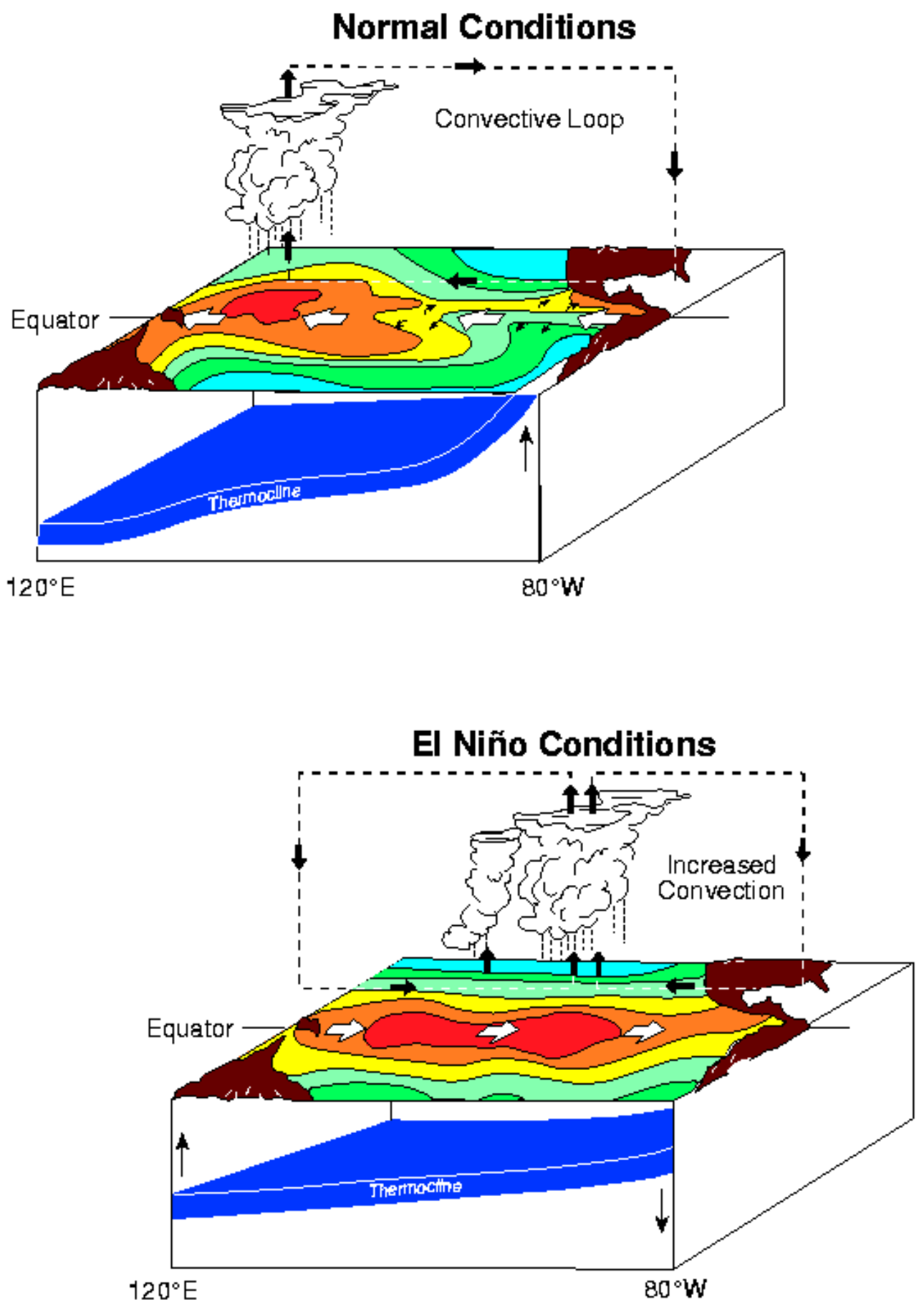

NOAAPMELTAO

Figure 1. Schematic of normal and El Niño conditions in the equatorial Pacific, illustrating the important components of the coupled air-sea system. Under normal conditions, the thermocline, which separates the warm upper ocean from the colder abyssal ocean, is drawn towards the surface in the east as the zonal winds blowing from 
east to west cause divergence in the oceanic surface currents away from the equator and colder sub-surface water is brought to the surface. This creates a zonal gradient in sea surface temperatures (SSTs), colder in the east and warmer in the west, that reinforces the easterly winds. The atmospheric circulation together with the pattern of SSTs places the deep convection over the western Pacific. Significant perturbations to any one of these components can potentially lead to a chain-reaction of positive feedback, developing into an ENSO event. See Section 2.2 for more details. (from McPhaden et al, 1998).

In the 1960s, Bjerknes $(1966,1969,1972)$ postulated that variability in ocean surface temperatures and in tropical Pacific surface winds were fundamentally coupled, and mutually reinforcing. He highlighted the role of equatorial oceanic upwelling and of SST gradients in modulating the meridional (Hadley) and zonal (Walker) overturning atmospheric circulations. These ideas have proven substantially correct, though incomplete as theory for the quasioscillatory nature of ENSO.

Theory behind ENSO's cyclic behavior developed during the 1970's and early 1980's as substantial progress was made in understanding the dynamics of the equatorial oceans. Of particular importance to current understanding was the description of how wind-forced equatorial Kelvin and Rossby waves, together with meridional boundary reflections, determine much of the observed variability in sea level and upper ocean circulation (Godfrey, 1975; Wyrtki, 1975; McCreary, 1976; O'Brien, 1976; Cane and Sarachik, 1977, 1981; Busalacchi and O’Brien, 1980, 1981; Philander and Pacanowski, 1981). In parallel, Gill (1980) proposed a simple mechanistic model for describing the heat-induced overturning circulations of the tropical atmosphere, which was then used to describe equatorial wind changes in response to SST variations associated with El Niño (Zebiak, 1982, 1986; Lindzen and Nigam, 1987). These complementary theories of how the ocean and atmosphere affect each other provided the essential elements for the first coupled models of ENSO (McCreary, 1983; Philander et al., 1985; Cane and Zebiak, 1985; Zebiak and Cane, 1987).

The Zebiak and Cane (1987; hereafter ZC) model was the first to describe self-sustained, continuously coupled oscillations arguably like the real ENSO. ZC also produced the first successful prediction of El Niño by forecasting the 1986-87 event 12 months in advance (Cane et al., 1986). ZC argued for the role of oceanic heat content, and in turn equatorial ocean dynamics, in setting the intrinsic time lags that could sustain an oscillation. Independent analyses (Suarez and Schopf, 1988; Battisti, 1988; Battisti and Hirst, 1989) presented a more complete theory known as the "delayed-oscillator" theory, which ascribes a critical role for oceanic adjustment (in the form of equatorial waves) in the evolution of the ENSO cycle. Elaboration and variations of this theory have been proposed more recently (e.g., Jin and Neelin, 1993a,b; Neelin and Jin 1993; Picaut et al., 1997; Jin, 1997a,b; Neelin et al., 1998; Wang and Weisberg, 2000), although the essential contributions of oceanic wave dynamics and strong air-sea coupling remain.

Over the past ten years numerous groups have developed increasingly complex and comprehensive general circulation models in an attempt to simulate ENSO better (e.g., Lau et al., 1992; Nagai et al., 1992; Latif et al., 1993; Roeckner et al., 1996; Frey et al., 1997; Shukla, 1998). Although important challenges still exist (Latif et al., 1998), notable progress has been made in simulating ENSO in many models (Stockdale et al., 1998a). These new results substantiate the theories derived from the simpler predecessors that indicate a degree of 
determinism, and thus potential predictability, in the coupled climate system that extends to several seasons.

\subsection{Climate predictability}

\subsubsection{ENSO teleconnections}

Progress in collecting routine weather observations and the growth of scientific curiosity converged at the beginning of the $20^{\text {th }}$ century allowing scientists to perform the first investigations of the global climate and its year-to-year variability (Allan et al., 1996). Through investigations of the Indian Summer Monsoon rainfall, Sir Gilbert Walker and colleagues documented various modes of seasonal climate variability (Walker, 1924; Walker and Bliss, 1932). Walker is credited with discovering and naming the Southern Oscillation (SO), the vacillation of sea level pressure spanning the tropical Pacific basin that is associated with the changes in tropical Pacific sea surface temperature during El Niño and La Niña extremes. However, other researchers had also discovered and discussed this tropical Pacific variability (Hildebrandson, 1897; Lockyer and Lockyer, 1902a,b, 1904; Brooks and Braby, 1921). Their early studies were able to link some modes of climate variability, principally the $\mathrm{SO}$, with seasonal rainfall patterns. These statistical relationships between regional rainfall or temperature patterns with larger scale modes of climate variability are often called "teleconnections".

Much of the early work by Walker and others fell from favor in the late 1920's through the 1950 's largely because many of the teleconnections failed to hold during this period. Many present-day researchers suspect that decadal and longer-term climate variability, which Walker's limited data could not take into account, can affect ENSO teleconnections (Gershunov and Barnett, 1998; Krishna Kumar et al., 1999; Power et al., 1999; Rodo et al., 1999; Rajagopalan et al., 2000). After World War II, a network of weather stations was fostered by the World Meteorological Organization (WMO), and continues to form the backbone of weather and climate observations into the present. Much of the more recent empirical work documenting the relationships between ENSO and precipitation and temperature are based on these data.

With increased understanding of ENSO in recent decades came a renewed interest in ENSO teleconnections. Several studies since the 1980's documented the large-scale patterns of rainfall associated with ENSO based on observed data. Ropelewski and Halpert $(1987,1989)$ highlighted broad regions in which precipitation anomalies exhibited a discernable response to the phase of ENSO. Correlation-based analyses (e.g., Kiladis and Diaz, 1989; Lau and Sheu, 1988) also show patterns of relatively strong relationships between ENSO and rainfall. The composite relationships between ENSO and regional rainfall or temperature variability do not occur in every ENSO event, however. As discussed in Section 3.3, the changes in SST boundary forcing shift the distribution of possible climate outcomes, making certain scenarios (such as abovenormal rainfall) more likely but not guaranteed. Rainfall or air temperature anomalies of the opposite sign to the most typical ENSO response can occur in even the strongest teleconnection regions (Figure 2). The degree to which ENSO events shift the range of climate outcomes locally depends on the region, season, and also the strength and spatial distribution of the ENSO-related SST anomalies. Two examples of how the rainfall anomalies expected during an El Niño event might be presented are shown for South America in Figure 3. The upper panel gives the information as a composite category (wetter or drier than average for DJF); whereas, the lower panel indicates how frequently the "expected outcome" occurred in previous El Niño events, also 
known as conditional probabilities. The conditioned probabilistic climate anomalies suggest the relative robustness of regional teleconnections associated with ENSO (Mason and Goddard, 2000). In addition to differences between events in tropical Pacific SST forcing and internal variability of the atmosphere, some studies suggest that extra-tropical SST anomalies may influence (Gershunov and Barnett, 1998) or be influenced by (Bladé, 1999) ENSO teleconnections. ENSO teleconnections are also affected by SST anomalies in the tropical Indian and Atlantic Oceans that produce their own regional climate variations. 
(a) Indonesia (Jun-Nov)

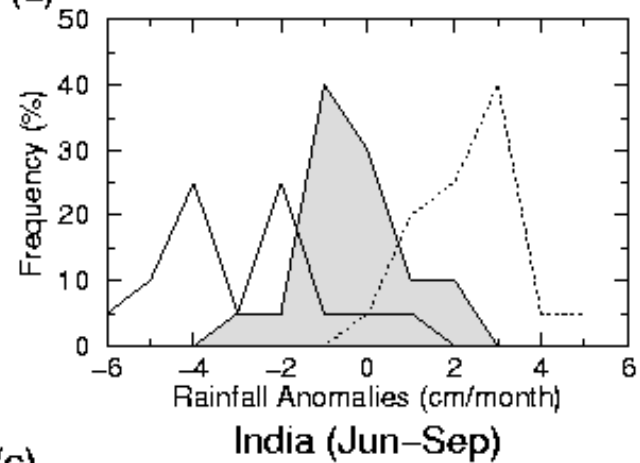

(c)

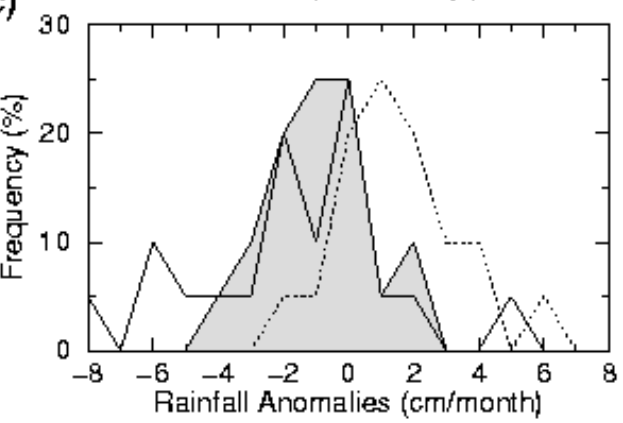

(e) Central E. Africa (Oct-Dec)
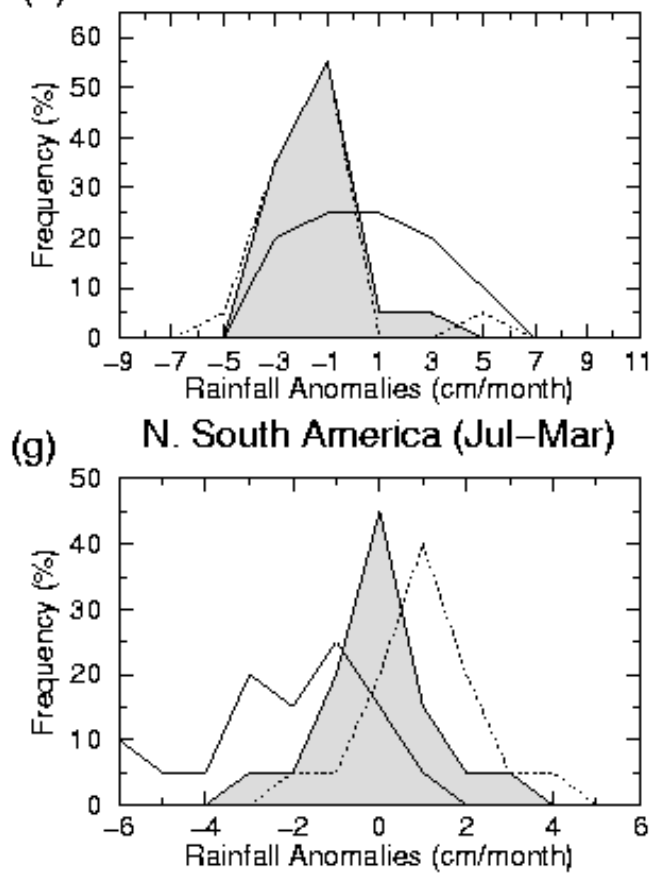

(b) Philippines (Oct-May)

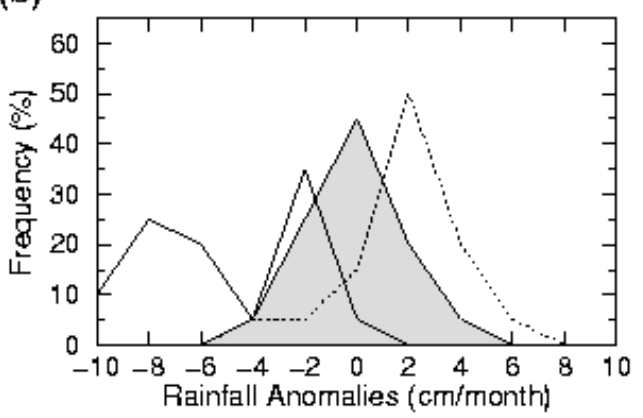

(d) Queensland, Australia (Nov-Feb)

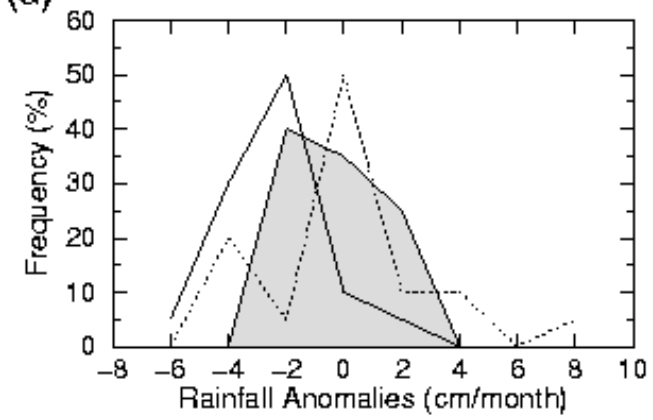

(f)
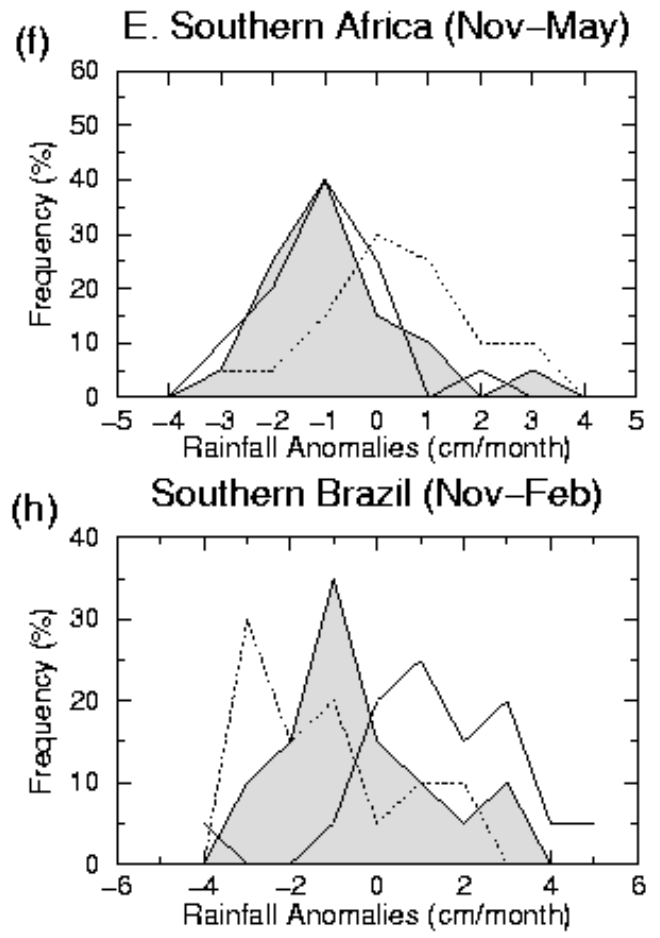

Figure 2. Probability distribution functions (PDFs) based on observed precipitation during the period 1890-1989. Three distributions are shown in each plot: 20 warmest El Niño events (heavy solid line); 20 coldest La Niña events, and 20 years for which 
NINO3.4 was closest to zero anomaly (light solid line, with light gray shading), based on ranked anomalies for the season indicated at the top of each panel. Regions and associated seasons are based on identified ENSO teleconnection patterns from Ropelewski and Halpert (1987). 
Warm episode rainfall expectations (DJF)

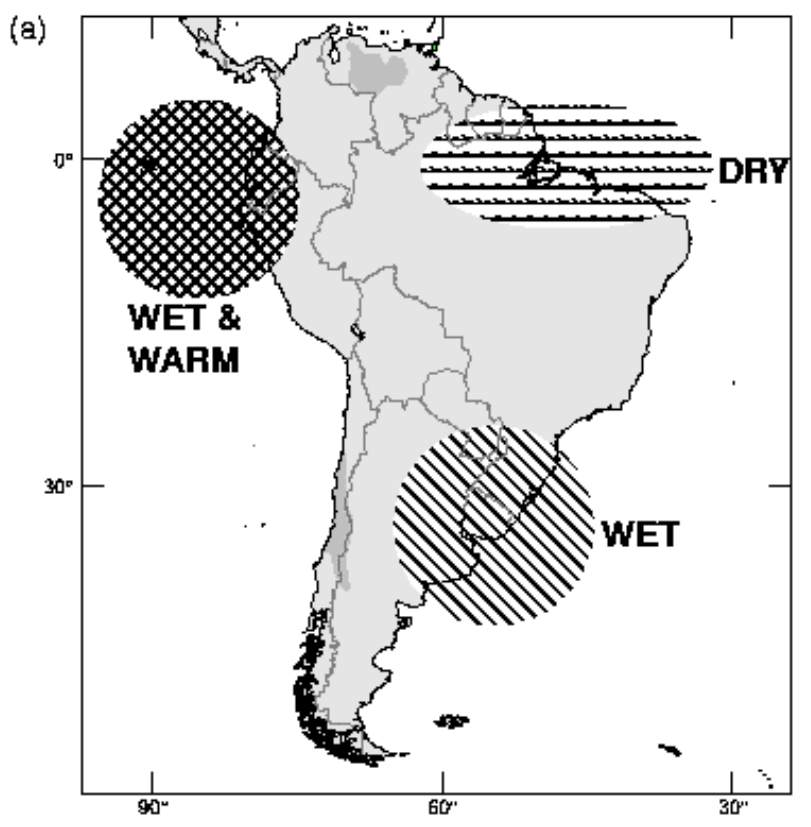

(b)

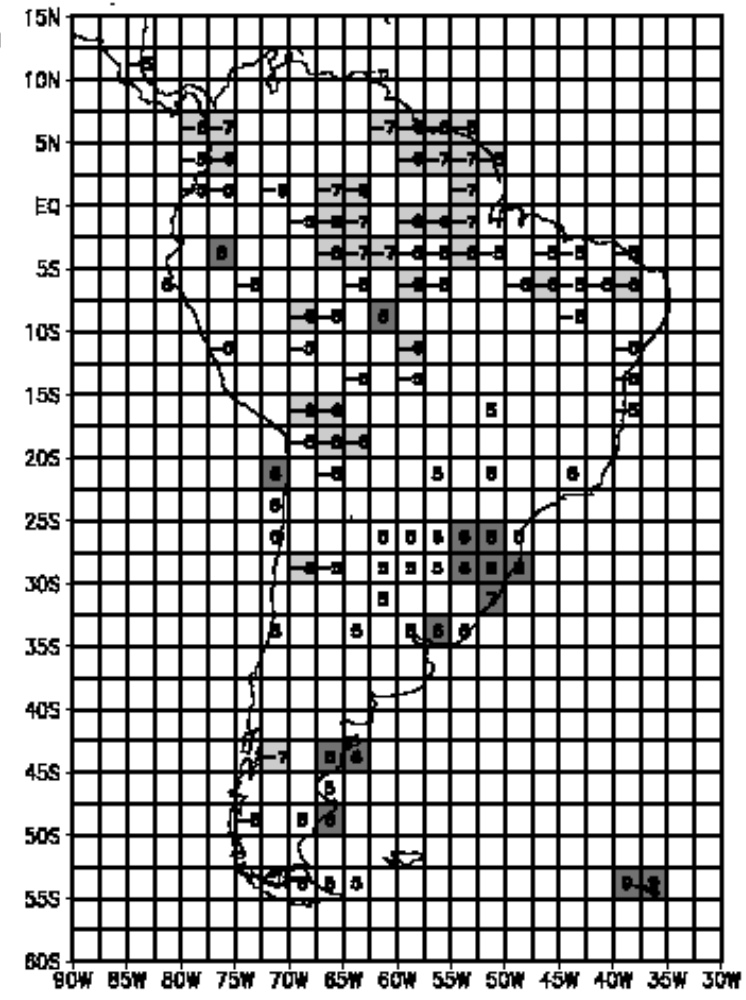

Figure 3. Expectations of anomalous rainfall during El Niño events for the DecemberJanuary-February season, based on historical observations. (a) Composite expectations (from Ropelewski and Halpert, 1987); (b) Conditional probabilities of rainfall being in 
the wettest (dark shading, positive numbers) or driest (light shading, negative numbers) tercile during the 10 strongest El Niño events since 1950.

\subsubsection{The influence of other ocean basins}

Atlantic Ocean Influence. Despite ENSO's widespread influence, the importance of the tropical Atlantic sector in affecting regional climate variability has been recognized since the 1970s. Relatively small changes in tropical Atlantic SSTs, particularly changes in the meridional gradient of SST, can shift the seasonal position of the Inter-Tropical Convergence Zone (ITCZ), directly impacting local climate. The average position of the ITCZ over the tropical Atlantic Ocean basin is oriented west-southwest to east-northeast and typically spans the deep tropics from northeastern Brazil to western Africa. The annual cycle of rainfall from northern Brazil to western Africa reflects the annual north and south excursions of the ITCZ. Thus, SST anomalies in the equatorial Atlantic Ocean, by varying the seasonal mean position of the Atlantic ITCZ, lead to interannual variability of rainfall over northern Brazil (Hastenrath and Lamb, 1977; Markham and McLain, 1977; Moura and Shukla, 1981; Hastenrath, 1984) and western Africa (Folland et al.,1986; Semazzi et al., 1988; Lamb and Peppler, 1991; Rowell et al., 1995; Ward, 1998).

The anomalous meridional SST gradient, which is sometimes referred to as the Atlantic Dipole (Weare, 1977; Hastenrath, 1978; Moura and Shukla, 1981), although perhaps erroneously (Houghton and Tourre, 1997; Enfield et al., 1999), is not independent of ENSO (Penland and Matrovosa, 1998; Latif and Grötzner, 2000). In the months following the peak of an El Niño event it is common for the northeast trade winds over the Atlantic to weaken, and warm SST anomalies to develop in the Caribbean and northern tropical Atlantic Ocean (e.g. Folland et al., 1986; Aceituno, 1988; Wolter 1987; Marengo and Hastenrath, 1993; Enfield and Mayer, 1997). Because of this relationship between tropical Atlantic SST variability and ENSO events, it may be difficult to separate ENSO teleconnections from the local tropical Atlantic teleconnections. Over the past decade, however, a number of studies have identified the relative influence of the eastern Pacific (ENSO) and equatorial Atlantic SSTs on rainfall over the Caribbean and northern South America (Hastenrath, 1995; Enfield, 1996; Enfield and Mayer, 1997; Enfield and Alfaro, 1999; Giannini et al., 2000).

A second mode of variability exists in the tropical Atlantic, which appears to be independent of the variability in the northern tropical Atlantic described above. This mode evolves similarly to ENSO with SST variability is focussed along the equator and coupling between the SST and wind stress anomalies (Hirst and Hastenrath, 1983a; Philander and Pacanowski, 1986; Reverdin and McPhaden, 1986; Richardson and Walsh, 1986; Servain and Legler, 1986; Colin and Garzoli, 1987; Zebiak, 1993). However, direct connection between this equatorial Atlantic variability and ENSO has not been established. This mode, which is most pronounced in boreal summer, can affect rainfall anomalies in the Gulf of Guinea region (Wagner and da Silva, 1994), and parts of central (Hirst and Hastenrath, 1983a,b; Nicholson and Entekhabi, 1987) and southern Africa (Jury, 1996).

Indian Ocean Influence. It is even more difficult to separate Indian Ocean teleconnections from tropical Pacific teleconnections than is the case for the Atlantic sector. SST variability in the Indian Ocean correlates highly with that of the tropical Pacific, with the tropical Pacific 
leading by approximately 3 months (e.g. Nicholson and Nyenzi, 1990; McCreary et al., 1993; Nicholson, 1997; Tourre and White, 1997; Goddard and Graham, 1999; Klein et al., 1999; Reason et al., 2000). Modeling studies show evidence that the atmospheric changes induced by ENSO events are capable of affecting the Indian Ocean as observed (Lau and Nath, 1996, Venzke et al., 2000).

The strong relationship between the Indian Ocean and the Pacific raises questions about which ocean's SST variability is actually responsible for the observed ENSO teleconnections in the Indian Ocean sector. Over southern and eastern equatorial Africa, where rainfall variability is correlated significantly with ENSO events (Figure 4a-c), attempts have been made to identify the relative contribution of the Pacific and Indian Ocean, and suggest that the Indian Ocean contributes more to the regional variability (Rocha and Simmonds, 1997; Tennant, 1998). Thus, many statistical approaches to forecasting seasonal rainfall over southern and eastern Africa consider conditions in the Indian Ocean (Hastenrath et al., 1995; Mason, 1998; Landman and Mason, 1999a; Thiaw et al., 1999). Modeling studies have demonstrated that the Indian Ocean drives the climate variability over eastern Africa (Figure 4d). Tropical Pacific forcing, applied in isolation, actually produces rainfall variability opposite to that observed over eastern equatorial Africa (Figure 4e; Goddard and Graham, 1999). In contrast, rainfall variability over the Indian sub-continent correlates better to tropical Pacific variability than to local Indian Ocean variability (Shukla and Misra, 1977; Weare, 1979; Pant and Parthasarathy, 1981; Ropelewski and Halpert, 1987).

The physical mechanisms associated with SST variability in the tropical Atlantic and Indian Oceans are not as well understood as those of ENSO. Most of the Atlantic SST forecast methods in common use are statistical. Similarly, whether the Indian Ocean's response to ENSO results from dynamics or thermodynamics is currently in debate (Saji et al., 1999; Venzke et al., 2000). The PIRATA program (Servain et al., 1998) may provide the observational data necessary for better understanding of Atlantic Ocean variability. A similar observing system in the Indian Ocean is clearly needed. In addition, a newly launched global system of "sounding buoys" under the ARGO program (Argo Science Team, 1999) may eventually contribute to further understanding and improved modeling for all the global tropical oceans. Until then, prediction of Indian and Atlantic SST is likely to remain in the realm of statistical/empirical techniques. 


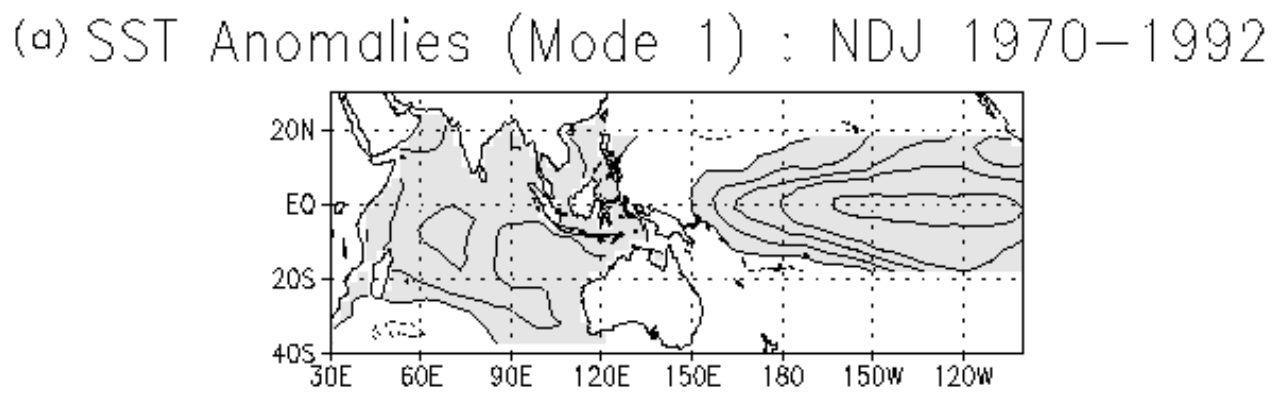

(b1) OBS Precip. v. 10 5STa

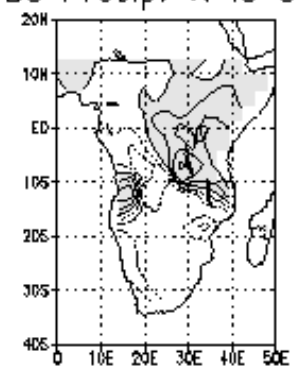

(c1) GOGA Precip. v. 10 SSTa

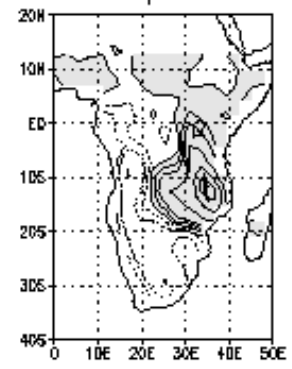

(d) I0GA Precip. v. 10 SSTa

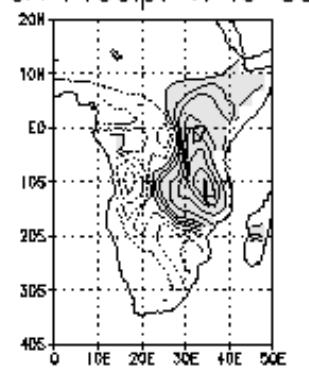

(b2) OBS Precip. v, P0 5STa

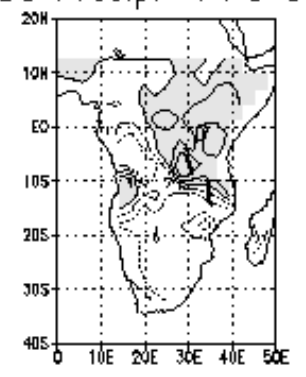

(c2) GOGA Precip. v. PO SSTa

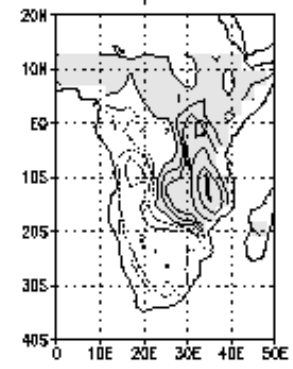

(e) POGA Precip. v. PO SSTa

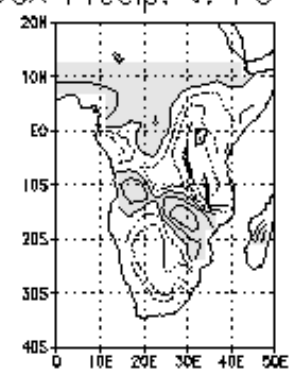

Figure 4. Results from GCM experiments showing importance of Indian Ocean for simulating observed precipitation response over eastern and southern Africa during the November-December-January season (Goddard and Graham, 1999). The top panel (a) 
shows the $1^{\text {st }}$ mode of SST (homogeneous predictor maps) from CCA analysis between the Indian Ocean SSTs and observed African precipitation anomalies and between the Pacific Ocean SSTs and African precipitation anomalies. Shading indicates positive temperature anomalies, with $0.2 \mathrm{C}$ contour levels. The subsequent panels show the African precipitation anomalies (heterogeneous predictand maps) related to Indian Ocean SSTs (left column: b1, c1, d) and those related to Pacific Ocean SSTs (right column: b2, $\mathrm{c} 2$, e), using rainfall anomalies from observations (b1,b2); a GCM forced with global observed SSTs (GOGA) (c1,c2); a GCM forced with observed SSTs only in the Indian Ocean (IOGA) and annual cycle of SSTs elsewhere (d); and a GCM forced with observed SSTs only in the tropical Pacific Ocean (POGA) and annual cycle of SSTs elsewhere. Shading and solid contours imply positive rainfall anomalies, with contours at starting at $+/-0.5 \mathrm{~mm} /$ day and an interval of $1.0 \mathrm{~mm} /$ day above magnitudes of 1.0 . Notice that the IOGA experiment (d) replicates the rainfall pattern seen in the analysis of the observations $(\mathrm{b} 1, \mathrm{~b} 2)$ and the GOGA experiments $(\mathrm{c} 1, \mathrm{c} 2)$, but the pattern of rainfall anomalies in the POGA experiment (e) is quite different.

\section{PREDICTING THE OCEAN-ATMOSPHERE SYSTEM}

\subsection{Predicting boundary conditions}

\subsubsection{Sea-surface temperature prediction}

Observations. Current predictions of the ocean boundary layer depend on several key observations that have been available in real-time since the 1980s. By far the most developed observing system for the global oceans is the TAO (Tropical Atmosphere-Ocean) buoy array, which consists of more than 70 moorings in the tropical Pacific $\left(8^{\circ} \mathrm{N}\right.$ to $8^{\circ} \mathrm{S}, 137^{\circ} \mathrm{E}$ to $95^{\circ} \mathrm{W}$; see Hayes et al., 1991 and McPhaden et al., 1998 for comprehensive summaries). These buoys make detailed measurements of surface winds, humidity, and temperature, and subsurface temperature and salinity, and continuously relay the information via satellites. The establishment of this observing system has allowed a more detailed understanding of processes surrounding ENSO, and it has provided critical information to initialize ocean models for seasonal predictions (Latif et al., 1998; Stockdale et al., 1998a). Another important data source for subsurface thermal conditions, particularly outside the tropical Pacific, are measurements from merchant ships that measure depth profiles of temperature and sea surface salinity. Observing ships also contribute to data sets of surface wind stress and surface air pressure. Other in situ measurements include a network of tide gauge stations that have been in place for decades (Wyrtki, 1985; Mitchum et al., 1994). Relatively recently, satellite-based data for SST, winds, and sea level topography have become available (e.g., Fu et al., 1994; Liu et al., 1996). The potential usefulness of this data is great, as satellite products have the capability to offer higher resolution and more uniform coverage in both space and time than other systems.

The best observed oceanic field is SST. Quality SST observations are important for all aspects of prediction. First, having access to such data provides the ability to closely monitor ENSO and other variability. Second, timely access to SST data allows for continuous verification of SST predictions that are used to forecast climate (see Section 3.2). Third, having reliable SST 
observations may reduce uncertainty in predictions of climate that are based on observed SSTs. And finally, some climate-based decisions are tied directly to these oceanic observations, such as for the fishery industry (Lehodey et al., 1997; Carr and Broad, 2000), in which case high resolution, accurate, and current observations are crucial (GOOS, 1998). The most commonly used products are obtained from a blending of in situ observations from ships of opportunity and buoys, and satellite observations (Reynolds and Smith, 1994). The relatively uniform coverage of the satellite measurements, and the large-scale bias correction of the satellite signal based on in situ measurements, provides for a high-quality analysis on weekly time scales. Prior to the satellite era (early 1980's) SST data is acceptably good in many areas since the mid-1950's.

For prediction of SSTs, especially through the use of dynamical models, other physical components of the air-sea system must be well measured and easily accessible. Crucial to all ocean model simulations or forecast initializations are surface fluxes, especially momentum fluxes. The first ENSO prediction schemes used only surface wind stress to generate oceanic initial conditions, and even in the presence of considerable ocean data, wind forcing remains an extremely important quantity for initializing ocean models. Sea-surface elevation is increasingly being considered in prediction, although in the initialization of the more complex models the use of sea level data remains exploratory (Chen et al., 1998; Segschneider et al., 1999; Ji et al., 2000). A current major problem is the decomposition of sea level into the separate contributions from temperature and salinity. In the absence of significant subsurface salinity measurements, the decomposition requires statistical estimates of inherently limited accuracy. Oceanic velocity data are also valuable, particularly as sources of validation for ocean models. Such data are provided routinely by drifting buoys and moored current meters, although the latter are available only at a very few sites.

Statistical forecasting methods. Most statistical forecasts of SSTs focus on the ENSO phenomenon and involve prediction of a field of tropical Pacific SSTs, or a simple area-average over representative regions of the equatorial Pacific, such as the NINO3 (SST anomaly averaged over the region $\left.5^{\circ} \mathrm{S}-5^{\circ} \mathrm{N} ; 150^{\circ} \mathrm{W}-90^{\circ} \mathrm{W}\right)$, NINO3.4 $\left(5^{\circ} \mathrm{S}-5^{\circ} \mathrm{N} ; 170^{\circ} \mathrm{W}-120^{\circ} \mathrm{W}\right)$, or NINO4 $\left(5^{\circ} \mathrm{S}-\right.$ $\left.5^{\circ} \mathrm{N} ; 160^{\circ} \mathrm{E}-150^{\circ} \mathrm{W}\right)$ areas. These ENSO predictions frequently are derived from previously observed in situ sea temperatures, surface pressure, and/or wind stress anomalies, although relationships with atmospheric anomalies outside of the tropical Pacific sector are sometimes considered (Xu and von Storch 1990; Barnett et al., 1991). The most commonly used statistical methods describe linear deterministic relationships between the predictor and a single predictand index, and include regression (Knaff and Landsea, 1997), method of analogues (van den Dool, 1994), and singular spectrum analysis (Keppenne and Ghil, 1992). Linear multivariate methods for forecasting ENSO in which the predictand is a field, most often SST, are widely used also. One class of such models keys on autoregression, either through Markov modeling (Xue et al., 2000) or through linear inverse methods optimized to fixed lead-times (Penland and Magorian, 1993; Penland and Sardeshmukh, 1995). The second class of models uses covariance or correlation between multiple fields, at fixed lead-times. The most commonly used algorithm is canonical correlation analysis (CCA) (Graham et al., 1987a,b; Barnston and Ropelewski, 1992), although other methods such as singular value decomposition (SVD), and combined empirical orthogonal functions (EOFs) have also been used (Bretherton et al., 1997). Recent attempts to use non-linear methods have been made (Tangang et al., 1997, 1998a,b; Hsieh and Tang, 1998), but do not provide significant improvements in skill over linear methods (Tang et al., 2000). 
Although probabilistic methods of statistical prediction have been used in climate forecasts (as discussed in Section 3.2), their application in forecasting SSTs has been minimal.

Outside the tropical Pacific, there are fewer examples of statistical forecasts of SSTs. However, some recent attention has been given to forecasts of global SSTs using autoregressive models (Navarra et al., 1998) and CCA (Mason et al., 1999; Landman and Mason, 2000). Also, tropical Atlantic temperatures are now regularly forecast using linear inverse modelling (Penland and Matrosova 1998) and CCA (Pezzi et al., 1998; Nobre and Repelli, 2000).

Dynamical forecasting methods. A spectrum of dynamical models, ranging from the relatively simple (so-called intermediate) models initially used to predict ENSO, to comprehensive coupled general circulation models, are used routinely for SST prediction (Latif et al., 1994, 1998; Stockton et al., 1998a). Intermediate models currently are run only in a regional context, focusing on the tropical Pacific and ENSO (e.g., Chen et al., 1999; Kleeman et al., 1995). Both atmospheric and oceanic components are represented dynamically, but simplified to the level of equatorial, linear, shallow-water equations. Parameterizations of the thermodynamics of both atmosphere and ocean are more complex, and nonlinear. Outputs are predicted winds and SST over the coupled domain.

The commonly used hybrid models involve a statistical atmosphere model, coupled to either an intermediate ocean model (Kang and Kug, 2000) or to an ocean GCM (Barnett et al., 1993). In all cases, the atmosphere model is derived from either SVD or CCA based on observed SST and surface wind (stress). Outputs are surface wind stress and SST predictions over the coupled domain, typically the tropical Pacific.

In recent years, development efforts have been focussed toward relatively comprehensive coupled models for SST prediction. One approach employs a full ocean GCM and a global atmospheric GCM, but air-sea coupling occurs only in the limited domain of the tropical Pacific, and either climatology or persistence of SST anomalies is prescribed elsewhere (Ji et al., 1996; Kirtman et al., 1997). The additional assumption of so-called anomaly coupling is often made; that is, the coupling fields (i.e. heat fluxes and wind stress) are computed from the simulated anomalies of each component model (relative to a forced, uncoupled climatology), added to the appropriate observed climatology. Anomaly coupling minimizes errors associated with simulating aspects of the observed mean climate or mean annual cycle, but at the possible expense of introducing incorrect parameter sensitivities under certain conditions (Neelin and Dijkstra, 1995).

The outputs of fully coupled, and global domain GCMs (e.g., Rosati et al., 1997; Stockdale et al., 1998a,b; Segschneider et al., 1999) include the full state space of both atmosphere and ocean (and land surface). Varying approaches are taken for the treatment of sea-ice in the polar regions: in some cases sea-ice is simply specified, in others an interactive sea-ice model is included. Sometimes the models are used in a one-tier approach, directly forecasting climate as well as SST (Stockdale et al., 1998b), but more typically the coupled GCMs are used to forecast SST only. In that case, the coupled models are configured at a moderate resolution of 3-4 degrees (adequate to resolve many of the critical tropical air-sea interactions), and then higher resolution AGCM's are used with the predicted SST's to forecast climate (see Section 3.2 below), an example of the two-tiered approach.

Apart from these global ocean modeling efforts, dynamical modeling of the Atlantic Ocean has received increasing attention over recent years (Philander, 1986; Zebiak, 1993; Chang et al., 1997). Very recently, some studies have been directed toward the Indian Ocean sector as well 
(Saji et al., 1999; Webster et al., 1999). Yet the level of understanding of coupled climate variability in these oceans is extremely limited, in comparison to that of the Pacific (i.e., ENSO). Central to the problem is the fact that the variability is weaker in these sectors, and most likely impacted remotely by ENSO and perhaps other factors. Additional basic research is needed, with continuing efforts to improve model simulations and predictions. In the extratropics, the situation is also very uncertain. To date there has been no convincing demonstration of significant local air-sea coupling in the extra-tropics operating at seasonal time scales, and involving the submixed layer ocean. This too continues as an area of active research.

Forecast performance. Since the first prediction of the 1986-87 El Niño (Cane et al., 1986), steadily intensifying efforts in statistical, dynamical, and hybrid model prediction have led to more than a dozen forecast systems that are currently being used to make regular predictions (Kirtman, 2000). Due to the known dominance of ENSO in global climate variability, forecast skill for ENSO indices such as NINO3, NINO3.4, NINO4 are important measures of performance. Comparisons among different forecast methods have been made for different ENSO events over the past decades (Barnett et al., 1988; Barnston et al., 1994; Barnston et al., 1999a; Landsea and Knaff, 2000). Figure 5 shows forecasts for the period covering mid-1996 to late 1998 from 3 dynamical and 3 statistical models; this is a subset of models from an extensive comparison study by Barnston et al. (1999a). It must be noted that the period shown is very limited and the apparent skill of any one tool may not be representative of its true ability. However, the magnitude of the 1997/98 El Nino event and its associated climate impacts make it an important case study for ENSO prediction tools. This comparison shown in Figure 5 reveals that at present, forecasting methods of all types are generally competitive. During the 1997-98 El Niño event, the GCM-based forecasts with active ocean data assimilation did perform better than simpler models without ocean data assimilation (for example, compare NCEP coupled model against the COLA coupled model, Figure 5). However, some statistical forecasts did as well as any dynamical model in predicting NINO3 (Barnston et al., 1999; Landsea and Knaff, 2000). The approximately equal of skill of the different forecast methods is not too surprising: the deterministic processes that the dynamical models describe explicitly lead to systematic patterns in the data, extractable and useful for statistical prediction. However, dynamical models have an inherent but yet unrealized advantage; namely, that with improved and more comprehensive representations of the real physics, there is room for further improvements in prediction skill. The only comparable means to improve statistical models is to increase the volume of observational data, a task fundamentally more limited. Thus, considerable energy is now being invested in improved dynamical prediction at many centers worldwide. 


\section{CSU CLPER (REGRESSION)}

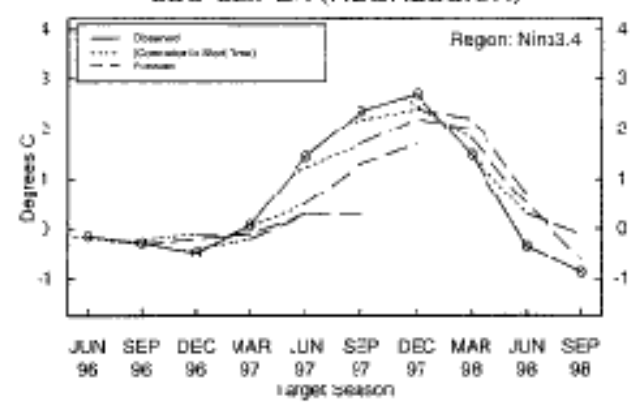

CDC INVEASE MODELING

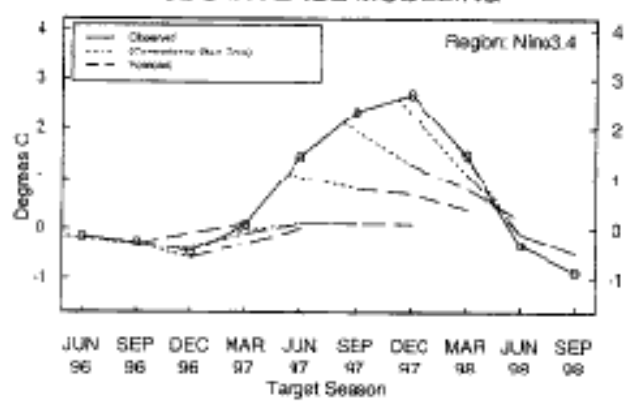

COLA COUPLEJ

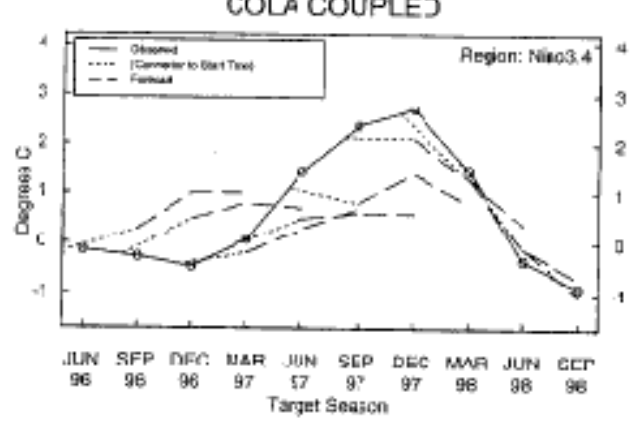

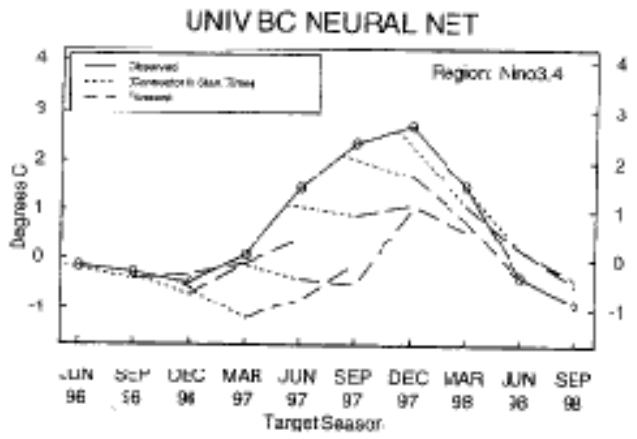

SCRIPPSIMPI HYBRID COUPLED
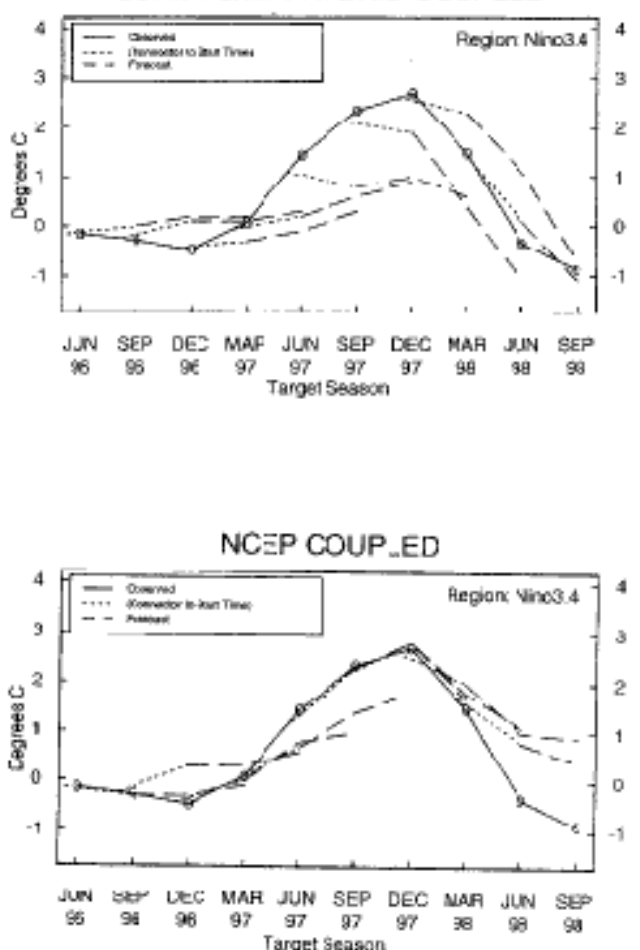

Figure 5. Plots of tropical Pacific SST forecasts (dashed lines) and observations (solid lines) over the Jun 1996 - Sep 1998 period for 6 models projecting the state of ENSO at lead times of 3.5, 6.5, and 9.55 months. The specific predicted regions and SST units vary by model as shown in the upper-right corner and by the vertical axis label, respectively. Dotted lines connect the observation centered at the approximate start time to the earliest (3.5 month lead) forecast. This is done for the readers' convenience only; the beginning of the dotted line does not represent the model's actual initialization nor its forecast at very short lead times. The 3-month periods shown on the abscissa are denoted by their middle month. The first three panels show the performance of the statistical models (indicated above each panel), the next three the dynamical models. 
High skill in forecasting ENSO events with lead-times of twelve months or more has been claimed (Cane et al., 1986; Latif et al., 1998). However, operational skill estimates, which provide the only truly unbiased indications of forecast skill, suggest that some ENSO events can be forecast qualitatively only a few months in advance (Barnston et al., 1999a; Landsea and Knaff, 2000), and occasionally only after an event has begun (Chen et al., 1997). The difficulty in predicting ENSO phase-changes has been attributed to seasonal variability in the predictability of the equatorial Pacific. A "springtime barrier" has been noted, as lower skill is generally observed for predictions that extend through boreal spring. (Blumenthal, 1991; Goswami and Shukla, 1991; Latif and Flügel, 1991; Latif and Graham, 1992; Webster and Yang, 1992; Balmaseda et al., 1995; Webster, 1995; Davey et al., 1996; Moore and Kleeman, 1996; Flügel and Chang, 1998; Latif et al., 1998). The assumed reason for such a barrier is that the ENSO signal (year-to-year variance in SST anomalies) is a minimum in March-May, but the noise of the tropical Pacific air-sea system is nearly constant (Xue et al., 1994). Thus the signal-to-noise ratio in the equatorial Pacific is small during boreal spring, and causes the forecast evolution through this season to be more sensitive to random variability. The spring barrier is most well defined during decades of relatively poor predictability (Balmaseda et al., 1995), but is not evident in all ENSO-prediction models, and so may not be an inherent feature of the ENSO phenomenon (Chen et al., 1995).

In addition to being a function of the ENSO phase, skill levels have varied inter-decadally, with relatively higher skill in the 1980s, and lower skill in the 1970s and 1990s (Chen et al., 1995; Balmaseda et al., 1995; Ji et al., 1996; Kirtman and Schopf, 1998). This low-frequency variability in the predictability of ENSO events may be a reflection of changes in the role of the delayed-oscillator mechanism in equatorial Pacific ocean-atmosphere dynamics (Goddard and Graham 1997).

Skill comparisons beyond the tropical Pacific and ENSO are few, as few predictions extend to the broader domain. Some statistical schemes target the tropical Atlantic and Indian Oceans (as discussed above), and near global domain coupled GCM forecasts exist already. Performance has been evaluated generally with temporal correlations between observed and forecast SST (Penland and Matrosova, 1998; Repelli and Nobre, 2000), but robust validation of many of the current coupled GCM forecasts is presently limited by sample sizes. The expense of running these models often limits the number of retrospective forecasts conducted, and further work is needed. Those skill measures that are available indicate that forecast skill outside the tropical Pacific is distinctly lower than that for ENSO. Since global SST forecasts are required for twotiered forecasting systems (Hunt, 1997; Mason et al., 1999) the need to improve skill beyond the tropical Pacific represents a major challenge for future forecast research.

\subsubsection{Land-surface prediction}

The land surface also serves as a boundary condition on the atmosphere, but it is often treated differently than SSTs. Prediction or even persistence of anomalous conditions of the land surface, such as snow or soil moisture, are rarely incorporated in climate prediction. A major limitation is that there is no global observational analysis of soil moisture (wetness) with which to validate or initialize models. Even climatological soil moisture generally is estimated using a model (Mintz and Serafini, 1992). Currently, weather forecast models typically are run with interactive land surface parameterizations, and the atmospheric data assimilation process results 
in estimates of soil moisture that can be utilized for climate purposes (Fennessy and Shukla, 1999), but this approach has not yet extended to seasonal climate forecasts.

Until recently the physics contained in the land surface component has been very crude and simplistic, and the land-surface did not interact with the overlying atmosphere. The first interactive land surface models followed the so-called "bucket" approach; i.e., a simple onedimensional system that includes a reservoir, a precipitation source, and calculated fluxes at the surface (Manabe et al., 1969). A more recent class of models includes explicit vegetation, and its impacts on surface energy, water, and momentum transfer (Sellers et al., 1986, Dickinson et al., 1998). This class of model has been further developed, and can be considered state-of-the-art at present. A new class of model under development will go further in attempting to account for sub-grid scale variability and the effects of topography on runoff (Koster et al., 2000).

Numerous studies using these land surface models have investigated and identified important impacts of land surface processes on climate and its variability (see reviews in Dirmeyer and Shukla, 1993; Eltahir and Bras, 1996). Studies focusing on seasonal prediction impacts are suggestive of important land surface initialization impacts under some conditions (Fennessy and Shukla, 1999). For example, the importance of initializing the soil moisture for simulations of drought and flood events at seasonal or longer time scales has been demonstrated (Brankovic et al., 1990; Fennessy et al., 1994). A number of new research initiatives under development will address this issue further, and can be expected to occupy an important position in the future research agenda.

\subsection{Predicting climate}

Observations. Routine observations of temperature and rainfall at selected locations have been taken for centuries. These observations are essential to diagnostics and process studies, for building statistical climate models, for understanding and improving dynamical climate models, and for validating both statistical and dynamical models. Routine real-time monitoring of the current climate, such as drought and flood conditions, is also important to provide the appropriate context for interpretation of climate forecasts.

Temperature measurements have been taken at sufficient spatial resolution to provide estimates of seasonal and annual global air temperatures over land from the mid- $19^{\text {th }}$ century to the present (Jones, 1994). While observations at less than two hundred adequately spaced locations are sufficient for global temperature estimates, far more observations are necessary for the study and specification of regional, seasonal to interannual variability. Europe, North America and Australia have fairly good records extending back a hundred years or more, but much of the remaining land areas of the world have had adequate regular temperature observations only from the 1950 s forward. The availability of good monthly station data in the latter half of the $20^{\text {th }}$ century is partly due to efforts of the World Meteorological Organization to coordinate the regular international exchange and archiving of monthly temperature and rainfall data. Some 1600 weather stations have been designated official climate stations and have agreed to exchange monthly climate summaries, called CLIMAT records, on a routine basis. However, the global observing network has thinned in the last two decades. A number of efforts are underway to arrest the recent decline in climate networks, such as the designation of a surface observing network of about 1000 stations under the Global Climate Observing System (GCOS). While these observing networks and the exchange of these data is an achievement, climate 
variability on decadal and longer temporal scales limit the use of this 50 -year record in some seasonal climate prediction problems.

The observational record for precipitation generally parallels that of temperature. However, the smaller spatial and temporal scales of variability exhibited by precipitation make global seasonal patterns of rainfall more difficult to classify. As with temperature, some regions, again mainly Europe, Australia and parts of North America, have reasonable historical precipitation records back to the beginning of the $20^{\text {th }}$ century. The advent of satellite precipitation estimates (Xie and Arkin, 1997) has provided high spatial resolution data sets for the study of global rainfall, including over the world's oceans, albeit with limitations in accuracy.

The simplest methods for seasonal climate prediction are based purely on local observations of past and current climate. The use of the climatological average as the "prediction" is a valid starting point, or one can assume that a recent seasonal to multi-year climate anomaly will persist through the upcoming season(s) (Huang et al., 1996). These methods have been used for centuries, and are used implicitly today by many people on a regular basis. The development of prediction methods that are superior to these simple approaches is the goal of most climate prediction research.

Statistical models. Implicit in any statistical model is that antecedent, current, or expected future values of predictor variables can be used to predict the future state or evolution of the predictand based upon historical observations of mathematical relationships between the predictors and predictands. With the development of global observing networks that measure air temperature, sea temperature, precipitation and some aspects of the atmospheric circulation, statistical prediction methods have evolved considerably through the $20^{\text {th }}$ century.

In most cases, statistical forecasts of seasonal climate anomalies depend heavily upon the SST boundary forcing, which is the fundamental source of predictability in two-tiered dynamical modeling approaches. Antecedent or forecast SSTs form the sole, or at least dominant, predictors of models for the Sahel (Bah, 1987; Folland et al., 1991; Barnston et al., 1996; Ward, 1998; Thiaw et al., 1999), eastern Africa (Mutai et al., 1998), southern Africa (Klopper et al., 1998; Landman and Klopper, 1998; Mason, 1998; Mattes and Mason, 1998; Landman and Mason, 1999a; Mason and Tyson, 1999), northeast Brazil (Ward and Folland, 1991; Uvo et al., 1998), the Pacific Islands and Alaska (Barnston and He, 1996; Yu et al., 1997), Australasia (Casey, 1998), Europe (Johansson et al., 1998), the United States (Barnston, 1994), and Canada (Shabbar et al., 1997). Most predictability is associated with the tropical Pacific. The skill of seasonal climate forecasts may be minimal in non-ENSO years (Barnston et al., 1999b; Landman and Mason, 1999a), but important exceptions include central Africa and the Indian monsoon areas (Yang et al., 1998). The simplest models include only a single ENSO index (Hutchinson, 1992), and simple average responses to ENSO events do provide seasonal forecasters with valuable initial guidance (Ropelewski and Halpert, 1996). A slightly more sophisticated approach to relating seasonal climate to ENSO indices uses both the present phase and the recent trend in the to indicate likelihood of above or below median precipitation (Stone and Auliciems, 1992). However, inter-El Niño differences in atmospheric circulation exist, and these differences may be inherently unpredictable in some cases (Kumar and Hoerling 1997). Thus, the probabilistic nature of such relationships should be emphasized (Mason and Goddard, 2000).

Some improvements in skill have been claimed when, in addition to SSTs, atmospheric predictors are included (Hastenrath et al., 1995; Makarau and Jury, 1997; Francis and Renwick 1998; Jury 1998; Jury et al., 1999a; Philippon and Fontaine, 1999). The addition of atmospheric 
predictors forms an important component of analog techniques (Livezey and Barnston, 1988; Wagner, 1989). In most cases, however, these predictors are aspects of the atmospheric ENSO signal, and so do not imply that the atmosphere has sufficient memory of its own to provide predictability at seasonal time scales. Included with this class of statistical models are those for the Indian Monsoon, where precursors indicate either some aspect of ENSO (Shukla, 1987; Krishna Kumar et al., 1995), despite a relatively weak ENSO-signal (Yang et al., 1998), or provide a measure of the pre-monsoon thermal conditions over the Asian land mass (Vernekar et al., 1995; Sankar Rao et al., 1996; Webster et al., 1998), in both cases implying that predictability is derived from boundary forcing.

All linear statistical prediction schemes suffer from similar instabilities in precursorpredictand relationships (Hastenrath, 1995; Francis and Renwick, 1998). Over India, for example, associations between ENSO and atmospheric precursors of the monsoon are unstable because of interdecadal variability in ENSO variance, and have led to interdecadal variability in monsoon predictability (Parthasarthy et al., 1991; Hastenrath and Greischar, 1993; Annamalai, 1995; Krishna Kumar et al., 1999a; Sahai et al., 2000). Recent weakening of the monsoon ENSO association is likely to compound the problem (Krishna Kumar et al., 1999b).

This lack of robustness in predictor-predictand relationships often reflects an absence of explicit references to physical processes in the construction of statistical models for seasonal climate prediction. Given the enormous pool of potential predictors, and limited temporal degrees of freedom of most geophysical data, statistical models require rigorous testing in operational settings to ensure significance. Even cross-validated estimates of skill can be biased (Barnston and van den Dool, 1993; Hastenrath, 1995), and so careful retro-active skill testing should be encouraged (Wilks, 1995) using a variety of skill score measures (Zhang and Casey, 2000).

Seasonal climate forecasts predominantly focus on mean temperatures or total rainfall; little progress has been made in forecasting more detailed variability such as rainfall onset (Ahago, 1992; Briggs and Wilks, 1996). Notable exceptions include attempts to forecast frequencies and tracks of tropical cyclones. The main focus has been on North Atlantic hurricanes (Gray et al., 1992, 1994; Hess et al., 1995; Lehmiller et al., 1997; Mielke and Berry, 2000), but some attention has been given to the Northwest Pacific (Chan et al., 1998), the Southwest Indian Ocean (Jury et al., 1999b), and the Southwest Pacific (Basher and Zheng, 1993). Looking beyond forecasts of seasonal conditions, very few efforts have been made to forecast climate at interannual time scales (White, 2000). In most cases such long-lead forecasts depend on the extrapolation of trends and cycles (Dyer and Tyson, 1977; Tyson and Dyer, 1978, 1980; Currie, 1993).

Regression models, including CCA, are the most commonly used statistical techniques for forecasting climate anomalies. Most models for the Indian monsoon use multiple linear regression, and this method, together with CCA, has been adopted extensively in Africa also. Auto-regressive approaches have received attention recently (Elfandy et al., 1994; Chu et al., 1995; Mentz et al., 2000), as have probabilistic methods, most notably discriminant analysis (Ward and Folland, 1991; Casey, 1995; Carter and Elsner, 1997; Lehmiller et al., 1997; Mason, 1998; Mattes and Mason, 1998; Mutai et al., 1998; Mason and Mimmack, 2000).

Numerical models. Two types of numerical models are currently used for climate prediction: atmosphere-only general circulation models (AGCMs) and coupled ocean-atmosphere general circulation models (CGCMs). Both are based on the full physical equations of motion. The 
atmospheric equations in these models can be solved either on model grid points or spectrally, where the highest spectral wave number resolved determines the effective grid resolution of the model. These models are not entirely free of statistical assumptions, however. Because of the relatively coarse resolution used in GCMs, physical processes occurring on scales smaller than the model's grid can resolve are parameterized empirically. Mathematical relationships, based on observed data, describe the larger-scale aggregate behavior of fundamentally small-scale processes such as convection and radiative transfer.

A 'two-tiered' climate prediction approach is used with AGCMs (Hunt, 1997; Bengtsson et al., 1993), in which the boundary conditions are predicted first and are then used to force the overlying atmosphere. The atmosphere is a slave to the prescribed boundary conditions. In CGCMs, both the atmosphere and the boundary conditions are allowed to evolve freely and influence each other. This free, coupled evolution is one advantage of the CGCM (or one-tiered approach). A primary drawback of the current generation of CGCMs is that the SST field tends to "drift" away from realistic values as the integration proceeds, thus forcing unrealistic patterns in the atmospheric anomalies. Drift may occur rapidly, because of an imbalance in initial conditions, or slowly, because of internal parameterization in one of the component models or from the coupling itself (i.e. flux errors) (Delecluse et al., 1998). Consequently, CGCMs are most often employed to predict only the SST field (Section 3.1.1). Model output statistics (MOS) corrections sometimes are applied to these predicted SST fields to bring the amplitude and/or spatial pattern into better agreement with the observed character of the variability before they are used to forced the atmospheric anomalies. Because of these model weaknesses, AGCMs are still more commonly used than CGCMs (Hunt, 1997; Mason et al., 1999); however, CGCMs are beginning to emerge in the arena of operational climate forecasting (Stockdale et al., 1998b).

Because numerical models are capable of outputting a full range of atmospheric variables (winds, humidity, cloudiness, heat fluxes, etc.), they are useful to climate research for process or diagnostics studies as well as prediction. Until recently, most emphasis had been placed on the prediction, analysis, and diagnosis of anomalous geopotential heights $(700 \mathrm{hPa}$ - important level for moisture transport; $500 \mathrm{hPa}$ - important steering level for mid-latitude storms; $200 \mathrm{hPa}$ important diagnostic of upper level divergence and thus convective activity in the tropics). Through the early 1990s, researchers were still inquiring whether or not GCMs were even suitable for seasonal climate prediction (Palmer and Anderson, 1994; Kumar and Hoerling, 1995; Kumar et al., 1995; Stern and Miyakoda, 1995). Clearly if a model is incapable of simulating the large-scale atmospheric circulation, it will not be able to simulate regional-scale variability such as rainfall. It is now accepted that GCMs can replicate much of the large-scale flow, including anomalous patterns in geopotential fields, although the correlation between a GCM's geopotential height fields and that from observations is generally higher in times of strong SST forcing (Kumar and Hoerling, 1998). Today, the typical variables examined for prediction purposes are those variables that concern society most: near-surface air temperature and precipitation.

The GCM seasonal predictions consist of an ensemble of integrations, i.e. a set of forecasts that verify at the same time (Sivillo et al., 1997). The ensemble members can differ in their boundary conditions, initial atmospheric conditions, and/or model physics. An ensemble approach allows for separation between the repeatable portion of the anomalous climate signal due to boundary layer forcing and the portion that is due to internal variability or chaos in the atmosphere. Ensemble-based predictions lead naturally to probabilistic climate forecasts (as discussed in Section 3.3). 
The detail in space and time that many users of forecast information claim is necessary has driven research into better resolving seasonal predictions for temperature and precipitation. Methods for increasing spatial and temporal resolution (downscaling) of the global predictions and the research needed to apply those methods in a prediction setting are discussed in Section 3.7.2.

Dynamical v. statistical tools. Recently researchers have begun to question the degree to which the added expense and complexity of GCMs compared to statistical models is justified, but detailed comparisons of statistical and dynamical model skill are still rare. Statistical predictions of the Indian monsoon rainfall do provide an example of a region in which statistical models continue to out-perform dynamical model predictions (Hastenrath, 1995). The dynamical predictions suffer from a consistently large ensemble spread (Webster et al., 1998), which is compatible with the theory that chaotic weather systems in the Southern Hemisphere may trigger breaks in the Asian monsoon, providing short-term predictability, but limiting seasonal predictability (Rodwell, 1997). Nevertheless, the statistical models have identified robust atmospheric precursors, and demonstrate useful skill over independent retro-active testing periods (Parthasarathy et al., 1991, 1993; Prasad and Singh, 1992; Singh et al., 1995; Yang et al., 1996; Thapliyal, 1997; Venkatesan et al., 1997; Singh and Chattopadhyay, 1998).

Over southern Africa, the dynamical models appear to be slightly better (Landman et al., 2000), possibly because of instability in important SST-climate associations that are likely to weaken the skill of linear statistical models for the region (Landman and Mason, 1999b). Over North America, the multi-year results from a statistical model are found to outperform some AGCMs (Anderson et al., 1999). However, at certain times, such as when ENSO is changing phase, the statistical response in climate over North America may not be robust and AGCMs may better simulate the appropriate climate shifts (Kumar et al., 2000b) due to the full global patterns of anomalous boundary conditions.

One advantage of numerical climate models over statistical models is that an extensive observational database is not required to generate a prediction. However, in order to make a meaningful forecast, observational data is crucial for both the assessment of the model's historical simulations or retrospective forecasts and also for the validation of current operational forecasts. Another advantage of numerical models is that they are not limited by non-stationarity of climate or by extreme or unusual outcomes that may not have occurred in the available historical record. However, numerical models are complex and can be expensive to run. Most importantly, the regions where numerical models exhibit skill vary with season and variable, and even different GCMs vary in where and when they show skill. The choice of whether to use a numerical or statistical model for seasonal prediction ultimately depends on the focus and resources of the forecast producer(s) and users. There are advantages to using both approaches in parallel.

\subsection{Estimating forecast uncertainty}

Due to the chaotic nature of the atmosphere, it is impossible to know exactly how the atmosphere will evolve beyond a few days. Thus, medium and long-range weather forecasts and seasonal climate forecasts usually are presented in probabilistic terms (Murphy, 1990; Tracton and Kalnay, 1993; Déqué et al., 1994; Palmer and Anderson, 1994; Barnett, 1995; Dix and Hunt, 1995; Harrison, 1995; Anderson, 1996; Molteni et al., 1996; Sivillo and Toth, 1997; Sivillo et 
al., 1997; Murphy, 1998; Stockdale et al., 1998b; Mason et al., 1999). Forecast uncertainty derives not only from model weaknesses, but also from the inherent unpredictability of the precise state of the atmosphere. Even with a perfect model, atmospheric internal variability would still impose finite uncertainty on the most likely climate outcome. Probabilistic forecasting provides a means of addressing both sources of forecast uncertainty by indicating the probability distribution of expected possible outcomes (Kumar et al., 2000a). Statistical and dynamical methods have been developed for estimating the probability distribution function (PDF) for climate outcomes for a coming season.

A climatological PDF of seasonal precipitation, for example, indicates the relative frequency with which accumulated precipitation of differing amounts were observed for that season over a historical period. In the case of forecasts of seasonal precipitation, a PDF indicates the probability with which different accumulated totals are estimated to occur. Simple statistical approaches to estimating the seasonal PDF for a region are based on conditional probabilities indicating the relative frequency with which a particular climate outcome was observed under certain boundary forcing, such as, El Niño or La Niña conditions (Mason and Goddard, 2000). Shown in Figure 2 are observed PDFs conditioned on ENSO phase for several regions with documented ENSO teleconnections (Ropelewski and Halpert, 1987). The gray shaded areas represent the neutral distribution, which is defined as the distribution of rainfall anomalies that occurred when the tropical Pacific SSTs were close to normal. The solid and dashed lines indicate the distributions of rainfall anomalies during El Niño and La Niña conditions, respectively. For most of the regions presented in Figure 2, the distributions during ENSO events are shifted positively or negatively relative to the neutral distribution. In some cases, such as central eastern Africa (Figure 2e) La Niña forcing does not lead to a shift in the PDF relative to neutral ENSO conditions, but El Niño conditions greatly enhances the probabilities for aboveaverage rainfall, even though below-average rainfall occurred during several El Niño events. Over India, the rainfall distribution during El Niño events does not seem that different from the distribution during normal years; however, the driest years in the record were observed to occur during El Niño events. The PDFs shown in Figure 2 illustrate that during years of anomalous boundary condition forcing, such as El Niño and La Niña events, both the mean and the spread of the distribution may change relative to the neutral distribution. Furthermore, the alterations to the distributions are not necessarily linearly affected by the boundary forcing (Hoerling et al., 1997). If it is assumed that these statistics are minimally affected by lower frequency variability, then the observed conditional probabilities, such as those shown in Figure 2, may be used in predictions of the future. The main problem with this approach, besides the assumption of climate stationarity, is that each El Niño and La Niña event is unique in amplitude, spatial structure, and evolution, all of which may lead to uniqueness in the associated climate response.

More sophisticated statistical methods of defining forecast probabilities have been implemented (Ward and Folland 1991; Casey 1995; Carter and Elsner 1997; Lehmiller et al., 1997; Mason 1998; Mattes and Mason 1998; Mutai et al., 1998; Mason and Mimmack 2000), but generally maintain the assumption of climate stationarity. Regression-based forecasting approaches can provide confidence intervals (Wilks, 1995), but these, while being indications of average model uncertainty, are poorly related to the inherent unpredictability of a particular forecast period.

Dynamical approaches use an ensemble of GCM predictions to sample the seasonal PDF (Murphy, 1990; Tracton and Kalnay, 1993; Brankovic et al., 1994; Déqué et al., 1994; Palmer and Anderson, 1994; Barnett, 1995; Dix and Hunt, 1995; Harrison, 1995; Anderson, 1996; 
Molteni et al., 1996; Brankovic and Palmer, 1997; Sivillo and Toth, 1997; Sivillo et al., 1997; Murphy, 1998; Stockdale et al., 1998b; Mason et al., 1999). It is known, however, that GCMs have varying degrees of systematic biases in the pattern, amplitude, and variance of their climate variability (Smith and Livezey, 1999; Anderson, 1996). Furthermore, the effect of climate uncertainties introduced by uncertainties in the evolution of the boundary conditions (Barnett, 1995) are rarely quantified in the predicted PDFs. Recalibration of forecast probabilities therefore is required.

\subsection{Forecast reliability and recalibration}

Because there is no guarantee that an ensemble distribution of possible outcomes will provide a reliable indication of forecast uncertainty, an important aspect of forecast skill is the reliability or calibration of forecast probabilities (Murphy and Winkler, 1987; Murphy 1993, 1997; Wilks 1995). The frequency of particular observed outcomes should match the relative frequency with which they are predicted. However, the fact that a forecast is ultimately matched against a single realization of nature introduces conceptual difficulties in verifying individual probabilistic forecasts. Probably the only fair assessment of probabilistic forecasts is to judge whether the forecaster is systematically over- or under-confident over a period of time by comparing the frequency of an outcome relative to the confidence of the forecast probabilities (Wilks, 1995, 2000; Murphy, 1997). In a reliable forecast system, the observations should fall between the $25 \%$-ile and $75 \%$-ile bounds of the forecast PDF $50 \%$ of the time, for example. Reliability and attributes diagrams (Hsu and Murphy, 1986; Wilks, 1995; Hamill, 1997) provide useful indications of the reliability of forecast probabilities, and can be supported by scores obtained from a decomposition of the half-Brier score (Brier, 1950; Murphy, 1973; Wilks, 1995). The area under a relative operating characteristics (ROC) curve is becoming a common indicator of forecast quality (Swets 1973; Mason, 1982; Harvey et al., 1992). However, it should be emphasized that the ROC area can be maximized without requiring the forecast probabilities to be perfectly reliable (Mason and Graham, 1999). Thus, the ROC area does not penalize if the forecast probabilities are systematically over- or under-confident, and this does not encompass all aspects of forecast quality.

Reliability of forecast probabilities can be achieved by issuing perpetual forecasts of the climatological probability of an event, and so reliability is a necessary, but not sufficient aspect of forecast skill. Other commonly used verification measures account for the importance of sharpness by penalizing forecasts that do not deviate from the climatological probability (Murphy, 1993, 1997; Wilks, 1995). For example, the RPSS (Ranked Probability Skill Score) (Epstein, 1969; Murphy, 1971; Wilks, 1995) and LEPSPROB (probabilistic version of the linear error in probability space score) (Ward and Folland, 1991; Potts et al., 1996) reach their highest values when the climate variability is correctly predicted with high probabilities.

Proper assessment of the reliability of a prediction tool can reveal biases in the tool's representation of the forecast probabilities. Methods such as the binned probability ensemble technique (Anderson, 1996; Hamill and Collucci, 1998) can indicate errors in the spread of an ensemble, but such methods do not indicate errors in the central tendency of the predicted PDF that may depend on the magnitude of the predicted climate anomaly (Mason et al., 2000) (Figure 6). Once model biases are identified, the forecast can be recalibrated such that the predicted PDF is more representative of the true uncertainty in the seasonal climate-state being forecast, and the errors of the forecast tool are minimized. 


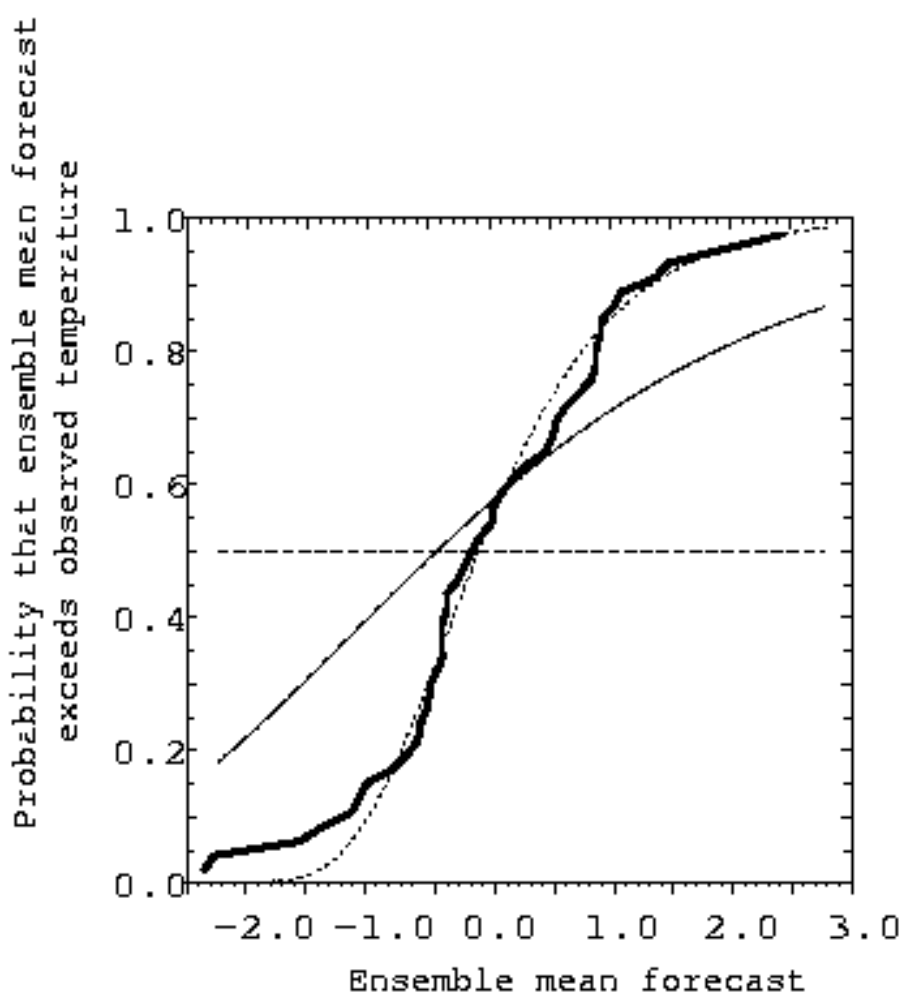

Figure 6. Conditional errors in the simulation of area-averaged September - November $2 \mathrm{~m}$ air temperature over eastern Africa $\left(10^{\circ} \mathrm{N}-10^{\circ} \mathrm{S}, 30^{\circ}-50^{\circ} \mathrm{E}\right), 1950-1994$. The thick solid line shows the cumulative distribution of observed standardized temperatures, while the thin solid line indicates the conditional exceedence probabilities (CEPs), showing how the probability that the ECHAM3.6 ensemble-mean simulation of air temperature exceeded the observed temperature varies as a function of the ensemble-mean temperature. In a model that simulates the central tendency of the seasonal PDF perfectly, the CEP should be independent of the ensemble-mean temperature (dashed horizontal line). In a model with no skill, the CEP will be equal to the climatological probability (dotted line). The CEPs can be defined using generalized linear regression (Mason et al., 2000).

Forecast probabilities of seasonal climate anomalies, including those from statistical models (Mason and Mimmack, 2000), appear to be less reliable than for short- and medium-term weather forecasts (Wilks, 2000a). The short history for which seasonal forecasts are available is an important reason for the lack of research into their reliability. Most measures of reliability, such as the Murphy (1973) decomposition of the half-Brier score and reliability and attributes diagrams (Hsu and Murphy 1986; Wilks 1995; Hamill, 2000), require a long history of forecasts to ensure that the conditional relative frequencies of an event can be estimated with minimal 
sampling error for each forecast probability bin (Wilks 1995). However, methods are being developed to indicate reliability from shorter histories of forecasts (Mason et al., 2000).

Some forecast recalibration methods can also be used to obtain a more complete description of the entire PDF (Wilks and Eggleston, 1992; Briggs and Wilks, 1996; Mason and Graham, 1999; Wilks, 2000b). Typically, most seasonal forecasts are expressed in terms of probabilities of positive or negative anomalies of seasonally averaged conditions, or in terms of tercile probabilities (Mason et al., 1999), but statistical methods can be used to estimate additional forecast detail. The lack of a sufficient history of forecasts precludes a more detailed description of the PDF with any confidence. Since most user requirements are for more detailed information, methods for increasing the information content of seasonal climate forecasts promise to be important research foci in the future.

\subsection{Combining predictions}

That the combination of predictions from different models can result in improvements in forecast skill has been long recognized in the weather forecasting field (Thompson 1976; Clemen and Murphy, 1986; Clemen and Winkler, 1987; Fraedrich and Leslie, 1987). The combination of forecasts has also been a topic of lively debate in economics (Clemen, 1989; Granger, 1989; Winkler, 1989). Objective forecast combination schemes have been applied to seasonal climate forecasts only recently (Fraedrich and Smith 1989; Casey, 1995; Krishnamurti et al., 1999, Graham et al., 2000). Reductions in forecast error have been demonstrated by combining weighted model predictions on the basis of previous model performance. The weighted combinations typically outperform simple averages of model predictions since greater weight is given to models with better historical performance. However, even though such methods of forecast combination will result in a decrease in mean squared-errors, they can weaken other skill measures and often reduce the information from the predicted PDFs (Zhang and Casey, 2000). More comprehensive validation is required to ensure improvements in forecast quality and value. A very straightforward approach to combining predictions from different tools that retains characteristics of the predicted PDF and retains skill is through pooling ensembles from different models. The skill of the pooled super-ensemble is not measurably higher or lower than that of the best tool included (Figure 7). The advantage gained by creating a super-ensemble in this way is that higher skill can be obtained for larger regions, because the best tool will vary with season and region. However, equal weighting of forecasts from models with both good and poor skill leads to a loss of sharpness, or refinement, and impacts on reliability will need to be considered carefully. Forecast combination constitutes an important direction for future research (Epstein, 1988), but needs to draw on experience from other applications.

Subjective forecast combination has become an important area of development with the advent of the regional forecast fora (e.g. Drought Monitoring Centre, 1998), and is used in the construction of the IRI "net assessments" (Mason et al., 1999), and the NCEP seasonal forecasts (van den Dool et al., 1998). The subjective process of blending forecasts for adjacent areas and of combining different forecasts for the same regions is known as "consensus forecasting". Although the subjective process in theory could be improved upon by implementing some objective combination techniques, the consensus forecasting approach has some practical value in that it permits a simple combination of all available forecasts when full or compatible verification data are unavailable. The risk is that forecasts with minimal or no skill can affect the 
consensus adversely, but the approach is supportable on the basis that a simple averaging of forecasts is often an improvement on any one forecast product.
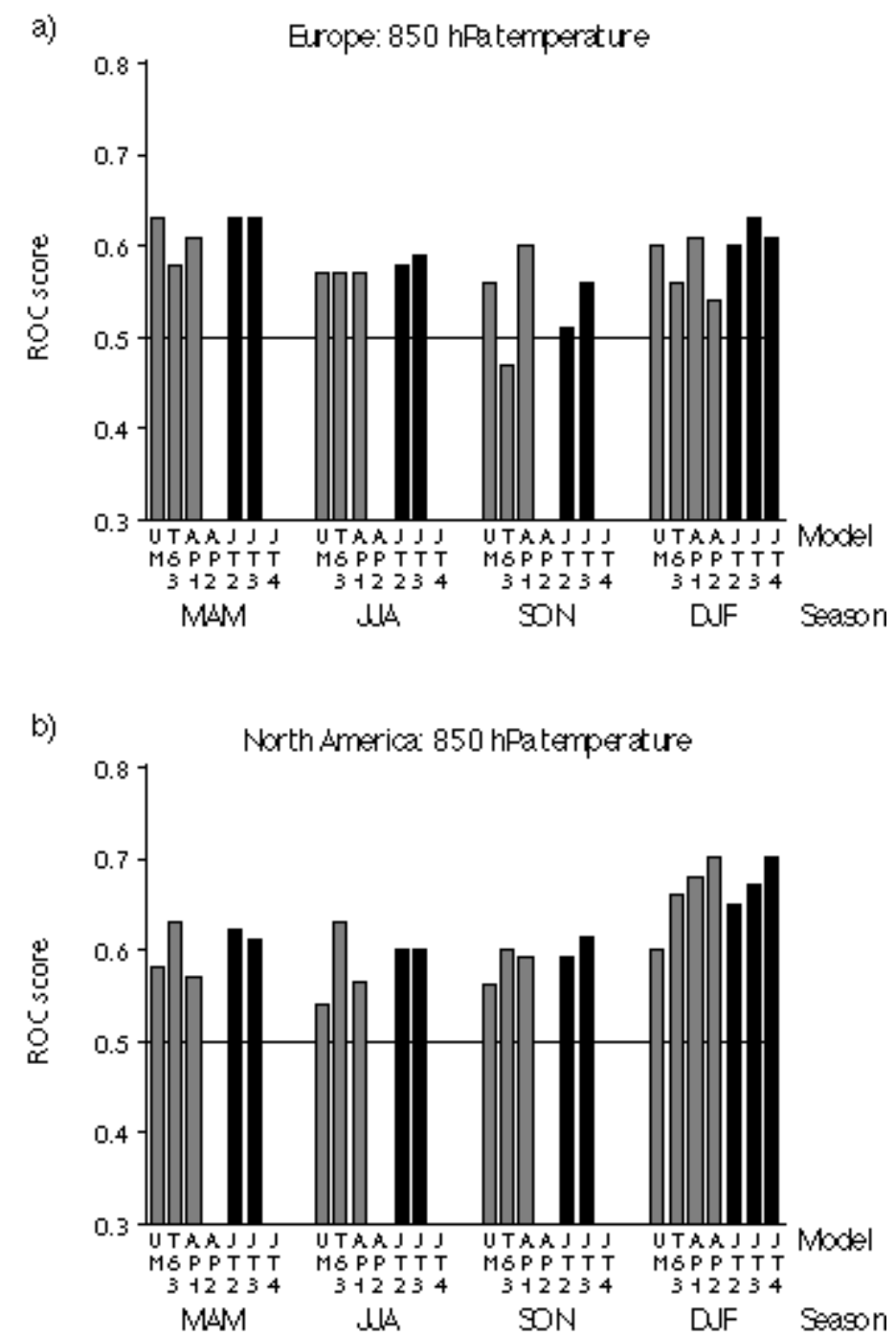

Figure 7. R.O.C. scores (area under relative operating charactistics curve) for belownormal $850 \mathrm{hPa}$ temperature. R.O.C. scores for above-normal temperature are identical. Results are from all four participating PROVOST models (hatched bars) and the multiple-model configurations: JT2, JT3, JT4 (solid bars). UM = UKMO Unified Model; T63 = ECMWF T63 model; AP1 = Météo France ARPËGE T42 L31 model; AP2 = the ARPÈGE T63 L31 (run at Electricite de France (EDF) - DJF season only); JT2 = UM+T63 (18 members); JT3 = UM+T63+AP1 $(27$ members $) ; \quad$ JT4 = UM+T63+AP1+AP2 (36 members, DJF only). (from Graham et al., 2000)

\subsection{Examples from 1997-98}


The exceptional El Niño event of 1997-98 provided an excellent test bed for climate prediction tools and many successes were advertised (Shukla, 1998). The evolution of tropical Pacific SST anomalies associated with the 1997-98 El Niño event were well forecast by both numerical and statistical means (Barnston et al., 1999), but the timing of the initial onset was not well predicted by any of the tools (Landsea and Knaff, 2000).

At its peak, the 1997-98 warm event exhibited a magnitude and spatial structure very similar to the 1982-83 El Niño event (Figure 8); these two El Niños are the strongest warm episodes experienced in the $20^{\text {th }}$ century. Overall, the SSTs throughout the tropics were warmer during 1997-98 than during 1982-83. The northern tropical Atlantic warmed in response to El Niño in the tropical Pacific, as often happens (Enfield and Mayer, 1997), and the southern tropical Atlantic, which has little relation to the variability in the Pacific, was also over $1{ }^{\circ} \mathrm{C}$ warmer than usual. By the end of 1997 the response of the atmospheric circulation over the Indian Ocean region was so strong that the local air-sea system actually developed La Niña-like conditions through coupled instability (Chambers et al., 1999; Webster et al., 1999). This feature appeared as a cold tongue in the eastern Indian Ocean accompanied by warm anomalies in the central/western Indian Ocean. As a result, considerable debate arose over whether coupled instability is a primary or anomalous mechanism for the warming of the central and western tropical Indian Ocean typical during El Niño events (Saji et al., 1999; Reason et al., 2000). The magnitude of the warming in the Indian Ocean was atypical and was not captured by statistical predictions. 


\section{December 1982}

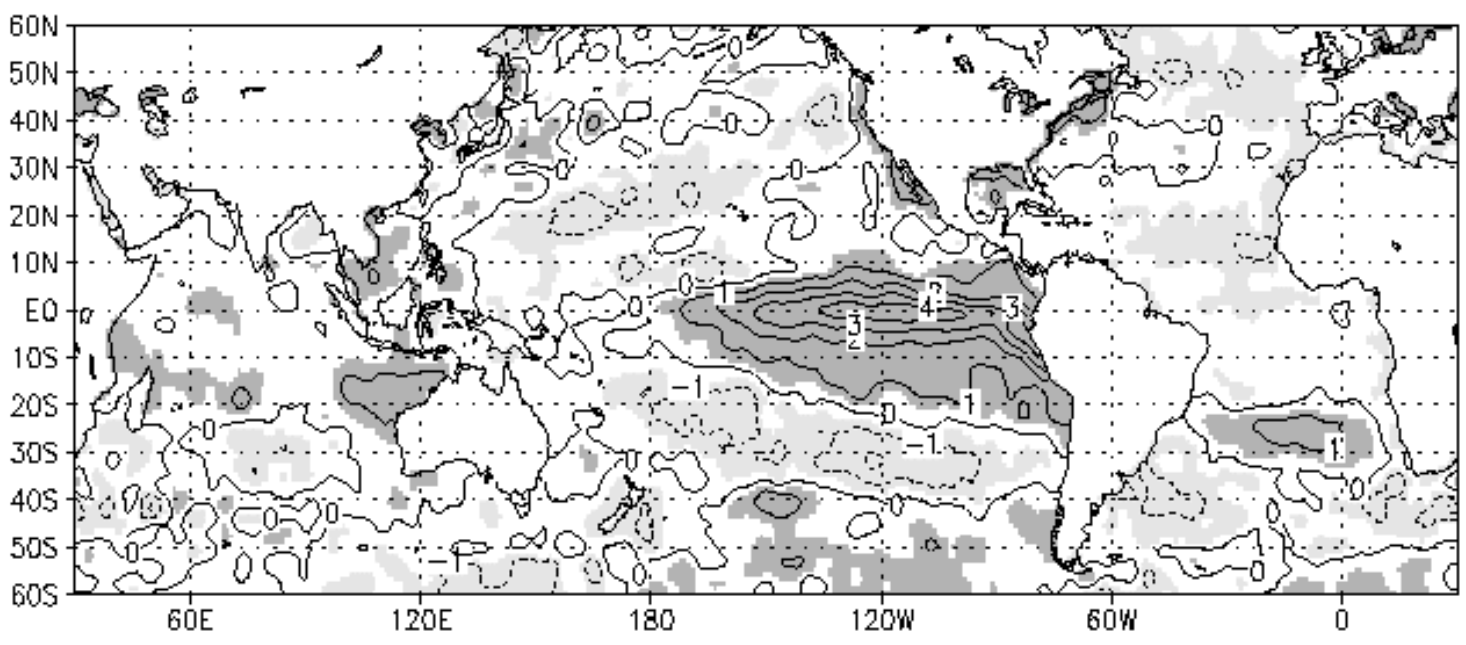

\section{December 1997}

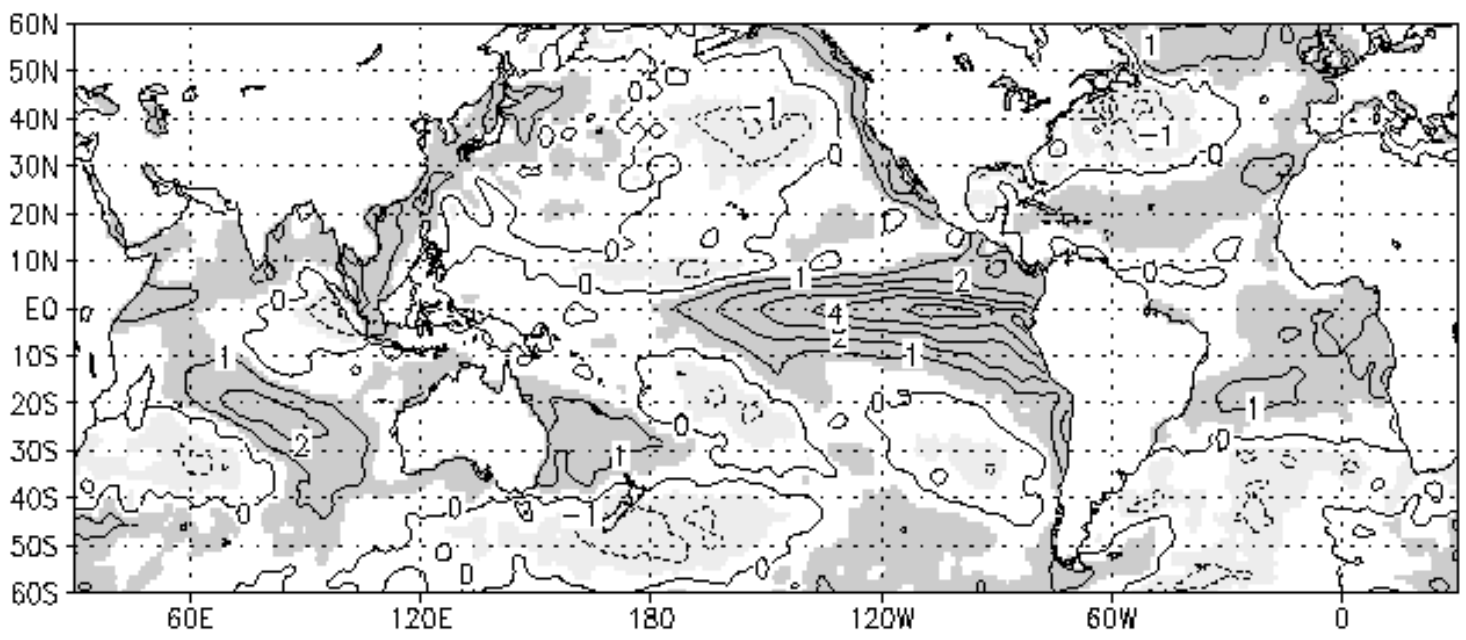

Figure 8. Sea surface temperature anomalies from NOAA's Climate Prediction Center (Reynolds and Smith, 1994) at the peak of the two strongest El Niño events of the $20^{\text {th }}$ century: (a) December 1982, and (b) December 1997. Units are degrees C. Light shading (values less than $-0.5 \mathrm{C}$ ) and dashed contours (1C interval) indicate negative anomalies, and darker shading (values greater than $0.5 \mathrm{C}$ ) and solid contours (1C interval) indicate positive anomalies. 
Although the strong SST forcing of El Niño resulted in climate anomalies in many areas that could have been predicted using simple linear statistics, a few regions with robust climate associations to El Niño, did not experience the expected anomalies during the 1997-98 event. Such examples invite investigation into whether differences between the deterministic prediction and the observed outcome are due to inherent uncertainty represented in the seasonal PDF, or are due to errors or omissions in the modeled climate. Queensland, Australia is a prime example of such climate surprises observed during the 1997-98 El Niño event (Goddard et al., 1998). During El Niño this region typically experiences lower seasonal totals over their rainy season (OctoberFebruary). Based on the conditional probabilities of observed rainfall during the 20 warmest October-November-December (OND) values of the NINO3 index from 1890-1989, the OND season has seen rainfall in the upper tercile $(>67 \%$-ile) of the climatological PDF during only one El Niño case (Figure 2d). The observations for OND 1997 (Figure 9) clearly indicate wellabove average rainfall over parts of Queensland, although the apparent extent of the coverage is highly dependant on the resolution of the observations. Statistical deterministic rainfall predictions for this area failed. 


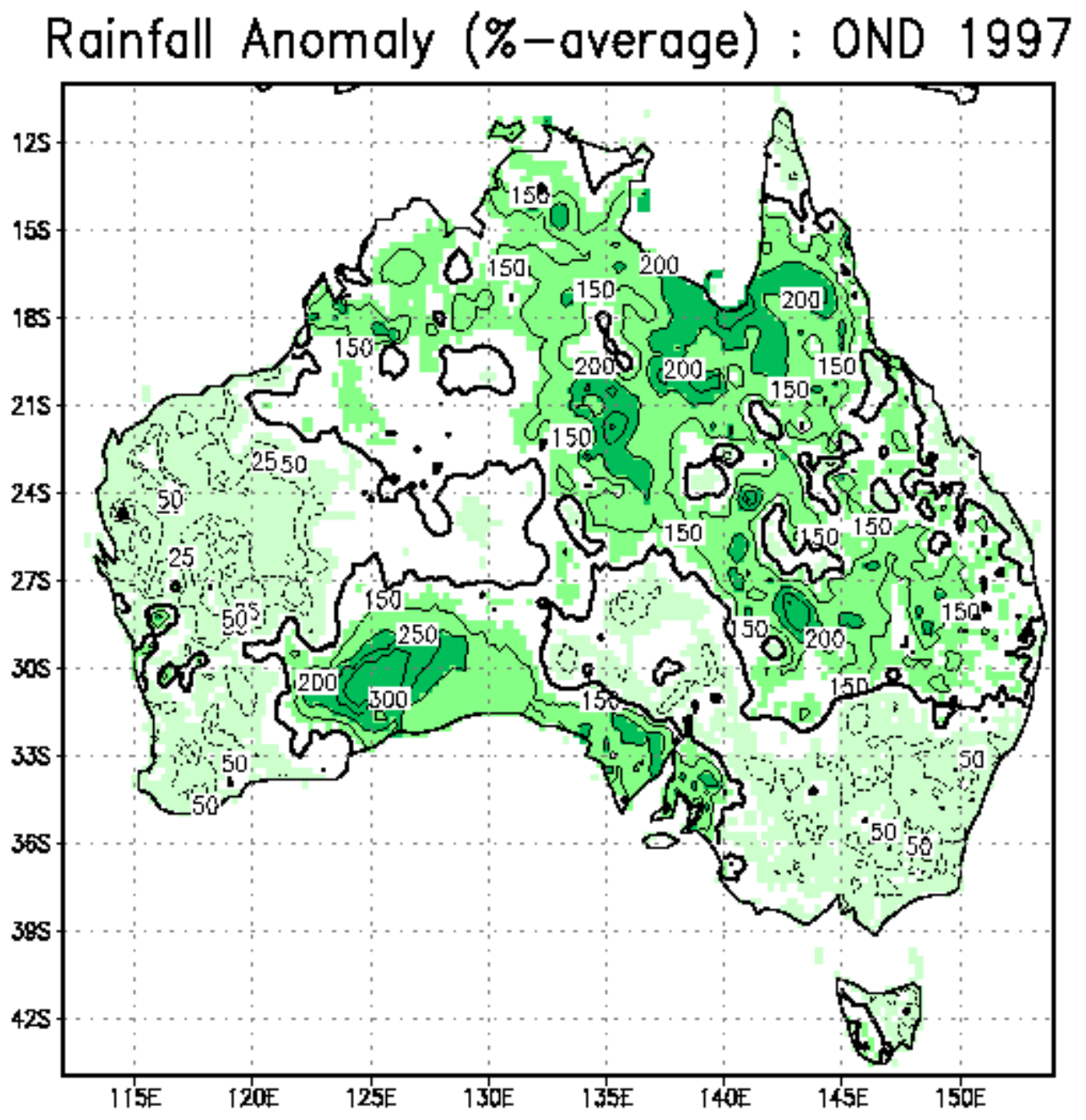

Figure 9. Observed rainfall anomalies over Australia for the October-NovemberDecember 1997 season. Units are percent of average for the OND season, based on 19611990 climatology. Very light shading (starting at 75\%-average) and dashed contours (25\%- and 50\%-average) indicate less than average rainfall. Darker shading (starting at $125 \%$-average, with very dark shading for rainfall anomalies greater than $200 \%$-average) and solid contours (150\%-, 200\%-, and 300\%-average) indicate above average rainfall. Data provided by Queensland Department of Natural Resources at $25 \mathrm{~km}$ gridded resolution.

Dynamical deterministic predictions for Queensland did not perform any better. The question pondered is whether dynamical probabilistic predictions were accurate as it is impossible to assess probabilistic forecasts for an individual season. Several of the models used by the 
International Research Institute (IRI) have statistically significant ensemble-averaged skill in simulating rainfall variability in this region for the OND season, but these models were not suggesting above-normal rainfall for OND 1997.

These AGCMs were unanimously indicating high probabilities of below-normal rainfall over Queensland under a selection of SST scenarios. Even when forced with observed SSTs for the period, high probabilities of widespread below-normal rainfall are simulated. In the previous one occasion on record that above-normal rainfall had been experienced during an El Niño event in the region, similar sea-surface temperature anomalies had occurred off the eastern coast of Australia, but again the models continued to simulate below-normal rainfall. Possibly with improved models it may be possible to generate more accurate ensemble forecasts under such conditions, but the possibility that the observed rainfall was simply an unlikely event cannot be ruled out.

\subsection{Future directions}

\subsubsection{Improved GCM physics and parameterizations.}

Current predictions are limited by very obvious systematic errors in atmosphere, ocean and land models, and especially coupled models. These errors result in incorrect model climatologies and "climate drift", which compromise forecasts at even modest lead-times of a few months. Diagnosing and rectifying errors in such complex models is extremely difficult, as many of the processes interact strongly, and can mask the true source of error. Still, it is possible to identify a number of important common problems with current models. For the atmosphere, parameterizations of convective and marine stratus clouds are extremely important and are in need of improvement. Likewise, improvements are necessary for boundary layer parameterizations, which control fluxes that govern coupling with the land surface and oceans. For the oceans, a primary concern is correctly parameterizing mixing processes in the surface layers, and more generally above the main thermocline. Arriving at more general mixing schemes that can cope with the wide range of conditions encountered in the equatorial and higher latitude oceans is a key problem of relevance to seasonal prediction.

\subsubsection{Data assimilation.}

In every dynamical forecast system it is necessary to initialize the ocean and atmosphere components. The methods used for initialization may be at least as important a limitation on current forecasts as model flaws (Chen et al., 1995, 1998; Behringer et al., 1998). The primary problem lies in the ocean, because the ocean contains the primary "memory" for time scales longer than a few weeks, and the observations are much more limited for the ocean, in most regions. The schemes that are currently used at operational centers involve optimum interpolation or 3-dimensional variational methods (Smith et al., 1991; Ji et al., 1995; Derber and Rosati, 1989), which are quite simple methods, typical of those used for atmospheric assimilation more than a decade ago. More sophisticated methods have been introduced, involving Kalman filter and adjoint approaches (e.g., Cane et al., 1996; Bennett et al., 1998), but are still experimental. At present, only thermal data is assimilated in ocean models used for prediction. Experiments have been done with altimeter data (Ji et al., 2000; Segschneider et al., 1999), and 
efforts are underway to include such data in prediction systems in the near future. Much more work is needed, not only in developing methodologies, but also in applying additional data sources that are presently available, such as satellite scatterometry. A major advancement now being proposed is in situ monitoring of upper-ocean temperature and salinity via programmable buoys. This or other enhanced real-time monitoring of the upper ocean is of fundamental importance to improving predictions, especially outside the tropical Pacific.

\subsubsection{Increased spatial and temporal resolution}

As the use of climate predictions increases, the demand for more detailed information also increases. Very localized predictions, often made using statistical tools, can be tailored to any spatial and temporal resolution desired. Dynamical predictions on regional and global scales, however, typically provide seasonally averaged climate at spatial scales on the order of hundreds of kilometers. In fact the GCMs run operationally by most centers use an effective grid resolution of approximately $2 \times 2$ degrees (approximately 200 kilometer grid spacing). A few approaches to gaining spatial and temporal resolution exist. One may increase the resolution of the global model, or if a specific region is of concern, one may choose a method of statistical or dynamical downscaling. Spatial downscaling may also have the added benefit of improving temporal information, such as the daily statistics of the weather within the seasonal climate. Rainfall in GCMs is generally considered to represent an average quantity over the grid box (Osborn and Hulme, 1998). As a result, GCMs generally overestimate the daily rainfall frequency and underestimate the rainfall variance relative to point observations.

Denser grid spacing in dynamical models obviously improves the resolution of the terrain, which can influence the large scale atmospheric circulation and also local orographically forced precipitation. For example, Figure 10 shows the climatology of precipitation over the United States for observations at 0.5 degree resolution (New et al., 1999) compared to that from an AGCM run at T42 spectral truncation (approximately 2.8 degrees resolution) and at T106 (approximately 1.2 degrees resolution). Not only are orographically related features improved such as the separation in rainfall maxima over the Sierra and northern Rocky mountains, but also features related to the strength and placement of the large scale flow are improved, such as the local rainfall maximum in the southeast. Certain gains of higher resolution global models are obvious, but they come at a price: the amount of computer time needed to run a model at high resolution, and the amount of storage space needed to archive the results are enormous. Furthermore, increasing the resolution of an AGCM is not trivial. Because the sub-grid scale parameterizations, such as convection, may be not be optimized for the higher resolution version, the results may actually be worse in some places (Boyle, 1992). 


\section{Observations}

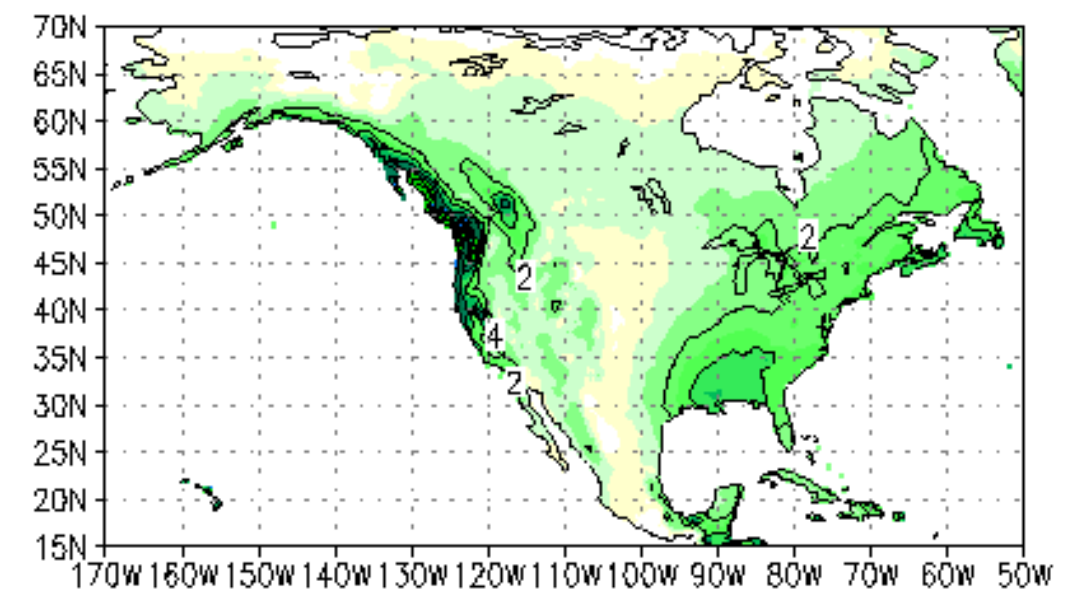

T42

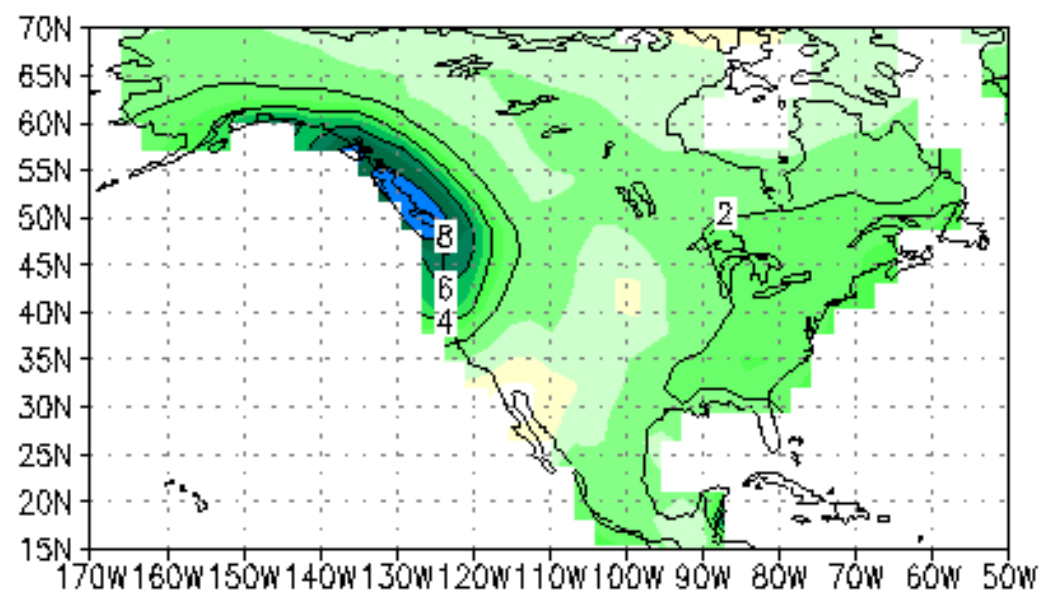

T106

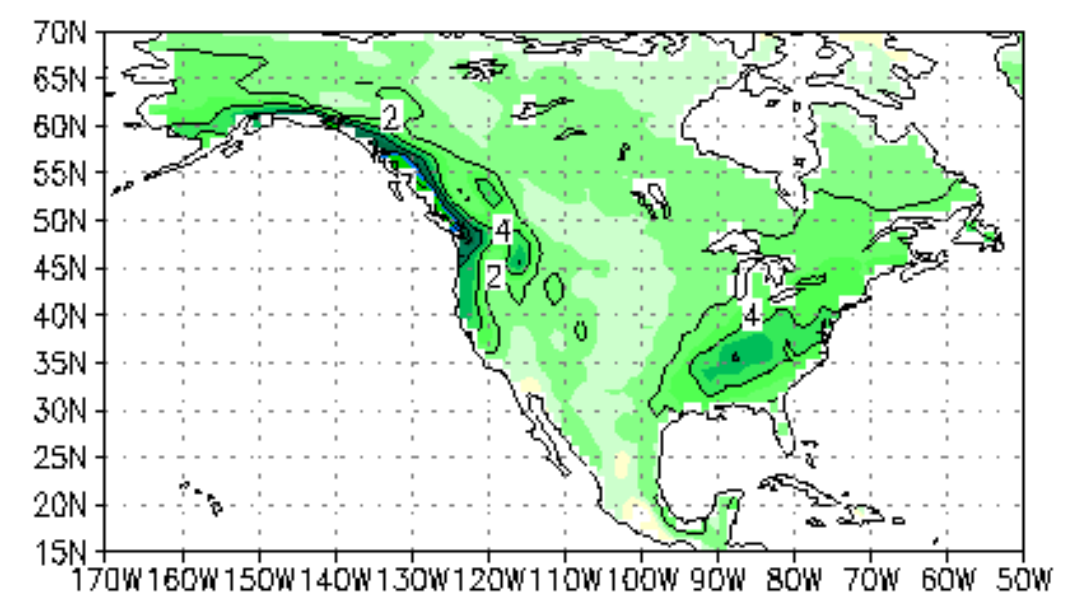


Figure 10. (a) Observed precipitation from University of East Anglia (New et al., 1999) at 0.5 degrees resolution; (b) AGCM simulated precipitation from model run at approximately 2.8 degrees resolution (T42); and, (c) AGCM simulated precipitation from model run at approximately 1.1 degrees resolution (T106). Units are mm/day. Shading contours at $0.25,0.5$, then every 1.0 over $1.0 \mathrm{~mm}$.day, superimposed are contour lines at 2.0 intervals over starting at $2.0 \mathrm{~mm} /$ day.

Alternatively, if increased resolution is required only over a specific area, one may nest a higher resolution limited area regional model within the global GCM. The regional model is driven by the time-dependant large-scale fields that are produced by the GCM. Inside the regional model domain, the terrain is better resolved and the physical equations are integrated on the higher resolution grid. The GCM drives the regional model by flow through the lateral boundaries (Giorgi et al., 1993) or by specifying the large scale flow structure throughout the domain which is then refined by the regional model (Juang and Kanamitsu, 1994). The most common problems with nested models are boundary effects resulting from the abrupt change in spatial scale and parameterizations that are not tuned for the region or high spatial resolution of the limited area model. Of course propagation of errors is also a concern, as the regional model will add detail and possibly even amplitude to errors in the large-scale circulation coming from the GCM. Assessment of gains from this approach is judged over multi-year, preferably ensemble, integrations of the regional model forced by the global model. When this approach succeeds, great improvements can be achieved not only in the details of the surface climate, but in spatial coverage of simulation skill and its level of statistical significance (Sun and Graham, 2000).

Using a regional model for prediction has yet another level of issues to consider. One must still have a multi-year integration so that anomalous behavior can be properly recognized relative to the model's time-averaged behavior. One must also consider how to treat the problem probabilistically. If the predictions are meant to refine potential climate scenarios, how should the ensemble member(s) from the global model be chosen? Should the treatment of the highly detailed prediction ensemble differ from that of the global prediction ensemble, because the downscaling process may produce locally stronger signals leading to locally larger uncertainty over the ensemble. The main scientific argument against dynamical downscaling using nested models is the physical inconsistencies introduced by the one-way flow of information from the global model to the regional model. There also exist global GCMs that have been designed with stretched or telescoping grids, which gradually increase resolution over the area of interest, avoiding the boundary problems and the inconsistent information flow problems possible in nesting experiments (Fox-Rabinovitz et al., 1997). The other issues of assessment and prediction are not avoided. The main practical argument against dynamical downscaling is the expense of computer time needed to run the historical simulations and predictions and the amount of storage space needed to archive the output. Again, the existence of a good observational network is crucial for validating the data from high resolution models. Especially for validation of higher order statistics of seasonal climate, such as characteristics of the daily rainfall, the observations must be available at a scale comparable to that of the model.

Several less complex and less costly approaches exist that currently may give comparable or even better results than dynamical downscaling for some cases. The simplest is statistical downscaling, in which local patterns of climate and the associated weather statistics are 
conditioned on some larger mode of the climate, such as ENSO, or more generally recent observations of global SSTs and/or atmospheric circulation. The larger scale SST or atmosphere patterns are often filtered to a lower dimensional space using empirical orthogonal functions (EOFs), for example, to focus on the dominant patterns of the variability. The main caveat in using statistical downscaling, as with any purely empirical method, is that the past climate on which the tool is based may not be representative of future variability.

A compromise exists between the empirical approach and the dynamical approach. Hybrid downscaling follows a similar methodology to statistical downscaling, but the downscaled climate is conditioned on the SST or atmospheric circulation prediction from a dynamical model for the same season, as opposed to the previous season's observations. A review comparing various statistical downscaling methods applied to GCM output can be found in Wilby and Wigley (1997). For some applications and in some regions hybrid downscaling may show marked improvement over purely statistical downscaling and may be comparable to dynamical methods (Gershunov et al., 2000). A dense network of observations is assumed in the statistical and hybrid approaches since these tools could not be constructed without them.

\section{APPLICATION OF CLIMATE PREDICTIONS}

\subsection{Rationale, impediments, approaches}

The primary motivation for public support of climate prediction science is the desire to reduce the enormous socio-economic costs of climate fluctuations, especially of the major floods and droughts to which less developed countries are so vulnerable (Glantz et al., 1991; NOAA, 1994; Glantz, 1996; Moura and Sarachik, 1997; Stern and Easterling, 1999; WMO, 1999; Agrawala et al., 2000). However, the presence of a skillful forecast product does not guarantee that benefits will accrue; these can only be realized through the parallel development of application science and the ongoing institutionalization of the lessons learned. This short section rounds out the paper's discussion of climate prediction science with a brief introduction for climate scientists to the issues involved in the application of climate predictions.

An application of climate prediction information may be defined as a conscious effort to use that information in decision making, in the expectation of benefits such as reduced risk, reduced costs, or increased production or profits. Decisions can range from simple choices about the priorities for a farmer's workday to million-dollar decisions about seasonal operating strategy for a hydro-electricity reservoir. Intrinsic to the decision process is a system that is sensitive to climate, a model of that system in the mind or computer of the user, and a range of decision options. The wide public interest in the El Niño implies that myriad day to day decisions are influenced by seasonal climate outlooks, but beyond this, progress in the systematic application of climate forecasts has been rather slow, being mainly limited to specific research-based projects in areas having very strong ENSO signals (Hammer et al., 2000).

Impediments to the application of climate forecasts arise from several causes. First, the climate exhibits only limited predictability and skillful forecasts are available only for some seasons and regions (as discussed in Section 3.2) - unlike the case of weather forecasts, where useable forecasts are available for all times of the year and all regions of the world. Climate forecasters do not always make the predictability limitations transparent or provide adequate useable guidance on the accuracy of the forecasts. Second, the uncertainty and probabilistic nature of climate forecast information is often difficult for the user to understand and to 
incorporate into their decision processes. Probabilistic forecasts are too often wrongly communicated or interpreted as deterministic forecasts, and the simplistic use of such deterministic forecasts may neglect the chance of costly failures. For other users the risk of such failures may negate the potential long-run value of the probabilistic forecasts. Third, current forecast products generally lack the spatial, temporal and element specificity that users seek for their specific decision making needs - forecast are generally made for 3-month seasons, large regions over $1000 \mathrm{~km}$ in width, and mean temperature and rainfall totals only. Fourth, users may not have sufficient understanding of their system or acceptable options for using a skillful forecast. Fifth, the huge diversity of user circumstances, and the lack of familiarity of the producer and the user with the basic knowledge and language of each other's world compound the above difficulties. Because there is a cost to learning and communication, the investment by the user may exceed the potential benefits to them of the forecast information.

Additionally, the application of climate prediction information necessarily spans a range of disciplines in the climatic, biophysical/ecological and socio-economic fields, and usually will need to be well grounded in a knowledge of the situation of a particular region, country, sector and user group. The goal of developing applications thus involves considerable complexity. At the most quantitative, technically sophisticated extreme, there are simulation models or decision support systems that can be driven by observed or model simulated historical data and to retrospectively explore and test complex decision options. Farm system models that incorporate details of soils, crops and management options are a particular focus for such applications research (Messina et al, 1999; Hammer, 2000; Jones et al., 2000). In public health, models of disease vectors are being studied (Linthicum et al., 1999, Bouma et al., 1997), while in water resources, reservoir management is a focus (Georgakakos et al., 1997; 1998.) A major issue in this research is how to downscale the spatially and temporally coarse output of global climate prediction models to meet the needs of crop models, which focus on specific fields or districts and are driven by daily weather data (Hansen, 2000). Generally, decision support systems studies have concentrated on the biophysical and economic parts of the spectrum, with little work on social systems modeling.

The application of climate forecasts has been explored largely by top-down approaches, by seeking uses for existing forecast information, and less commonly by a bottom-up approach, by examining a decision situation to identify niches and needs for climate forecasts (Stern and Easterling, 1999). It is also possible to take an "end-to-end" approach (NOAA, 1994), which emphasizes that the effective application of climate predictions requires consideration of the full span of factors and their interactions, including social behavior, institutional constraints, sector system models (e.g. crop-climate models), the design and communication of forecast products, the choice of prediction models, and the adequacy of observational data (fig. 11). The end-toend approach applies to both the research stage and to the operational stage. Both cases require transdisciplinary collaboration and close interaction between users, producers, their intermediaries, and the applications scientists. 


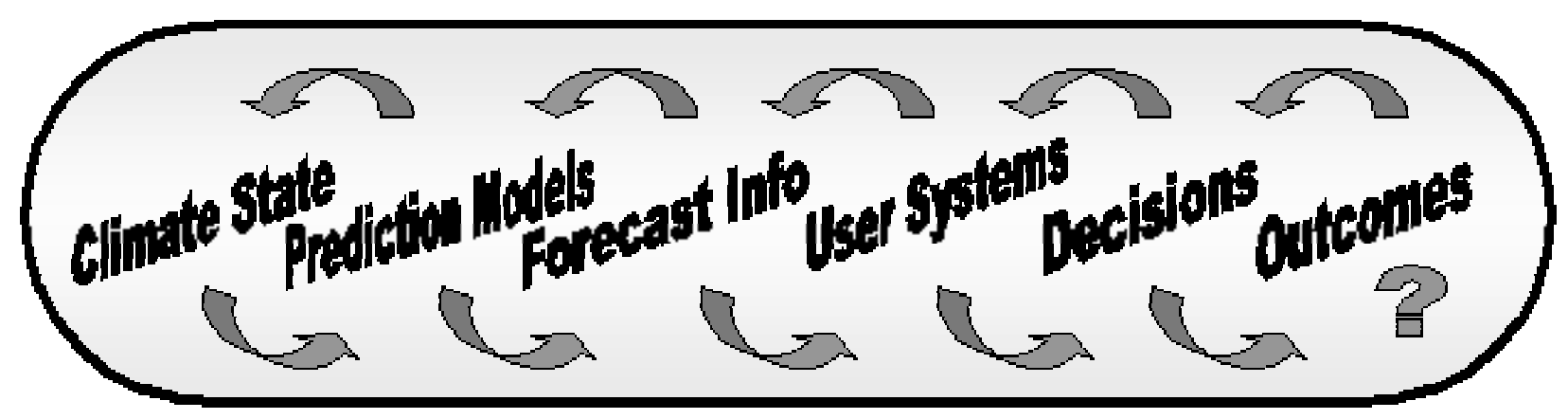

Figure 11. Schematic representation of the end-to-end concept, which indicates that desired outcomes require attention to all processes throughout the chain - physical, biological, socio-economic. An application involves a complex web of interactions, transformations and multiple feedbacks along the whole chain.

\subsection{The user and societal perspective}

If societal benefit is the goal of climate prediction then it is clear that a strong orientation toward users, the decision-making process, and the social setting is required in applications research. There is a wealth of related information in the fields of development studies, global change, technology transfer, and weather forecast application upon which to draw. Furthermore, experience with users forms a critical basis for guiding the priorities for prediction research, as well as justifying the funding for such research. As an example, user demand for predictions of extreme seasonal rainfall has led to the development of an $85 \%$ ile rainfall forecast at the IRI (Mason et al., 1999).

Whether or not a formal quantified decision model exists, there will always be some qualitative mental model in the mind of the user, based on custom, direct experience and hearsay. These may incorporate traditional or evolving coping strategies, for example water harvesting and storage practices, and diversification of crop types. Such mental models filter the incoming information and shape the interpretation and hence degree of effectiveness of forecast use, depending on the source, form, mode and language of the communication. Typically, people want a forecast to be set in a context of their past and recent experience, for example by comparing with the previous year's situation, or with a particular extreme event. Such mental analogues are valuable because they contain a vast richness of information on the behavior of the whole system with which the user is concerned (e.g. for a farmer this might include patterns of weeds, pests, animal health, harvesting problems, produce quality and prices, damage to farm roads, debt status, credit availability, community confidence, government policy shift, etc.) However, from the climate perspective, individual analogues can be misleading, as the climate outcome in any particular year is only one realization (possibly even an unlikely one) from a distribution of possibilities.

Usually a user will face a cascade of multiple decision possibilities, some being of the "no regret" type, such as advancing the maintenance of machinery, where the cost of the marginal action and the potential for losses are small, and some involving very high costs, or the potential for intolerable losses, such as bankruptcy or the total loss of the family's animal herd. In principle, a decision situation can be described by utility or cost-loss functions for the distribution of possible decisions and outcomes. In the simple binary case (event occurring or 
not, event forecast or not), a 2x2 matrix can be used to represent net economic consequences of a single decision, as well as its component costs and gains (see Katz and Murphy, 1997). This approach can be useful to help users conceptualize and assess the potential consequences of decisions, such as the trade-offs between long-term average gains versus short-term risks, though ordinarily the user will have more that just two options to consider and accurate cost/loss data will not be available. It should also be recognized that users face a multiplicity of decisions and that relative to the effects of prices, social or political expectation, imposed regulations, etc, a forecast of the season's climate may form only a minor component of most decisions. For these and other reasons, even a technically skillful forecast is not necessarily a useful forecast for the decision maker.

The design and communication of prediction information to users is an active subject of research. Typically the forecast information is communicated to the end-user or decision makers by an intermediary such as a journalist, agricultural extension worker, government officer, or climate consultant, and end-users are likely to have more than just one source of information, including web sites, advisors, the media, acquaintances and community leaders. There are often several steps in the information wholesaling process, in which each intermediary interprets and transforms the information to suit the intended recipient, possibly with the aid of a system model. Dissemination by rural radio and the use of local languages is being explored in parts of Africa (J. Phillips, N. Ward, pers. comm.) The media is a valuable channel for timely broadcast of basic information, but it may distort the message to make it simpler or more sensational or due to lack of expertise (Nicholls and Kestin, 1998.) Institutions may be externally constrained, structurally unable or unwilling to hear, learn or apply new climate prediction methods (Rayner et al., 2000).

The justification of an application ultimately lies in the benefits it generates. Public expenditures on climate prediction research and operational forecasting are rightly argued for on the grounds of the potential benefits but as yet there is relatively little detailed understanding and quantification of these benefits and how they might be distributed in the community. In less developed tropical countries that are particularly vulnerable to climatic stresses, the primary benefits being sought are those of increased resilience of livelihoods and of land use-such things are difficult to measure even over long periods. Some studies in developed countries have reported good benefit/cost ratios at a macroeconomic level though many assumptions are involved (Katz and Murphy, 1997; Solow et al., 1998). There will be winners and losers. For example, any increased agricultural production resulting from widespread use of climate prediction-based farming strategies will act to drive down prices bringing benefits to consumers but not necessarily to farmers (Mjelde et al., 1998; Mjelde et al, in press). A study of the use of climate information by the main actors in Peru's fisheries (artisanal fishers, factory fishing companies, company labor, and fisheries conservators/regulators) showed that the design of forecast products and dissemination strategy plays an important role in determining the actors' options for action and the participation by actors and others in the resulting benefits and detriments (Pfaff et al., 1999; Broad et al., in press).

\subsection{Demonstration and implementation}

Finally, in order to achieve lasting benefits of climate prediction information, it is necessary for applications researchers to go beyond basic research, to progressively undertake pilot and demonstration projects and associated capacity building for the people and institutions expected to carry out the applications in individual countries (NOAA, 1999). It is also necessary for the 
climate operations community to provide an operational infrastructure that fosters the generation and exchange of appropriate climate data and forecast products between countries, together with initiatives to enhance the user-producer interface. These implementation activities are an integral part of the end-to-end concept. 
REFERENCES

Aceituno, P., 1988. 'On the functioning of the Southern Oscillation in the South American sector', Mon. Wea. Rev., 116, 505-524.

Agrawala, S., Broad, K. and Guston, D.H., 2000. 'Integrating climate forecasts and societal decision making: challenges to an emergent boundary organization'. Science, Technology, and Human Values. (in press).

Ahago, V. O., 1992. 'Numerical forecast of the onset of the 1990 seasonal long rains in Kenya', Meteorol. Mag., 121, 123-130.

Allan, R., Lindesay, J., and Parker, D. 1996. El Nino Southern Oscillation and climate variability, CSIRO, Australia.

Anderson, J. L., 1996. 'A method for producing and evaluating probabilistic forecasts from ensemble model integrations', J. Climate, 9, 1518-1530.

Anderson, J. L., van den Dool, H., Barnston, A. G., Chen, W., Stern, W., Ploshay, J., 1999. 'Present-day capabilities of numerical and statistical models for atmospheric extratropical seasonal simulation and prediction', Bull. Amer. Meteorol. Soc., 80, 1349-1362.

Annamalai, H., 1995. 'Intrinsic problems in the seasonal prediction of the Indian-summer monsoon rainfall', Meteorol. Atmos. Phys., 55, 61-76.

Argo Science Team, 1999. 'On the design and implementation of Argo: an initial plan for a global array of profiling floats', International CLIVAR Project Office Report No. 21, GODAE Report No. 5, 32 pp. (available from Argo web site: http://www.argo.ucsd.edu

Bah, A., 1987. 'Towards the prediction of Sahelian rainfall from sea surface temperatures in the Gulf of Guinea', Tellus, 39A, 39-48.

Balmaseda, M. A., Davey, M. K., and Anderson, D. L. T., 1995. 'Decadal and seasonal dependence of ENSO prediction skill', J. Climate, 8, 2705-2715.

Barnett, T.P., 1995. 'Monte Carlo climate forecasting', J. Climate, 8, 1005-1022.

Barnett, T. P., Dümenil, L., Schlese, U., Roeckner, E., and Latif, M., 1991. 'The Asian snow cover-Monsoon-ENSO connection', in Glantz, M. H., Katz, R. W., and Nicholls, N., (eds), Teleconnections Linking Worldwide Climate Anomalies: Scientific Basis and Societal Impact, Cambridge University Press, pp. 191-225.

Barnett, T. P., Graham, N. E., Cane, M. A., Zebiak, S. E., Dolan, S. C., O’Brien, J., and Legler, D., 1988. 'On the prediction of the El Niño of 1986-1987', Science, 241, 192-196.

Barnett, T.P., Latif, M., Graham, N. E., Flügel, M., Pazan, S., and White, W. B., 1993. 'ENSO and ENSO related predictability, I, Prediction of equatorial Pacific sea surface temperature with a hybrid coupled ocean-atmosphere model', J. Climate, 6, 1545-1566.

Barnston, A.G., 1994. 'Linear statistical short-term climate predictive skill in the Northern Hemisphere', J. Climate, 7, 1513-1564.

Barnston, A. G., Glantz, M. H., and He, Y., 1999a. 'Predictive skill of statistical and dynamical climate models in forecasts of SST during the 1997-98 El Niño episode and the $1998 \mathrm{La}$ Niña onset', Bull. Amer. Meteorol. Soc., 80, 217-244.

Barnston, A. G., and He, Y. X., 1996. 'Skill of canonical correlation analysis forecasts of 3month mean surface climate in Hawaii and Alaska', J. Climate, 9, 2579-2605.

Barnston, A. G., and Ropelewski, C. F., 1992. 'Prediction of ENSO using canonical correlation analysis', J. Climate, 5, 1316-1345.

Barnston, A. G., Thiaw, W. M., and Kumar, V., 1996. 'Long-lead forecasts of seasonal precipitation in Africa using CCA', Wea. Forecasting, 11, 506-520. 
Barnston, A. G., and van den Dool, H. M., 1993. 'A degeneracy in cross-validated skill in regression-based forecasts', J. Climate, 6, 963-977.

Barnston, A. G., van den Dool, H. M., Zebiak, S. E., Barnett, T. P., Ji, M., Rodenhuis, D. R., Cane, M. A., Leetmaa, A., Graham, N. E., Ropelewski, C. R., Kousky, V. E., O’Lenic, E. A., and Livezey, R. E., 1994. 'Long-lead seasonal forecasts - Where do we stand?', Bull. Amer. Meteorol. Soc., 75, 2097-2114.

Battisti, D.S., 1988. 'The dynamics and thermodynamics of a warming event in a coupled tropical atmosphere/ocean model', J. Atmos. Sci., 45, 2889-2919.

Battisti, D.S. and Hirst, A.C., 1989. 'Interannual variability in the tropical atmosphere/ocean system: Influence of the basic state, ocean geometry, and non-linearity', J. Atmos. Sci., 46, 1687-1712.

Behringer, D.W., Ji, M., Leetma, A., 1998. 'An improved coupled mode for ENSO prediction and impications for ocean initialization. Part I: the ocean data assimilation system', Mon. Wea. Rev., 126, 1013-1021.

Bengtsson, L., Schlese, U., Roeckner, E., Latif, M., Barnett, T. P., and Graham, N. E., 1993. 'A Two tiered approach to long-range climate forecasting', Science, 261, 1026-1029.

Bennet, A.F., Boon, B.S., Harrison, D.E., and McPhaden, M.J., 1998. 'Generalized inversion of tropical atmosphere-ocean data and a coupled mode of the tropical Pacific', J. Climate, 11, 1768-1792.

Bjerknes, J., 1966. 'A possible response of the atmospheric Hadley circulation to equatorial anomalies of ocean temperature', Tellus, 18, 820-829.

Bjerknes, J., 1969. 'Atmospheric teleconnections from the equatorial Pacific', Mon. Wea. Rev., 97, 163-172.

Bjerknes, J., 1972. 'Large-scale atmospheric response to the 1964-65 Pacific equatorial warming', J. Phys. Oceanogr., 2, 212-217.

Bladé, I., 1999. 'The influence of mid-latitude ocean-atmosphere coupling on the low-frequency variability of a GCM. Part II: Interannual variability induced by tropical SST forcing', J. Climate, 12, 21-45.

Blumenthal, M. B., 1991. 'Predictability of a coupled ocean-atmosphere model', J. Climate, 4, 766-784.

Bouma, M.J., Poveda, G., Rojas, W, Chavasse, D., Quiñones, M., Cox, J. and Patz, J. 1997. 'Predicting high-risk years for malaria in Colombia using parameters of El Niño South Oscillation', Trop. Med. Internat. Health, 2, 1122-1127.

Boyle, J.S., 1993. 'Sensitivity of dynamical quantities to horizontal resolution for a climate simulation using the ECMWF (cycle 33) model', J. Climate, 6, 796-815.

Brankovic, C., Molteni, F., Tibaldi, S., and Cubasch, U., 1990. 'Extended-range predictions with the ECMWF models: Time-lagged ensemble forecasting', Q. J. Roy. Meteor. Soc., 116, 867912.

Brankovic, C., and Palmer, T. N., 1997. 'Atmospheric seasonal predictability and estimates of ensemble size', Mon. Wea. Rev., 125, 859-874.

Brankovic, C., Palmer, T. N. and Ferranti, L., 1994. 'Predictability of seasonal atmospheric variations', J. Climate, 7, 217-237.

Brier, G.W. 1950. 'Verification of forecasts experssed in terms of probability', Mon. Wea. Rev., 78, $1-3$. 
Briggs, W. M., and Wilks, D. S., 1996. 'Extension of the Climate Prediction Centre long-lead temperature and precipitation outlooks to general weather statistics', J. Climate, 9, 3496-3504.

Broad, K., Pfaff, A.P. and Glantz, M.H., 2000. 'Effective and equitable dissemination of seasonal-to-interannual climate forecasts: policy implications from the Peruvian fishery during El Niño 1997-98'. Journal of Policy Analysis \& Management. in press

Brooks, C. E. P. and Braby, H. W., 1921. 'The clash of the trades in the Pacific', Q. J. R. Meteorol. Soc., 47, 1-13.

Busalacchi, A. J. and O'Brien, J. J., 1980. 'Seasonal variability in a model of the tropical Pacific', J. Phys. Oceanogr., 10, 1929-1952.

Busalacchi, A. J. and O'Brien, J. J., 1981. 'Interannual variability of the equatorial Pacific in the 1960s', J. Geophys. Res., 86, 10901-10907.

Cane, M.A., Kaplan, A., Miller, R.N., Tang, B., Hackert, E.C., and Busalacchi, A.J., 1996. 'Mapping tropical Pacific sea level: Data assimilation via a reduced state space Kalman filter', J. Geophys. Res., 101, 22599-22617.

Cane, M. A. and Sarachik, E. S., 1977. 'Forced baroclinic ocean motions, II, The linear equatorial bounded case', J. Mar. Res., 35, 395-432.

Cane, M. A. and Sarachik, E. S., 1981. 'The response of a linear baroclinic equatorial ocean to periodic forcing', J. Mar. Res., 39, 651-693.

Cane, M. A. and Zebiak, S. E., 1985. 'A theory for El Niño and Southern Oscillation', Science, 228, 1085-1087.

Cane, M. A., Zebiak, S. E., and Dolan, S. C., 1986. 'Experimental forecasts of El Niño', Nature, 321, 827-832.

Carr, M. -E., Broad, K., 2000. 'Satellites, society and the Peruvian fisheries during the 1997-98 El Niño', in Halpern, D., (ed), Satellites, Oceanography and Society, Elsevier Science B.V., in press.

Carson, D.J., 1998. 'Seasonal forecasting', Q. J. Roy. Meteorol. Soc., 124, 1-26.

Carter, M.M. and Elsner, J.B. 1997. A statistical method for forecasting rainfall over Puerto Rico', Wea. Forecasting, 12, 515-525.

Casey, T. M., 1995. 'Optimal linear combination of seasonal forecasts', Austr. Meteorol. Mag., 44, 219-224.

Casey, T. M., 1998. 'Assessment of a seasonal forecast model', Austr. Meteorol. Mag., 47, 103-111.

Chambers, D. P., Tapley, B. D., and Stewart, R. H., 1999. 'Anomalous warming in the Indian Ocean coincident with El Niño’, J. Geophys. Res., 104, 3035-3047.

Chan, J. C. L., Shi, J. E., and Lam, C. M., 1998. 'Seasonal forecasting of tropical cyclone activity over the western North Pacific and the South China Sea', Wea. Forecasting, 13, 997-1004.

Chang, P., Li., J., and Li, H., 1997. 'A decadal climate variation in the tropical Atlantic Ocean from thermodynamic air-sea interactions', Nature, 385, 516-518.

Charney, J.G. and Shukla, J., 1981. Monsoon Dynamics, Cambridge University Press, New York, 99-109.

Chen, D., Zebiak, S. E., Busalacchi, A. J., and Cane, M. A., 1995. 'An improved procedure for El Niño forecasting: implications for predictability’, Science, 269, 1699-1702. 
Chen, D., Cane, M.A., Zebiak, S.E., and Kaplan, A., 1998. 'The impact of sea level data assimilation on the Lamont model prediction of the 1997/98 El Niño', Geophys. Res. Lett., 25, 2837-2840.

Chen, Y. -Q., Battisti, D. S., Palmer, T. N., Barsugli, J., and Sarachik, E. S., 1997. 'A study of the predictability of tropical Pacific SST in a coupled ocean/atmosphere model using singular vector analysis: the role of the annual cycle and the ENSO cycle', Mon. Wea. Rev., 125, 831-845.

Chu, P. S., Katz, R. W., and Ding, P., 1995. 'Modeling and forecasting seasonal precipitation in Florida - a vector time-domain approach', Int. J. Climatol., 15, 53-64.

Clemen, R. T., 1989. 'Combining forecasts - a review and annotated-bibliography', Int. J. Forecasting, 5, 559-583.

Clemen, R. T., and Murphy, A. H., 1986. 'Objective and subjective precipitation probability forecasts: some methods for improving forecast quality', Wea. Forecasting, 1, 213-218.

Clemen, R. T., and Winkler, R. L., 1987. 'Calibrating and combining precipitation probability forecasts', in Viertl, R. (ed), Probability and Bayesian Statistics, Plenum Press, London, 97-110.

Colin, C., and Garzoli, S. L., 1987. 'In situ wind measurements and the ocean response in the equatorial Atlantic during the SEQUAL-FOCAL experiment', J. Geophys. Res., 92, 3729-3740.

Currie, R. G., 1993. 'Luni-solar 18.6- and 10-11-year solar cycle signals in South African rainfall', Int. J. Climatol., 13, 237-256.

Davey, M. K., and Anderson, D. L. T., 1998. 'A comparison of the 1997/98 El Niño with other such events', Weather, 53, 295-302.

Davey, M.K., Anderson, D.L.T., and Lawrence, S., 1996. 'A simulation of variability in ENSO forecast skill', J. Climate, 9, 240-246.

Delecluse, P., Davey, M. K., Kitamura, Y., Philander, S. G. H., Suarez, M., and Bengtsson, L., 1998. 'Coupled general circulation modeling of the tropical Pacific', J. Geophys. Res., 103, 14357-14373.

Déqué, M., Dreveton, C., Braun, A., and Cariolle, D., 1994. 'The climate version of Arpege/IFS: a contribution to the French community climate modeling', Clim. Dyn., 10, 249-266.

Derber, J. D., and Rosati, A., 1989, 'A global oceanic data assimilation system', J. Phys. Oceanogr., 19, 1333-1347.

Dickinson, R.E., Shaikh, M., Bryant, R., and Graumlich, L. 1998. 'Interactive canopies for a climate model', J. Climate, 11, 2823-2836.

Dirmeyer, P. A., and Shukla, J., 1993. 'The effect on regional and global climate of expansion of the world's deserts', Quart. J. Roy. Meteor. Soc., 122, 451-482.

Dix, M.R. and Hunt, B.G., 1995. 'Chaotic influences and the problem of deterministic seasonal prediction', Int. J. Climatol., 15, 729-752.

Drought Monitoring Centre - Nairobi, 1998. 'Climate Outlook Forum for Eastern Africa Subregion for the period ending December 1998', 58pp, (available from the Drought Monitoring Centre - Nairobi).

Dyer, T. G. J., and Tyson, P. D., 1977. 'Estimating above and below normal rainfall periods over South Africa 1972-2000', J. Appl. Meteorol., 16, 145-147.

Elfandy, M. G., Ashour, Z. H., and Taiel, S. M. M., 1994. 'Time-series models adoptable for forecasting Nile floods and Ethiopian rainfalls', J. Climate, 12, 1974-1989. 
Eltahir, E. A. B., and Bras, R. L., 1996. 'Precipitation recycling', Rev. Geophys., 34, 367-378.

Enfield, D. B., 1996: 'Relationship of inter-American rainfall to tropical Atlantic and Pacific SST variability', Geophys. Res. Lett., 23, 3305-3308.

Enfield, D. B., and Mayer, D.A., 1997. 'Tropical Atlantic sea surface temperature variability and its relation to El Niño-Southern Oscillation', J. Geophys. Res., 102, 929-945.

Enfield, D. B., Mestas-Nunez, A., Mayer, D. A., and Cid-S., L., 1999. 'How ubiquitous is the dipole relationship in the tropical Atlantic sea surface temperatures?', J. Geophys. Res., 104, 7841-7848.

Enfield, D. B., and Alfaro, E. J., 1999. 'The dependence of Caribbean rainfall on the interactions of the tropical Atlantic and Pacific', J. Climate, 12, 2093-2103.

Epstein, E.S. 1969. 'A scoring system for probability forecasts of ranked categories', J. Appl. Meteor., 8, 985-987.

Epstein, E.S., 1988. 'Long-range weather prediction: limits of predictability and beyond', Wea. Forecasting, 3, 69-75.

Fennessey, M. J., and Shukla, J., 1999. 'Impact of initial soil wetness on seasonal atmospheric prediction', J. Climate, 12, 3167-3180.

Flügel, M., and Chang, P., 1998. 'Does the predictability of ENSO depend on the seasonal cycle?', J. Atmos, Sci., 55, 3230-3243.

Folland, C. K., Owen, J. A., Ward, M. N., and Colman, A. W., 1991. 'Prediction of seasonal rainfall in the Sahel region of Africa using empirical and dynamical methods', $J$. Forecasting, 10, 2-56.

Folland, C. K., Palmer, T. N., and Parker, D. E., 1986, 'Sahel rainfall and world-wide sea temperatures', Nature, 320, 602-607.

Fox-Rabinovitz, M. S., Stenchikov, G. L., Suarez, M. J., and Takacs, L. L., 1997. 'A finite difference GCM dynamical core with a variable resolution stretched grid', Mon. Wea. Rev., 125, 2943-2968.

Fraedrich, K., and Leslie, L. M., 1987. 'Combining predictive schemes in short-term forecasting', Mon. Wea. Rev., 125, 1640-1644.

Fraedrich, K., and Smith, N. R., 1989. 'Combining predictive schemes in long-range forecasting', J. Climate, 2, 291-294.

Francis, R. I. C. C., and Renwick, J. A., 1998. 'A regression-based assessment of the predictability of New Zealand climate anomalies', Theor. Appl. Climatol., 60, 21-36.

Frankignoul, C., 1985. 'Sea surface temperature anomalies, planetary waves and air-sea feedback in the middle latitudes', Rev. Geophys., 23, 357-390.

Frey, H., Latif, M., and Stockdale, T., 1997. 'The coupled GCM ECHO2, I, The tropical Pacific', Mon. Wea. Rev., 125, 703-720.

$\mathrm{Fu}$, L. -L., Christensen, E. J., and Yamarone, C. A., 1994. 'TOPEX/POSEIDON mission overview', J. Geophys. Res., 99, 24369-24381.

Gershunov, A. and Barnett, T., 1998. 'Interdecadal modulation of ENSO teleconnections', Bull. Amer. Meteorol. Soc., 79, 2715-2725.

Gershunov, A., Barnett, T. P., Cayan, D. R., Tubbs, A., and Goddard, L., 2000, 'Predicting and downscaling ENSO Impacts on intraseasonal precipitation statistics in California: The 19971998 event', J. Hydrometeol., in press.

Giannini, A., Kushnir, Y., and Cane, M. A., 2000. 'Interannual variability of Caribbean rainfall, ENSO, and the Atlantic Ocean', J. Climate, 13, 297-311. 
Gill, A.E., 1980. 'Some simple solutions for heat induced tropical circulation', Q. J. Roy. Meteorol. Soc., 106, 447-462.

Giorgi, F., Marinucci, M.R., and Bates, G.T., 1993. 'Development of a second-generation regional climate model (RegCM2). Part I: Boundary-layer and radiative transfer processes', Mon. Wea. Rev., 121, 2794-2831.

Goddard, L., and Graham, N.E., 1997. 'El Niño in the 1990s', J. Geophys. Res., 102, 10423-10436.

Goddard, L. and Graham, N.E., 1999. 'The importance of the Indian Ocean for simulating rainfall anomalies over eastern and southern Africa', J. Geophys. Res., 104, 19099-19116.

Goddard, L., Mason, S. J., Graham, N. E., and Thiaw, W., 1998. 'Climate surprises of the 199798 El Niño', in Proceedings of the $23^{\text {rd }}$ Annual Climate Diagnostics and Prediction Workshop, American Meteorological Society, 34-37.

Godfrey, J. S., Houze, R. A. Jr., Johnson, R. H., Lukas, R., Redelsperger, J. -L., Sumi, A., and Weller, R., 1998. 'Coupled Ocean-Atmosphere Response Experiment (COARE): An interim report', J. Geophys. Res., 103, 14395-14450.

Georgakakos, A.P, Georgakakos, K.P., Yao, H., Guetter, A.K., Grimm, A.M., and Munhoz da Cunha. 1997. 'Integrated forecast control schemes for operational reservoir management with application in Southern Brazil'. In: 13th Conference on Hydrology, 77th AMS annual Meeting, Long Beach, California, 2-7 February 1997.

Georgakakos, A. P., Yao, H., Mullusky, M.G., and Georgakakos, K.P., 1998. 'Impacts of climate variability on the operational forecast and management of the upper Des Moines River basin'. Water Resources Research, 34(4), 799-821.

Glantz, M. H. 1996. Currents of Change: El Niño's impact on climate and society. Cambridge: Cambridge University Press.

Glantz, M. H., Katz, R.W., and Nicholls, N. (eds.) 1991. Teleconnections linking workdwide climate anomalies: scientific basis and societal impact. Cambridge: Cambridge University Press.

GOOS First Session, 1998. Intergovernmental Oceanographic Commission Reports of Meetings of Experts and Equivalent Bodies. IOC-WMO-UNEP-ICSU-FAO Living Marine Resources Panel of the Global Ocean Observing System (GOOS), Paris UNESCO GOOS Report No. 54.

Goswami, B., and Shukla, J., 1991. 'Predictability of a coupled ocean-atmosphere model', $J$. Climate, 4, 3-22.

Graham, N. E., Michaelson, J., and Barnett, T. P., 1997. 'An investigation of the El NiñoSouthern Oscillation cycle with statistical models, I, Precursor field characteristics', $J$. Geophys. Res., 92, 14251-14270.

Graham, N. E., Michaelson, J., and Barnett, T. P., 1997. 'An investigation of the El NiñoSouthern Oscillation cycle with statistical models, II, Model results', J. Geophys. Res., 92, 14271-14289.

Graham, R. J., Evans, A. D. L., Mylne, K. R., Harrison, M. S. J., and Robertson, K. B., 2000. 'As assessment of seasonal predictability using Atmospheric General Circulation Models', Q. J. R. Meteorol. Soc., in press.

Granger, C. W. J., 1989. 'Combining forecasts - 20 years later', J. Forecasting, 8, 167-173.

Gray, W. M., Landsea, C. W., Mielke, P. W., and Berry, K. J., 1992. 'Predicting Atlantic seasonal hurricane activity 6-11 months in advance', Wea. Forecasting, 7, 440-455. 
Gray, W. M., Landsea, C. W., Mielke, P. W., and Berry, K. J., 1994. 'Predicting Atlantic basin seasonal tropical cyclone activity by 1 June', Wea. Forecasting, 9, 103-115.

Grimm, A. M., Ferraz, S.E.T., and Gomes, J., 1998. 'Precipitation anomalies in Southern Brazil associated with El Niño and La Niña events', J. Climate, 11, 2863-2880.

Grimm, A. M., Barros, V. R., and Doyle, M. E., 2000. 'Climate variability in Southern South America associated with El Niño and La Niña events', J. Climate, 13, 35-58.

Gutzler, D.S., and Shukla, J., 1984, 'Analogs in the wintertime 500mb height field', J. Atmos. Sci., 41, 177-189.

Hamill, T. M., 1997. 'Reliability diagrams for multicategory probabilistic forecasts', Wea. Forecasting, 12, 736-741.

Hamill, T., and Collucci, S. J., 1998. 'Verification of Eta-RSM short-range ensemble forecasts', Mon. Wea. Rev., 125, 1312-1327.

Hammer, G. L., Nicholls, N., and Mitchell, C. (eds.) 2000. Applications of Seasonal Climate Forecasting in Agricultural and Natural Ecosystems: The Australian Experience. In: Atmospheric and Oceanographic Sciences Library, 21. Kluwer, Dordrecht, 482 pp.

Hammer, G.L., 2000. 'A general systems approach to applying seasonal climate forecasts'. In Applications of Seasonal Climate Forecasting in Agricultural and Natural Ecosystems: The Australian Experience. Atmospheric and Oceanographic Sciences Library, 21. Kluwer, Dordrecht.

Hansen, J.W., (ed.) 2000. Proceedings of Workshop on Linking Climate Prediction Model Output with Crop Model Requirements, Palisades, New York, 28-29 April 2000. International Research Institute for Climate Prediction, New York. [In preparation.]

Harvey, L. O., Hammond, K. R., Lusk, C. M., and Mross, E. F., 1992. 'The application of signal detection theory to weather forecasting behavior', Mon. Wea. Rev., 120, 863-883.

Hastenrath, S., 1978. 'On modes of tropical circulation and climate anomalies', J. Atmos. Sci., 35, 2222-2231.

Hastenrath, S., 1984. 'Predictability of north-east Brazil droughts', Nature, 307, 531-533.

Hastenrath, S., 1987. 'On the prediction of India monsoon rainfall anomalies', J. Climate Appl. Meteor, 26, 847-857.

Hastenrath, S., 1995. 'Recent advances in tropical climate prediction', J. Climate, 8, 1519-1532.

Hastenrath, S., and Greischar, L., 1993. 'Changing predictability of Indian monsoon rainfall anomalies', Proc. Ind. Acad. Sci., 102, 35-47.

Hastenrath, S., Greischar, L., and van Heerden, J., 1995. 'Prediction of the summer rainfall over South Africa', J. Climate, 8, 1511-1518.

Hastenrath, S., and Heller, L., 1977. 'Dynamics of climatic hazards in northeast Brazil', Q. J. Roy. Meteor. Soc., 103, 77-92.

Hastenrath, S., and Lamb, P., 1977. 'Some aspects of circulation and climate over the eastern equatorial Atlantic', Mon. Wea. Rev., 105, 1019-1023.

Hayes, S. P., Mangum, L. J., Picaut, J., Sumi, A., and Takeuchi, K., 1991. 'TOGA-TAO: A moored array for real-time measurements in the tropical Pacific Ocean', Bull. Amer. Meteorol. Soc., 72, 339-347.

Hess, J. C., Elsner, J. B., and LaSeur, N. E., 1995. 'Improving seasonal hurricane predictions for the Atlantic basin', Wea. Forecasting, 10, 425-432.

Hildebrandson, H.H., 1897. 'Quelque recherches sur les entres d'action de l'atmosphere', K. Sven. Vetenskaps akad. Handl., 29, 1-33. 
Hirst, A. C., and Hastenrath, S., 1983. 'Atmosphere-ocean mechanisms of climate anomalies in the Angola - tropical Atlantic sector', J. Phys. Oceanogr., 13, 1146-1157.

Hoerling, M.P., Kumar, A., Zhong, M., 1997. 'El Nino, La Nina, and the nonlinearlity of their teleconnections', J. Climate, 10, 1769-1786.

Houghton, R. W., and Tourre, Y. M., 1992. 'Characteristics of low frequency SST fluctuations in the tropical Atlantic', J. Climate, 5, 765-771.

Hsieh, W. W., and Tang, B., 1998. 'Applying neural network models to prediction and data analysis in meteorology and oceanography', Bull. Amer. Meteorol. Soc., 79, 1855-1870.

Hsu, W. -R., and Murphy, A. H., 1986. 'The attributes diagram: a geometrical frame work for assessing the quality of probability forecasts', Int. J. Forecasting, 2, 285-293.

Huang, B. and Shukla, J., 1997. 'Characteristics of the interannual and decadal variability in a general circulation model of the tropical Atlantic Ocean', J. Phys. Oceangr., 27, 1693-1712.

Huang, J., van den Dool, H.M., and Barnston, A.G., 1996. 'Long-lead seasonal temperature prediction using optimal climate normals', J. Climate, 9, 809-817.

Hunt, B.G., 1997. 'Prospects and problems for multi-seasonal predictions: some issues arising from a study of 1992', Int. J. Climatol., 17, 134-154.

Hutchinson, P., 1992. 'The Southern Oscillation and prediction of Der season rainfall in Somalia', J. Climate, 5, 525-531.

Inwards, R., 1994. Weather Lore: A Collection of Proverbs, Sayings and Rules Concerning the Weather, Senate, London, $190 \mathrm{pp}$.

Ji, M., Leetma, A., and Derber, J., 1995. 'An ocean analysis system for seasonal to interannual climate studies', Mon. Wea. Rev., 123, 460-481.

Ji, M., Leetmaa, A., and Kousky, V. E., 1998. 'An improved coupled model for ENSO prediction and implications for ocean initialization. Part II: the coupled model', Mon. Wea. Rev., 126, 1022-1034.

Ji, M., Leetmaa, A., and Kousky, V. E., 1996. 'Coupled model forecasts of ENSO during the 1980s and 1990s at the National Meteorological Center', J. Climate, 9, 3105-3120.

Ji, M., Reynolds, R.W., and Behringer, D.W., 2000. 'Use of TOPEX/Poseidon sea level data for ocean analyses and ENSO prediction: some early results', J. Climate, 13, 216-231.

Jin, F. -F. and Neelin, J. D., 1993a. 'Modes of interannual tropical ocean-atmosphere interaction - a unified view, I, Numerical results', J. Atmos. Sci., 50, 3477-3503.

Jin, F. -F. and Neelin, J. D., 1993b. 'Modes of interannual tropical ocean-atmosphere interaction - a unified view, III, Analytical results in a fully coupled case', J. Atmos. Sci., 50, $3523-3540$.

Johansson, A., Barnston, A.G., Saha, S., and van den Dool, H.M., 1998. 'On the level of forecast skill in northern Europe', J. Atmos. Sci., 55, 103-127.

Jones, J.W., O'Brien, J.J., Podestá, G., Zazueta, F., and Hansen, J.W., 2000. 'Agricultural applications of climate predictions: bridging the gap between research and its application in the SE USA'. In: Proceedings of the International Forum on Climate Prediction, Agriculture and Development. International Research Institute for Climate Prediction, Palisades, New York. (in press.)

Jones P. D., 1994. 'Hemispheric surface air temperature variations: A reanalysis and an update to 1993', J. Climate, 11, 1794-1802.

Juang, H.-M. H. and Kanamitsu, M., 1994. 'The NMC regional spectral model', Mon. Wea. Rev., 122, 3-26. 
Jury, M. R., 1996. 'Regional teleconnection patterns associated with summer rainfall over South Africa, Namibia and Zimbabwe', Int. J. Climatol., 16, 135-153.

Jury, M. R., 1998. 'Statistical analysis and prediction of KwaZulu-Natal climate', Theor. Appl. Climatol., 60, 1-10.

Jury, M. R., Mulenga, H. M., and Mason, S. J., 1999a. 'Development of statistical long-range models to predict summer climate variability over southern Africa', J. Climate, 12, 1892-1899.

Jury, M. R., Pathack, B., and Parker, B., 1999b. 'Climatic determinants and statistical prediction of tropical cyclone days in the southwest Indian Ocean', J. Climate, 12, 1738-1746.

Kang, I.S. and Kug, J.S. 2000. 'An El Nino prediction system using an intermediate ocean and a statistical atmosphere', Geophys. Res. Lett., 27, 1167-1170.

Katz, R. W. and Murphy, A., (eds.) 1997. Economic Value of Weather and Climate. Cambridge. Cambridge: Cambridge University Press.

Keppenne, C. L. and Ghil, M., 1992. 'Adaptive filtering and the Southern Oscillation Index', J. Geophys. Res., 97, 20449-20454.

Kiladis, G. N., and Diaz, H. F., 1989. 'Global climatic anomalies associated with extremes extremes in the Southern Oscillation', J. Climate, 12, 1854-1992.

Kirtman, B. P., 2000. Experimental Long Lead Forecast Bulletin. Center for Ocean-AtmosphereLand Studies. 9 (1). [Available from COLA, 4041 Powder Mill Road, Suite 302, Calverton, MD, 20705-3106, USA, or on-line at http://www.iges.org/ellfb]

Kirtman, B.P., Shukla, J., Huang, B., Zhu, Z., and Schneider, E.K. 1996. 'Multiseasonal predictions with a coupled Tropical Ocean - Global Atmosphere system', Mon. Wea. Rev., 125, 789-808.

Kirtman, B. P., and Schopf, P. S., 1998. 'Decadal variability in ENSO predictability and prediction', J. Climate, 11, 2804-2822.

Kleeman, R., Moore, A. M., and Smith, N. R., 1995. 'Assimilation of subsurface thermal data into a simple ocean model for the initialisation of an intermediate tropical coupled oceanatmosphere forecast model', Mon. Wea. Rev., 123, 3103-3113.

Klein, S. A., Soden, B. J., and Lau, N. -C., 1999. 'Remote sea surface temperature variations during ENSO: Evidence for a tropical atmospheric bridge', J. Climate, 12, 917-932.

Klopper, E., Landman, W. A., and van Heerden, J., 1998. 'The predictability of seasonal maximum temperature in South Africa', Int. J. Climatol., 18, 741-758.

Knaff, J.A. and Landsea, C.W. 1997. 'An El Nino Southern Oscillation climatology and persistence (CLIPER) forecasing scheme', Wea. Forecasting, 12, 633-652.

Koster, R.D., Suarez, M.J., and Heiser, M. 2000. 'Variance and predictability of precipitation at seasonal-to-interannual timescales', J. Hydromet., 1, 26-46.

Krishna Kumar, K., Soman, M. K., and Rupa Kumar, K., 1995. 'Seasonal forecasting of Indian summer monsoon rainfall: a review', Weather, 50, 449-466.

Krishna Kumar, K., Kleeman, R., Cane, M. A., and Rajagopalan, B., 1999a. 'Epochal changes in Indian monsoon-ENSO precursors', Geophys. Res. Lett., 26, 75-78.

Krishna Kumar, K., Rajagopalan, B., and Cane, M. A., 1999b. 'On the weakening relationship between the Indian monsoon and ENSO', Science, 284, 2156-2159.

Krishnamurti, T. N., Kishtawal, C. M., LaRow, T. E., Bachiochi, D. R., Zhang, Z., Williford, C. E., Gadgil, S., and Surendran, S., 1999. 'Improved weather and seasonal climate forecasts from multimodel superensembles', Science, 285, 1548-1550. 
Kumar, A., and Hoerling, M. P., 1995. 'Prospects and limitations of seasonal atmospheric GCM predictions', Bull. Amer. Meteorol. Soc., 26, 335-345.

Kumar, A. and Hoerling, M.P., 1998. 'Annual cycle of Pacific/North American seasonal predictability associated with different phases of ENSO', J. Climate, 11, 3295-3308.

Kumar, A., Hoerling, M.P., Ji, M. and Sardeshmukh, P., 1996, 'Assessing a GCM's suitability for making seasonal predictions', J. Climate, 9, 115-129.

Kumar, A., Barnston, A., Peng, P., Hoerling, M. P., and Goddard., L., 2000a. 'Changes in the spread of the variability of the seasonal mean atmospheric states associated with ENSO', $J$. Climate, in press.

Kumar, A., Wang, W., Hoerling, M. P., Leetma, A., and Ji, M., 2000b, 'The sustained North American warming of 1997 and 1998', J. Climate, submitted.

Landman, W. A., and Klopper, E., 1998. '15-year simulation of the December to March rainfall season of the 1980s and 1990s using canonical correlation analysis (CCA)', WaterSA, 24, 281-285.

Landman, W. A., and Mason, S. J., 1999a. 'Operational prediction of South African rainfall using canonical correlation analysis', Int. J. Climatol., 19, 1073-1090.

Landman, W. A., and Mason, S. J., 1999b. 'Change in the association between Indian Ocean seasurface temperatures and South African summer rainfall', Int. J. Climatol., 19, 1477-1492.

Landman, W. A., and Mason, S. J., 2000. 'Near-global forecasts of austral summer sea-surface temperatures using canonical correlation analysis', J. Climate, submitted.

Landman, W. A., and Mason, S. J., Tyson, P. D., and Tennant, W. J., 2000. 'Retro-active skill of multi-tiered forecasts of summer rainfall over southern Africa', Int. J. Climatol, accepted for publication.

Landsea, C. W., and Knaff, J. A., 2000. 'How much "skill" was there in forecasting the Great 1997-98 El Niño', Bull. Amer. Meteorol. Soc., in press.

Lamb, P. J. and Peppler, R. A., 1991. 'West Africa', in Glantz, M. H., Katz, R. W., and Nicholls, N. (eds), Teleconnections Linking Worldwide Climate Anomalies, Cambridge University Press, Cambridge, pp. 121-189.

Larow, T.E. and Krishnamurti, T.N. 1998. 'Initial conditions and ENSO prediction using a coupled ocean-atmosphere model', Tellus, 50, 76-94

Latif, M., and Flügel, M., 1991. 'An investigation of short-range climate predictability in the tropical Pacific', J. Geophys, Res., 96, 2661-2673.

Latif, M., and Graham, N. E., 1992. 'How much predictive skill is contained in the thermal structure of an OGCM?', J. Phys, Oceanogr., 22, 951-962.

Latif, M., Barnett, T. P., Cane, M. A., Flügel, M., Graham, N. E., von Storch, H., Xu, J. -S., and Zebiak, S. E., 1994. 'A review of ENSO prediction studies', Climate Dyn., 9, 167-179.

Latif, M., Anderson, D. L. T., Barnett, T. P., Cane, M. A., Kleeman, R., Leetmaa, A., O’Brien, J., Rosati, A., and Schneider, E., 1998. 'A review of the predictability and prediction of ENSO', J. Geophys. Res., 103, 14375-14393.

Latif, M., and Grötzner, A., 2000. 'The equatorial Atlantic oscillation and its response to ENSO', Climate Dyn., 16, 213-218.

Latif, M., Sterl, A., Maier-Reimer, E., and Junge, M. M., 1993. 'Structure and predictability of the El Niño/Southern Oscillation phenomenon in a coupled ocean-atmosphere general circulation model', J. Climate, 6, 700-708.

Lau, K. M. and Sheu, P. J., 1988. 'Annual cycle, quasi-biennial oscillation and Southern Oscillation in global precipitation', J. Geophys. Rev, 93, 10975-10988. 
Lau, N. -C., Philander, S. G. H., and Nath, M. J., 1992. 'Simulation of ENSO-like phenomena with a low-resolution coupled GCM of the global ocean and atmosphere', J. Climate, 5, 284307.

Lau, N. -C., and Nath, M. J., 1996, "The role of the "Atmospheric Bridge" in linking tropical Pacific ENSO events to extratropical SST anomalies', J. Climate, 9, 2036-2057.

Legras, B. and Ghil, M., 1985. 'Persistent anomalies, blocking and variations in atmospheric predictability', J. Atmos. Sci., 42, 433-471.

Lehmiller, G. S., Kimberlain, T. B., and Elsner, J. B., 1997. 'Seasonal prediction models for North Atlantic basin hurricane location', Mon. Wea. Rev., 125, 1780-1791.

Lehodey, P., Bertignac, M., Hampton, J., Lewis, A., and Picaut, J., 1997. 'El Niño Southern Oscillation and tuna in the western Pacific', Nature, 389, 715-718.

Lindzen, R. S. and Nigam, S., 1987. 'One the role of sea surface temperature gradients in forcing low-level winds and convergence in the tropics', J. Atmos. Sci., 44, 2418-2436.

Linthicum, K.J., Anyamba, A., Tucker, C.J., Kelley, P.W., Myers, M.F., and Peters, C.J.. 1999. 'Climate and satellite indicators to forecast Rift Valley Fever'. Science, 285, 397-400.

Liu, W. T., Tang, W., and Atlas, R., 1996. 'Responses of the tropical Pacific to wind forcing as observed by spaceborne sensors and simulated by an ocean general circulation model', $J$. Geophys. Res., 101, 16345-16359.

Livezey, R. E., and Barnston, A. G., 1988. 'An operational multifield analog prediction system for the United States seasonal temperatures. Part I: system design and winter experiments', $J$. Geophys. Res., 93, 19053-19074.

Lockyer, N. and Lockyer, W.J.S., 1902. 'On the similarity of the short-period pressure variation over large areas', Proc. R. Soc. London, 71, 134-135.

Lockyer, N. and Lockyer, W.J.S., 1904. 'The behavior of the short-period atmospheric pressure variation over the earth's surface', Proc. R. Soc. London, 73, 457-470.

Lorenz, E. N., 1963. 'Deterministic nonperiodic flow', J. Atmos. Sci. 20 130-141.

Lorenz, E. N., 1984. 'Irregularity; a fundamental property of the atmosphere', Tellus, 36A, 98110.

Lorenz, E. N., 1990. 'Can chaos and intransitivity lead to interannual variability?' Tellus, 42A, 378-389.

Makarau, A, and Jury, M. R., 1997. 'Predictability of Zimbabwe summer rainfall', Int. J. Climatol., 17, 1421-1432.

Marengo, J. A., and Hastenrath, S., 1993. 'Case studies of extreme climate events in the Amazon basin', J. Climate, 6, 617-627.

Markhan, C.G. and McLain, D.R., 1977. 'Sea surface temperature related to rain in Ceara, northeast Brazil', Nature, 265, 320-323.

Mason, S. J., 1998. 'Seasonal forecasting of South African rainfall using a non-linear discriminant analysis model', Int. J. Climatol., 18, 147-164.

Mason, S. J., and Goddard, L., 2000. 'Probabilistic precipitation anomalies associated with ENSO', Bull. Amer. Meteorol. Soc., under revision.

Mason, S. J., and Graham, N. E., 1999, 'Conditional probabilities, relative operating characteristics, and relative operating levels', Wea. and Forecasting, 14, 713-725.

Mason, S. J., and Mimmack, G. M., 2000. 'Comparison of some statistical methods of probabilistic seasonal climate forecasting', J. Climate, under revision. 
Mason, S. J., and Tyson, P. D., 2000. 'The occurrence and predictability of droughts over southern Africa', in Wilhite, D. A. (ed), Drought. Volume 1: A Global Assessment, Routledge, New York, 113-134.

Mason, S. J., Goddard, L., Graham, N. E., Yulaeva, E., Sun, L., and Arkin, P. A., 1999. 'The IRI seasonal climate prediction system and the 1997/98 El Niño event', Bull. Amer. Meteorol. Soc., 80, 1853-1873.

Mason, S. J., Galpin, J. S., Graham, N. E., and Goddard, L., 2000. 'Forecast reliability given moderately sized samples', J. Climate, submitted.

Mattes, M., and Mason, S. J., 1998. 'Evaluation of a seasonal forecasting procedure for Namibian rainfall', S. Afr. J. Sci., 94, 183-185.

McCreary, J. P., 1983. 'A model of tropical ocean-atmosphere interaction', Mon. Wea. Rev., 111, 370-387.

McCreary, J. P., Kundu, P. K., and Molinari, R., 1993. 'A numerical investigation of the dynamics and thermodynamics and mixed layer processes in the Indian Ocean', Prog. Oceanogr., 31, 181-244.

McPhaden, M. J., Busalacchi, A. J., Cheney, R., Donguy, J. R., Gage, K. S., Halpern, D., Ji, M., Julian, P., Meyers, G., Mitchum, G. T., Niiler, P. P., Picaut, J., Reynolds, R. W., Smith, N., and Takeuchi, K., 1998. 'The Tropical Ocean - Global Atmosphere observing system: a decade of progress', J. Geophys. Res., 103, 14169-14240.

Mentz, R. P., D'Urso, M. A., Jarma, N. M., and Mentz, G. B., 2000. 'Cyclical components of local rainfall data', Int. J. Climatol., 20, 211-228.

Messina, C.M., Hansen, J.W., and Hall, A.J., 1999. 'Land allocation conditioned on ENSO phases in the Pampas of Argentina'. Agricultural Systems, 60,197-212.

Mitchum, G., Kilonsky, B., and Miyamoto, B. 1994. 'Methods for maintaining a stable datum in a sea level moitoring system', paper presented at OCEANS 94 OSATES, Institute of Electrical and Electronics Engineers/Oceanic Engineering Society, Parc de Penfeld, Brest, France, Sept.13-16, 1994.

Mielke, P. W., and Berry, K. J., 2000. 'Euclidean distance based permutation methods in atmospheric sciences', Data. Min. Know. Disc., 4, 7-27.

Mintz, Y. and Serafini, Y., 1992. 'A global monthly climatology of soil moisture and water balance', Climate Dyn., 8, 13-17.

Mjelde, J.W., Hill, H.S.J., and Griffiths, J.F., 1998. 'A review of current evidence on climate forecasts and their economic effects in agriculture', American J. Ag. Econ. 80 (5), 1089-1095

Mjelde, J.W., Penson, J.B., and Nixon, C.J., 2000. 'Dynamic aspects of the impact of the use of improved climate forecasts in the corn belt region'. J. Appl. Meteorol., in press.

Molteni, F., Buizza, R., Palmer, T.N., and Petroliagis, T. 1996. 'The ECMWF ensemble prediction system: Methodology and validation', Q. J. Roy. Meteor. Soc., 122, 73-119.

Moore, A. M., and Kleeman, R., 1996. 'The dynamics of error growth and predictability in a coupled model of ENSO', Q. J. Roy. Meteor. Soc., 122, 1405-1446.

Moura, A.D. and Sarachik, E.S., 1997. 'Seasonal-to-interannual climate prediction and applications: new institutions, new possibilities'. WMO Bulletin, 46(4), 342-47.

Moura A.D. and Shukla, J., 1981. 'On the dynamics of droughts in Northeast Brazil: observations, theory, and numerical experiments with a general circulation model', J. Atmos. Sci., 38, 2653-2675.

Mureau, R., Molteni, F. and Palmer, T. N., 1993. 'Ensemble prediction using dynamicallyconditioned perturbations', Q. J. Roy. Meteorol. Soc., 119, 299-323. 
Murphy, A.H.1971. 'A note of the ranked probability score', J. Appl. Meteor., 10, 155-156.

Murphy, A. H., 1973. 'A new vector partition of the probability score', J. Appl. Meteor., 12, 595-600.

Murphy, A.H. 1998. 'The early history of probability forecasts: some extensions and clarifications', Wea. Forecasting, 13, 281-293.

Murphy, A. H., 1993: What is a good forecast? An essay on the nature of goodness in weather forecasting. Wea. Forecasting, 8, 281-293.

Murphy, A. H., 1997. 'Forecast verification', in Katz, R. W., and Murphy, A. H., (eds), Economic Value of Weather and Climate Forecasts, Cambridge University Press, Cambridge, 19-74.

Murphy, A. H., and Winkler, R. L., 1987. 'A general framework for forecast verification', Mon. Wea. Rev., 115, 1330-1338.

Murphy, J. M., 1988. 'The impact of ensemble forecasts on predictability', Q. J. Roy. Meteorol. Soc., 114, 463-494.

Murphy, J.M. 1990. 'Assessment of the practical utility of extended range ensemble forecasts', $Q$. J. Roy. Meteor. Soc., 116, 89-125.

Mutai, C. C., Ward, M. N., and Colman, A. W., 1998. 'Towards the prediction of the East Africa short rains based on sea-surface temperature-atmosphere coupling', Int. J. Climatol., 18, 975-997.

Nagai, T., Tokioka, T., Endoh, M., and Kitamura, Y., 1992. 'El Niño-Southern oscillation simulated in an MRI atmosphere-ocean coupled general circulation model', J. Climate, 5, 1202-1233.

Navarra, A., Ward, M. N., and Rayner, N. A., 1998: 'A stochastic model of SST for climate simulation experiments', Climate Dyn., 14, 473-487.

Neelin, J. D., Battisti, D. S., Hirst, A. C., Jin, F. F., Wakata, Y., Yamagata, T., and Zebiak, S. E., 1998. 'ENSO theory', J. Geophys. Res., 103, 14261-14290.

Neelin, J. D. and Dijkstra, H. A., 1995. 'Ocean-atmosphere interaction and the tropical climatology, I, The dangers of flux correction', J. Climate, 8, 1325-1342.

Neelin, J.D. and Jin, F.-F., 1993. 'Modes of interannual tropical ocean-atmosphere interaction -a unified view, II, Analytical results in the weak coupling limit', J. Atmos. Sci., 50, 35043522.

Neelin, J. D., and Zeng, N., 2000. 'A quasi-equilibrium tropical circulation model implementing and simulation', J. Atmos. Soc., in press.

New, M., Hulme, M., and Jones, P., 1999. 'Representing twentieth-century space-time climate variability. Part I: Development of a mean monthly terrestrial climatology', J. Climate, 12, 829-856.

Nicholls, N., 1999. 'Cognitive illusions, heuristics, and climate prediction'. Bull. Amer. Meteorol. Soc., 80, 1385-1397.

Nicholls, N. and Kestin, I., 1998. 'Communicating climate'. Climatic Change, 40, 417-420.

Nicholson, S. E., 1997. 'An analysis of the ENSO signal in the tropical Atlantic and western Indian Oceans', Int. J. Climatol., 17, 345-375.

Nicholson, S. E., and Nyenzi, B. S., 1990. 'Temporal and spatial variability in the tropical Atlantic and Indian Oceans', Meteorol. Atmos. Phys., 41, 1-17.

NOAA. 1994. A Proposal to Launch a Seasonal-to-Interannual Climate Prediction Program, Office of Global Programs, National Oceanic and Atmospheric Administration, Washington, DC, 20p. 
NOAA. 1999. An Experiment in the Application of Climate Forecast:NOAA-OGP Activities Related to the 1997-98 El Niño Event, Office of Global Programs, National Oceanic and Atmospheric Administration, Washington, DC, 20p.

[See also http://www.ogp.noaa.gov/mpe/csi/appdev/index.htm]

Orlove, B. S., Chiang, J. H. C., and Cane, M. A., 2000. 'Forecasting Andean rainfall and crop yeild from the influence of El Niño of Pleiades visibility', Nature, 403, 68-71.

Osborn, T. J., and Hulme, M., 1998. 'Evaluation of the European daily precipitation characteristics from the atmospheric model intercomparison project', Int. J. Climatol., 18, 505-522.

Pant, G. B., and Parthasarathy, B., 1981. 'Some aspects of an association between the Southern Oscillation and Indian summer monsoon', Arch. Meteorol. Geophys. Bioklimatol., Ser. B, 29, $245-252$.

Palmer, T. N. and Anderson, D. L. T., 1994. 'The prospects for seasonal forecasting', Q. J. Roy. Meteorol. Soc., 120, 755-793.

Palmer, T. N., Brankovic, C., Moletini, F., Tibaldi, S., Ferranti, L., Hollingsworth, A., Cubasch, U. and Klinker, E. 1990. 'The European Centre for Medium-Range Weather Forecasts (ECMWF) Program on extended-range forecasting', Bull. Amer. Meteorol. Soc., 71, 13171330.

Parthasarathy, B., Kumar, K. R., and Deshpande, V. R., 1991. 'Indian-summer monsoon rainfall and 200-mbar meridional wind index - application for long-range prediction', Int. J. Climatol., 11, 165-176.

Parthasarathy, B., Kumar, K. R., and Munot, A. A., 1993. 'Homogeneous Indian monsoon rainfall - variability and prediction', Proc. Ind. Acad. Sci., 102, 121-155.

Peng, P., Kumar, A., Barnston, A. G., and Goddard, L., 2000. 'Skills of the SST-forced global climate variability of the NCEP-MRF-9 and the Scripps/MPI ECHAM3 models', J. Climate, in press.

Penland, C. and Magorian, T., 1993. 'Prediction of Niño-3 sea surface temperatures using linear inverse modeling', J. Climate, 6, 1067-1076.

Penland, C., and Matrovosa, L., 1998. 'Prediction of tropical Atlantic sea surface temperatures using linear inverse modeling', J. Climate, 11, 483-496.

Penland, C., and Sardeshmukh, P. D., 1995. 'The optimal growth of tropical sea surface temperature anomalies', J. Climate, 8, 1999-2024.

Pezzi, L. P., Repelli, C. R., Nobre, P., Cavalcanti, I. F. A., and Sampaio, G., 1998. 'Forecasts of tropical Atlantic SST using a statistical ocean model at CPTEC/INPE - Brazil', Exp. LongLead Forecast Bull., 7 (1), 28-31.

Pfaff, A., Broad, K., and Glantz, M.H., 1999. 'Who benefits from climate forecasts?' Nature, 397 (25 February), 645-646.

Philander, S. G. H., 1986. 'Unusual conditions in the tropical Atlantic Ocean in 1984', Nature, 322, 236-238.

Philander, S.G.H. and Seigel, A.D. 1985. 'Simulation of El Nino of 1982-83', in Coupled OceanAtmosphere Models, edited by J. Nihoul, pp. 517-541, Elsevier, New York.

Philander, S. G. H. and Pacanowski, R. C., 1981. 'Response of the equatorial ocean to periodic forcing', J. Geophys. Res., 86, 1903-1916.

Philander, S. G. H. and Pacanowski, R. C., 1986. 'The mass and heat budget in a model of the tropical Atlantic Ocean', J. Geophys. Res., 91, 14212-14220. 
Philippon, N., and Fontaine, B., 1999. 'A new statistical predictability scheme for JulySeptember Sahel rainfall (1968-1994)', Comptes Rendus Acad. Sci. Ser. II, 329, 1-6.

Picaut, J., Masia, F., and du Penhoat, Y., 1997. 'An advective-reflective conceptual model for the oscillatory nature of ENSO', Science, 277, 663-666.

Potts, J.M., Folland, C.K., Jolliffe, I.T., and Sexton, D., 1996. 'Revised "LEPS" scores fir assessing climate model simulations and long-range forecasts', J. Climate, 9, 34-53.

Power, S., Casey, T., Folland, C., Colman, A., and Mehta, V., 1999. 'Inter-decadal modulation of the impact of ENSO on Australia', Clim. Dyn., 15, 319-324.

Prasad, K. D., and Singh, S. V., 1992. 'Possibility of predicting Indian monsoon rainfall on reduced spatial and temporal scales', J. Climate, 5, 1357-1361.

Rajagopalan, B., Cook, E., Lall, U., and Ray, B., 2000. 'Spatio-temporal variability of ENSO and SST teleconnections to summer drought over the U.S.A. during the twentieth century', $J$. Climate, in press.

Rajagopalan, B., Kushnir, Y., and Tourre, Y. M., 1998. 'Observed decadal mid-latitude and tropical Atlantic Climate Variability', Geophys. Res. Lett., 25, 3967-3970.

Rayner, S., Lach, D., Ingram, H., and Houck, M., 2000. 'The Usability of Probabilistic Climate Forecasting Information in Water Resource Decision Making'. In: Project Summaries, Economic and Human Dimensions Program, Office of Global Programs, National Oceanic and Atmospheric Administration, Washington, DC. [ http://www.ogp.noaa.gov/mpe/csi/econhd/fy99/lach99.htm]

Reason, C. J. C., Allan, R. J., Lindesay, J. A., and Ansell, T. J., 2000. 'ENSO and climatic signals across the Indian Ocean basin in the global context: Part I, Interannual composite patterns', Int. J. Climatol., in press.

Reinhold, B. B., 1987. 'Weather regimes: the challenge in extended-range forecasting', Science, 235, 437-441.

Repelli, C.A., and Nobre, P., 2000. 'Statistical prediction of sea surface temperature over the tropical Atlantic', Int. J. Climatol., in press.

Reverdin, G., and McPhaden, M. J., 1986. 'Near-surface current and temperature variability observed in the equatorial Atlantic from drifting buoys', J. Geophys. Res., 91, 6569-6581.

Reynolds, R.W. and Smith, T.M., 1994. 'Improved global sea surface temperature analysis using optimal interpolation', J. Climate, 8, 1572-1583.

Richardson, P. L., and Walsh, D., 1986. 'Mapping climatological seasonal variations of surface currents in the tropical Atlantic using ship drifts', J. Geophys. Res., 91, 10537-10550.

Roads, J. O., 1985. 'Temporal variations in predictability', J. Atmos. Sci., 42, 884-903.

Rocha, A. and Simmonds, I., 1997. 'Interannual variability of south-eastern African summer rainfall. Part I: Relationships with air-sea interaction processes', Int. J. Climatol., 17, 235265.

Rodo, X., Baert, E., Comin, F. A., 1997. 'Variations in seasonal rainfall in southern Europe during the present century: relationships with the North Atlantic Oscillation and the El NiñoSouthern Oscillation', Clim. Dyn., 13, 275-285.

Rodwell, M. J., 1997. 'Breaks in the Asian monsoon: The influence of Southern Hemisphere weather systems', J. Atmos. Sci., 54, 2597-2611.

Roeckner, E., Oberhuber, J.M., Bacher, A., Christoph, M., and Kirchner, I. 1996. 'ENSO variability and atmospheric response in a global coupled atmosphere-ocean GCM', Clim. Dyn., 12, 737-754. 
Ropelewski, C. F., and Halpert, M., 1987. 'Global and regional scale precipitation patterns associated with the El Niño/Southern Oscillation', Mon. Wea. Rev., 115, 1606-1626.

Ropelewski, C. F., and Halpert, M., 1989. 'Precipitation patterns associated with the high index phase of the Southern Oscillation', J. Climate, 2, 268-284.

Ropelewski, C. F., Lamb, P. J., and Portis, D. H., 1993. 'The global climate for June-August 1990: Drought returns to sub-Saharan Africa and warm Southern Oscillation episode conditions develop in the central Pacific', J. Climate, 6, 2188-2212.

Rosati, A., Miyakoda, K., and Gudgel, R., 1997. 'The impact of ocean initial conditions on ENSO forecasting with a coupled model', Mon. Wea. Rev., 125, 754-772.

Rowell, D.P., Folland, C.K., Maskell, K. and Ward, N.M., 1995. 'Variability of summer rainfall over tropical north Africa (1906-1992): Observations and modelling', Q. J. R. Meteorol. Soc., 121, 669-704.

Sahai, A. K., Soman, M. K., and Satyan, V., 2000. 'All India summer monsoon rainfall prediction using an artificial neural network', Climate Dyn., 16, 291-302.

Saji, N.H., Goswami, B.N., Vinayachandran, P.N., Yamagata, T., 1999. 'A dipole mode in the tropical Indian Ocean', Nature, 401, 360-363.

Sankar Rao, M., Lau, K. M., and Yang, S., 1996. 'On the relationship between Eurasian snow cover and the Asian summer monsoon', Int. J. Climatol., 16, 605-616.

Segschneider, J., Anderson, D.L.T., and Stockdale, T., 2000. 'Towards the use of altimetry for operational seasonal forecasting', J. Climate, submitted.

Sellers, P.J., Mintz, Y., Sud, Y.C., and Dalcher, A., 1986. 'A Simple Biosphere Model (SiB) for use within general circulation models', J. Atmos. Sci., 43, 505-531.

Semazzi, F. H. M., Mehta, V., and Sud, Y. C., 1988. -An investigation of the relationship between Sub-Saharan rainfall and global sea surface temperatures', Atmos.Ocean, 26, 118138.

Servain, J., and Legler, D. M., 1986. 'Empirical orthogonal function analyses of tropical Atlantic sea surface temperature and wind stress: 1964-1979', J. Geophys. Res., 91, 14181-14191.

Servain, J., Busalacchi, A. J., McPhaden, M. J., Moura, A. D., Reverdin, G., Vianna, M., and Zebiak, S. E., 1998. 'A Pilot Research Moored Array in the Tropical Atlantic (PIRATA)', Bull. Amer. Meteorol. Soc., 79, 2019-2031.

Shabbar, A. and Barnston, A.G., 1996. 'Skill of seasonal climate forecasts in Canada using canonical correlation analysis', Mon. Wea. Rev., 124, 2370-2385.

Shukla, J., 1998. 'Predictability in the midst of chaos: a scientific basis for climate forecasting', Science, 282, 728-731.

Shukla, J., 1987. 'Interannual variability of Monsoons', in Fein, J. S., and Stephens, P. L. (eds), Monsoons, Wiley, New York, 399-464.

Shukla, J., 1981. 'Dynamical predictability of monthly means', J. Atmos. Sci., 38, 2547-2572.

Shukla, J. and Misra, B. M., 1977. 'Relationships between sea-surface temperature and wind speed over the Arabian Sea and monsoon rainfall over India', Mon. Wea. Rev., 105, 9981002.

Shukla, J. and Mooley, D. A., 1987. 'Empirical prediction of the summer monsoon rainfall over India', Mon. Wea. Rev., 115, 695-703.

Shukla J., and Paolino, D. A., 1983. 'The Southern Oscillation and long range forecasting of the summer monsoon rainfall over India', Mon. Wea. Rev., 111, 1830-1837.

Singh, D., Bradram, C. V. V., and Mandal, G. S., 1995. 'New regression-model for Indiansummer monsoon rainfall', Meteorol. Atmos. Phys., 55, 77-86. 
Singh, G. P., and Chattopadhyay, J., 1998. 'Relationship between mid-latitude circulation indices and Indian northeast monsoon rainfall', Pure Appl. Geophys., 152, 811-818.

Sivillo, J. K., Ahlquist, J. E., and Toth, Z., 1997. 'An ensemble forecasting primer', Wea. Forecasting, 12, 809-818.

Smith, N.R., Blomley, J.E., and Meyers, G., 1991. 'A univariate statistical interpolation scheme for subsurface thermal analyses in the tropical oceans', Prog. Oceanogr., 28, 219-256.

Smith, T. M., and Livezey, R. E., 1999. 'GCM systematic error correction and specification of the seasonal mean Pacific-North America region atmosphere from global SSTs', J. Climate, 12, 273-288.

Solow, A. R., Adams, R.F., Bryant, K.J., Legler, D.M., O‘Brien, J.J., McCarl, B.A., Nayda, W. and Weiher, R., 1998. 'The value of improved ENSO prediction to U.S. agriculture'. Climatic Change, 39, 47-60.

Somerville, R. C. J., 1987. 'The predictability of weather and climate', Clim. Change, 11, 239246.

Stern, P. C. and Easterling, W.E., 1999. Making Climate Forecasts Matter (Panel on the Human Dimesions of Seasonal-to-Inerannual Climate Variability), National Academy Press, Washington DC. $175 \mathrm{pp}$.

Stern, W. and Miyakoda, K., 1995. 'Feasibility of seasonal forecasts inferred from multiple GCM simulations', J. Climate, 8, 1071-1085.

Stockdale, T. N., Busalacchi, A. J., Harrison, D. E., and Seager, R., 1998a. 'Ocean modeling for ENSO', J. Geophys. Res., 103, 14325-14355.

Stockdale, T. N., Anderson, D. L. T., Alves, J. O. S., and Balmaseda, M. A., 1998b. 'Global seasonal rainfall forecasts using a coupled ocean-atmosphere model', Nature, 392, 370-373.

Stone, R.S. and Auliciems, A., 1992. 'SOI phase relationships with rainfall in eastern Australia', Int. J. Climatol., 12, 625-636.

Suarez, M. J. and Schopf, P. S., 1988. 'A delayed action oscillator for ENSO', J. Atmos. Sci., 45, 3283-3287.

Sun, L. and N.E. Graham, 2000. 'Climate simulation over East Africa using the NCEP regional spectral model', J. Geophys. Res., submitted.

Swets, J. A., 1973. 'The relative operating characteristic in psychology', Science, 182, 9901000.

Tang, B. Y., 1995. 'Periods of linear development of the ENSO cycle and POP forecast experiments', J. Climate, 8, 682-691.

Tang, B. Y., Hsieh, W. W., Monahan, A. H., and Tangang, F. T., 2000. 'Skill comparisons between neural networks and canonical correlation analysis in predicting the equatorial Pacific sea surface temperatures', J. Climate, 13, 287-293.

Tangang, F. T., Hsieh, W. W., and Tang, B. Y., 1997. 'Forecasting the equatorial Pacific sea surface temperatures by neural network models', Climate Dyn., 13, 135-147.

Tangang, F. T., Hsieh, W. W., and Tang, B. Y., 1998a. 'Forecasting the regional sea surface temperatures of the tropical Pacific by neural network models, with wind stress and sea level pressure as predictors', J. Geophys. Res., 103, 7511-7522.

Tangang, F. T., Tang, B. Y., Monahan, A. H., and Hsieh, W. W., 1998b. 'Forecasting ENSO events: a neural network - extended EOF approach', J. Climate, 11, 29-41.

Thapliyal, V., 1997. 'Preliminary and final long range forecast for seasonal monsoon rainfall over India', J. Arid Env, 36, 385-403. 
Thiaw, W., Barnston, A. G., and V. Kumar, 1999. 'Predictions of African rainfall on the seasonal timescale', J. Geophys. Res., 104, 31589-31597.

Thompson, P. D., 1957. 'Uncertainty of initial state as a factor in the predictability of large-scale atmospheric flow patterns', Tellus, 9, 275-295.

Thompson, P. D., 1976. 'How to improve accuracy by combining independent forecasts', Mon. Wea. Rev., 105, 228-229.

Tourre, Y. M., and White, W. B., 1997. 'Evolution of the ENSO Signal over the Indo-Pacific Domain', J. Phys. Oceanogr., 27, 683-696.

Tourre, Y. M., Rajagopolan, B., and Kushnir, Y., 1999. 'Dominant patterns of climate variability in the Atlantic Ocean during the last 136 years', J. Climate, 12, 2285-2299.

Tracton, M.S. and Kalnay, E. 1993. 'Operational ensemble prediction at the National Meteorological Center: practical aspects', Wea. Forecasting, 8, 379-398.

Trenberth, K. E., Branstator, G. W., Karoly, D., Lau, N. -C., and Ropelewski, C. F., 1998. 'Progress during TOGA in understanding and modeling global teleconnections associated with tropical sea surface temperatures', J. Geophys. Res., 103, 14291-14324.

Tyson, P. D. and Dyer, T. G. J., 1978. 'The predicted above-normal rainfall of the seventies and the likelihood of droughts in the eighties in South Africa', S. Afr. J. Sci., 74, 372-377.

Tyson, P. D. and Dyer, T. G. J., 1980. 'The likelihood of droughts in the eighties in South Africa', S. Afr. J. Sci., 76, 340-341.

Uvo, C. B., Repelli, C. A., Zebiak, S. E., and Kushnir, Y., 1998. 'The relationships between tropical Pacific and Atlantic SST and northeast Brazil monthly precipitation', J. Climate, 13, 287-293.

Van den Dool, H. M., 1994. 'Searching for analogs, how long must we wait?', Tellus, 46A, 314324.

Van den Dool, H.M., Hoopingarner, J., O'Lenic, E., Wagner, A.J., Barnston, A.G., Livezey, R.E., Unger, D., Artusa, A., and Churchill, R., 1998. ' $3^{\text {rd }}$ annual review of skill of CPC real time long lead predictions', in Proceedings of the $23^{\text {rd }}$ Annual Climate Diagnostics and Prediction Workshop, American Meteorological Society, 9-12.

Venzke, S., Latif, M, and Villock, A., 2000. 'The Coupled GCM ECHO-2, II: Indian Ocean response to ENSO', J. Climate, in press.

Venkatesan, C., Raskar, S. D., Tambe, S. S., Kulkarni, B. D., and Keshavamurty, R. N., 1997. 'Prediction of all India summer monsoon rainfall using error-back-propagation neural networks', Meteorol. Atmos. Phys., 62, 225-240.

Vernekar, A. D., Zhou, J., and Shukla, J., 1995. 'The effect of Eurasian snow cover on the Indian Monsoon', J. Climate, 8, 248-266.

Wagner, A. J., 1989. 'Medium- and long-range forecasting', Wea. Forecasting, 4, 413-426.

Wagner, R.G., and da Silva, A., 1994. 'Surface conditions associated with anomalous rainfall in the Guinea coastal region', J. Climatol., 14, 179-199.

Walker, G. T., 1924. 'Correlation of seasonal variations in weather IX: A further study of world weather', Mem. Indian Meteorol. Dep., 24, 275-332.

Walker, G. T. and Bliss, E. W., 1932. 'World Weather V', Mem. Roy. Meteor. Soc, 4, 53-84.

Wallace, J. M., Rasmusson, E. M., Mitchell, T. P., Kousky, V. E., Sarachik, E. S., and von Storch, H., 1998. 'On the structure and evolution of ENSO-related climate variability in the tropical Pacific: Lessons from TOGA', J. Geophys. Res., 103, 14241-14259.

Wang, C. and Weisberg R., 2000. 'The 1997-98 El Nino evolution relative to previous El Nino events', J. Climate, 13, 488-501. 
Ward, N. M., 1998. 'Diagnosis and short-lead prediction of summer rainfall in tropical North Africa at interannual and multidecadal timescales', J. Climate, 12, 3167-3191.

Ward, N. M., and Folland, C. K., 1991. 'Prediction of seasonal rainfall in the north Nordeste of Brazil using eigenvectors of sea-surface temperatures', Int. J. Climatol., 11, 711-743.

Weare, B. C., 1977. 'Empirical orthogonal function analysis of Atlantic surface temperatures', Q. J. R. Meteorol. Soc., 193, 467-478.

Weare, B. C., 1979. 'A statistical study of the relationship between ocean temperature and Indian monsoon', J. Atmos. Sci., 36, 2279-2291.

Webster, P. J., 1995. 'The annual cycle and the predictability of the tropical coupled oceanatmosphere system', Meteorol. Atmos. Phys., 56, 33-55.

Webster, P. J., Moore, A. M., Loschnigg, J. P., and Leben, R. R., 1999. 'Coupled oceanatmosphere dynamics in the Indian Ocean during 1997-98', Nature, 401, 356-360.

Webster, P. J., Magaña, V. O., Palmer, T. N., Shukla, J., Tomas, R. A., Yanai, M., and Yasunari, T., 1998. 'Monsoons: Processes, predictability, and the prospects for prediction', J. Geophys. Res., 103, 14451-14510.

Webster, P. J., and Yang, S., 1992. 'Monsoon and ENSO: selectively interactive systems', Quart. J. Roy. Meteor. Soc., 118, 877-925.

White, W. B., 2000. 'Influence of the Antarctic circumpolar wave on Australia precipitation from 1958-1996', J. Climate, in press.

Wilby, R. L., and Wigley, T. M. L., 1997, 'Downscaling general circulation model output: A review of methods and limitations', Prog. Phys. Geogr., 21, 530-548.

Wilks, D. S., 1995. Statistical Methods in the Atmospheric Sciences, International Geophysics Series, Vol. 59, Academic Press, San Diego, 464 pp.

Wilks, D. S., 2000a. 'Diagnostic verification of the Climate Prediction Center long-lead outlooks, 1995-1998', J. Climate, in press.

Wilks, D. S., 2000b. 'On the interpretation of probabilistic climate forecasts', J. Climate, in press.

Wilks, D.S. and Eggleston, K.L. 1992. 'Estimating monthly and seasonal precipitation distributions using the 30-day and 90-day outlooks', J. Climate, 5, 252-259.

Winkler, R. L., 1989. 'Combining forecasts - a philosophical basis and some current issues', Int. J. Forecasting, 5, 605-609.

WMO. 1999. The 1997-1998 El Niño Event: A Scientific and Technical Retrospective, WMO No. 905, World Meteorological Organization, Geneva, 96pp.

Wolter K., 1987. 'The Southern Oscillation in the surface circulation and climate over the tropical Atlantic, eastern Pacific, and Indian oceans', J. Clim. and Appl. Meteor., 26, 540-558.

Wyrtki, K., 1985. 'Water displacements in the Pacific and the genesis of El Nino cycles', $J$. Geophys. Res., 90, 7129-7132.

Xie, P. and Arkin, P. A., 1997. 'Global precipitation: A 17-year monthly analysis based on gauge observations, satellite estimates, and numerical model outputs', Bull. Amer. Meteor. Soc., 78, 2539-2558.

$\mathrm{Xu}$, J. -S., and von Storch, H., 1990. 'Principal oscillation pattern: prediction of the state of ENSO', J. Climate, 3, 1316-1329.

Xue, Y., Cane, M. A., Zebiak, S. E., and Blumenthal, M. B., 1994. 'On the prediction of ENSO: A study with a low-order Markov model', Tellus, 46A, 512-528. 
Yang, S., Lau, K. M., and Sankar Rao, M., 1996. 'Precursory signals associated with the interannual variability of the Asian summer monsoon', J. Climate, 10, 1787-1820.

Yang, X. -Q., Anderson, J. L., and Stern, W. F., 1998. 'Reproducible forced modes in AGCM ensemble integrations and potential predictability of atmospheric variations in the extratropics' J. Climate, 11, 2942-2959.

Yu, Z. P., Chu, P.S., and Schroeder, T., 1997, 'Predictive skills of seasonal to annual rainfall variations in the US Affiliated Pacific Islands: Canonical correlation analysis and multivariate principal components regression approaches', J. Climate, 10, 2586-2599.

Zebiak, S. E., 1993. 'Air-sea interaction in the equatorial Atlantic region', J. Climate, 6, 15671586.

Zebiak, S. E., 1986. 'Atmospheric convergence feedback in a simple model for El Niño', Mon. Wea. Rev., 114, 1263-1271.

Zebiak, S. E., 1982. 'A simple atmospheric model of relevance to El Niño', J. Atmos. Sci., 39, 2017-2027.

Zebiak, S. E. and Cane, M. A., 1987. 'A model El Niño Southern Oscillation', Mon. Wea. Rev., 115, 2262-2278.

Zeng, N., Neelin, J. D., Lau, K. -M., and Tucker, C. J., 1999. 'Enhancement of interdecadal climate variability in the Sahel by vegetation interaction', Science, 286, 1537-1540.

Zhang, H., and Casey, T., 2000. 'Verification of categorical probability forecasts', Wea. Forecasting, 15, 80-89. 